\author{
UNIVERSIDADE DE SÃO PAULO \\ INSTITUTO DE QUÍMICA DE SÃO CARLOS
}

\title{
CARBOXIMETILQUITOSANAS: PREPARAÇÃO, CARACTERIZAÇÃO E APLICAÇÃO COMO AGENTES DE ESTABILIZAÇÃO DE SUSPENSÕES AQUOSAS DE
}

ALUMINA.

\author{
Juliana Colombo Lamas
}

Dissertação apresentada ao Instituto de Química de São Carlos, da Universidade de São Paulo para a obtenção do título de Mestre em Ciências (Físico-Química).

Orientadora: $\operatorname{Prf}^{\mathrm{a}}$. Dr ${ }^{\mathrm{a}}$. Elisabete Frollini

São Carlos

2008 
Aos meus pais, por todo incentivo;

e ao Edson pelo apoio incondicional. 


\section{AGRADECIMENTOS}

À Prof ${ }^{\mathrm{a}}$. Dr ${ }^{\mathrm{a}}$ Elisabete Frollini pela orientação, dedicação e por todas as oportunidades;

Ao Instituto de Química de São Carlos pelo apoio institucional e infraestrutura necessária a realização deste trabalho;

À ALCOA alumínio, pelo material cedido;

À Bianca M. Cerrutti e Márcia B. Cardoso por todo o auxílio durante o trabalho;

A todos os integrantes do grupo de Físico-Química Orgânica, pelo companheirismo, descontração e ajuda no trabalho realizado.

Ás bibliotecárias do IQSC pelo auxilio nas referências bibliográficas;

Aos técnicos: Márcia, Mauro e Silvana, pelas análises realizadas;

Aos pesquisadores Luiz Alberto Colnago e Lucimara Ap. Forato (EMBRAPA Instrumentação Agropecuária) e à especialista de laboratório Cristiane M. Xavier (USP/São Paulo) pelas análises de RMN;

Às minhas amigas inseparáveis Daniela, Fabiana e Marília pelo apoio e carinho em todos os momentos;

Aos moradores do Bloco $\mathrm{C}$, ala 3 do alojamento por toda a alegria e amizade;

A CAPES (Coordenação de Aperfeiçoamento de Pessoal de Nível Superior) pela bolsa concedida; 


\section{SUMÁRIO}

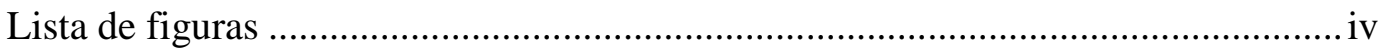

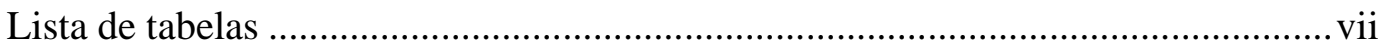

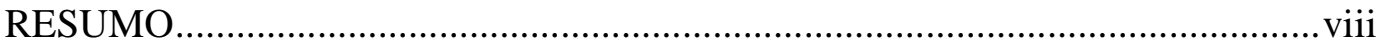

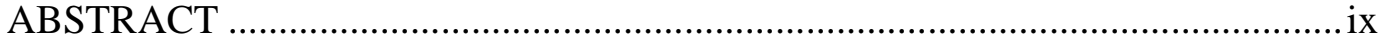

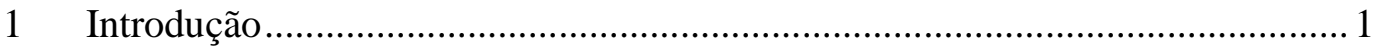

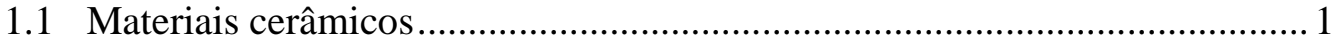

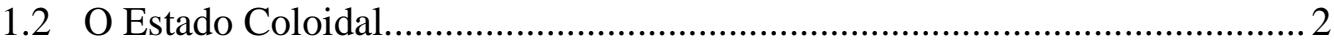

1.3 Interações partícula - partícula.................................................................. 4

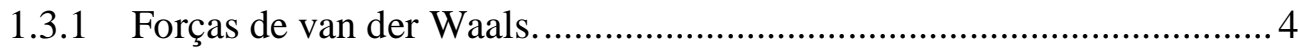

1.3.2 Movimento Browniano................................................................... 5

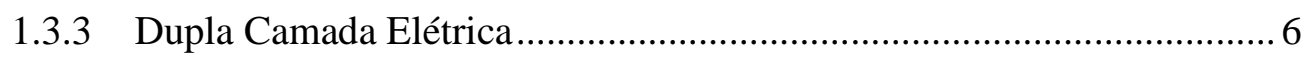

1.4 Teoria Derjaguin - Landau e Verwey - Overbeek (DLVO) ........................... 8

1.5 Mecanismos de Estabilização................................................................... 10

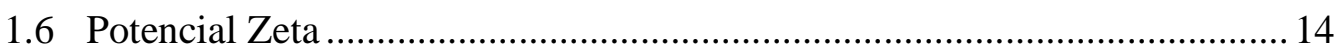

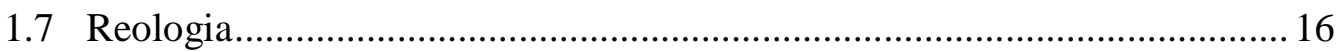

1.8 Diâmetro de Partícula ................................................................................. 19

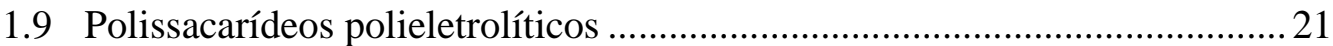

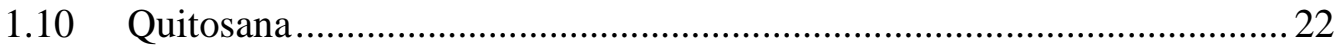

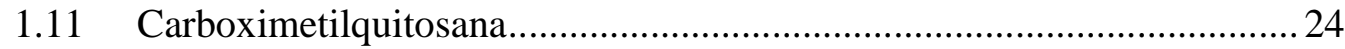

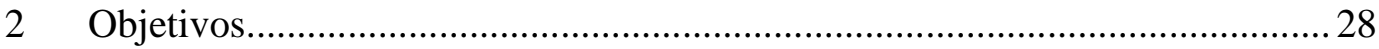

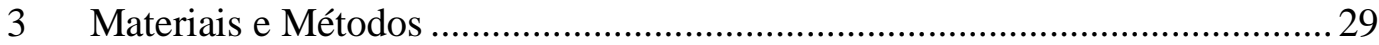

3.1 Quitosana e sua purificação .......................................................................2 29

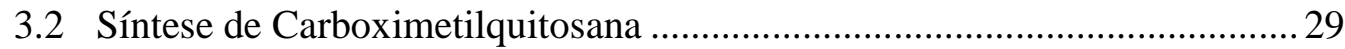


3.2.1 Síntese usando Dimetilacetamida/Cloreto de Lítio (DMAc/LiCl) como

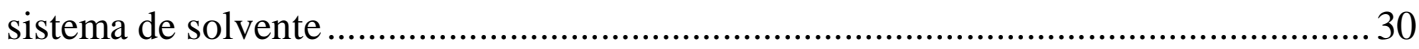

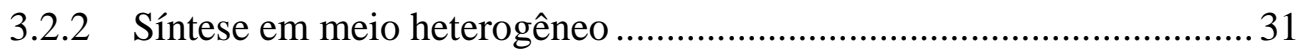

3.3 Purificação das amostrar de carboximetilquitosana .................................. 31

3.4 Caracterização das amostras de Quitosana e Carboximetilquitosana............ 32

3.4.1 Análises condutimétricas e pontenciométricas (GE; LUO, 2005;

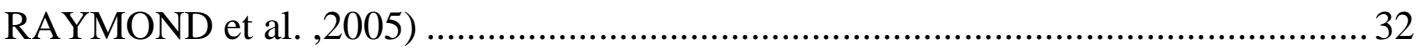

3.4.2 Espectroscopia na Região do Infravermelho ....................................... 33

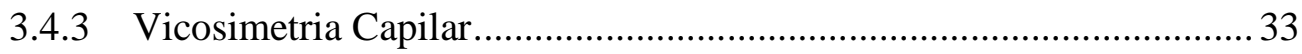

3.4.4 Espectroscopia de Ressonância Magnética Nuclear $\left(\operatorname{RMN}^{1} \mathrm{H}\right)$............ 34

3.4.5 Preparação de carboximetilquitosana na forma ácida .......................... 35

3.4.6 Análise Térmica: Termogravimetria …............................................. 35

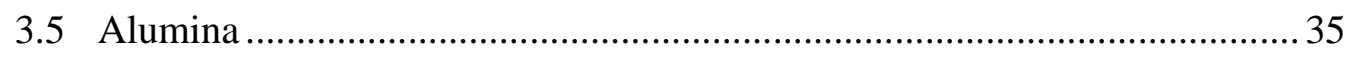

3.6 Avaliação da Estabilização de suspensões aquosas de Alumina ................... 36

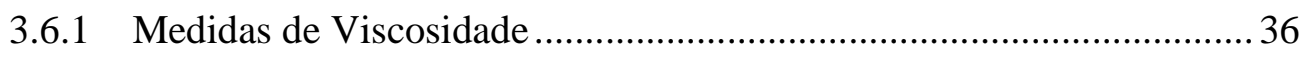

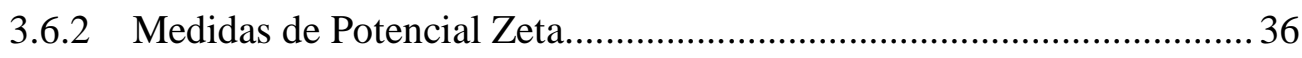

3.6.3 Medidas de Diâmetro médio de Partícula ............................................. 37

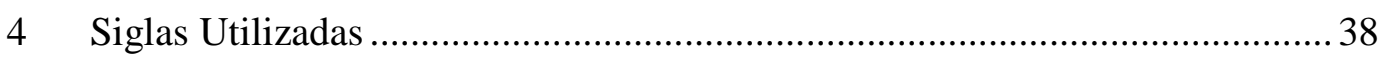

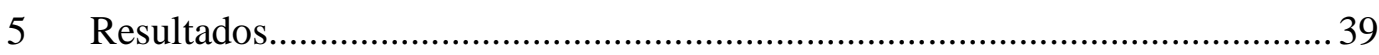

5.1 Preparação e Purificação das amostras........................................................ 39

5.2 Análise Condutimétrica e Potenciométrica ................................................. 40

5.3 Espectroscopia na região do infravermelho .......................................... 43

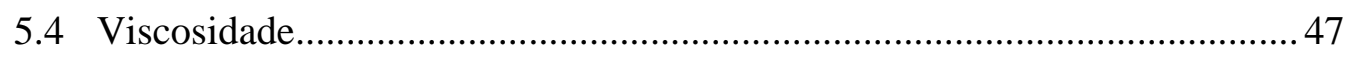

5.5 Espectroscopia de Ressonância Magnética Nuclear $\left(\operatorname{RMN}^{1} \mathrm{H}\right) \ldots \ldots \ldots \ldots \ldots \ldots . . . . . .49$

5.6 Carboximetilquitosana na forma ácida ................................................... 51 
5.7 Análise Térmica: Termogravimetria

5.8 Avaliação da atuação de CMQ como agente de estabilização de suspensões de alumina.. 56

5.8.1 Medidas de viscosidade .56

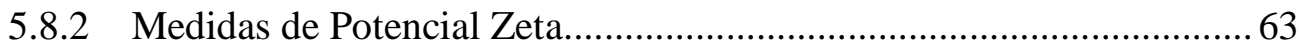

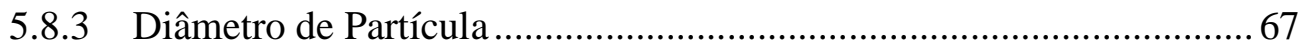

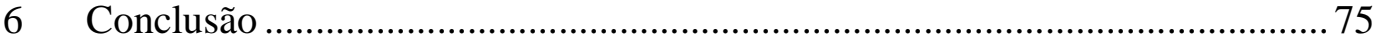

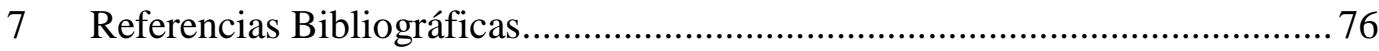

Anexo A - Curva de titulação condutimétrica e potenciométrica para a quitosana. 85

Anexo B - Espectro na região do infravermelho ……............................................ 87

Anexo C - Espectros de carboximetilquitosana na forma ácida ...............................8 89

Anexo D - Curvas termogravimétricas as amostras carboximetilidas.......................90

Anexo E - Espectro de Ressonância Magnética Nuclear $\left(\operatorname{RMN}^{1} \mathrm{H}\right)$ de

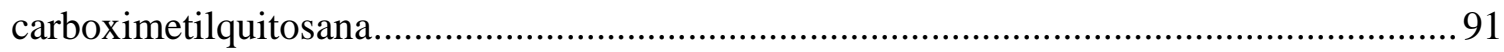




\section{LISTA DE FIGURAS}

FIGURA 1: REPRESENTAÇÃO ESQUEMÁTICA DA DUPLA CAMADA ELÉTRICA.......................... 7

FIGURA 2: ENERGIA POTENCIAL DE INTERAÇÃO PARTÍCULA-PARTÍCULA EM FUNÇÃO DA

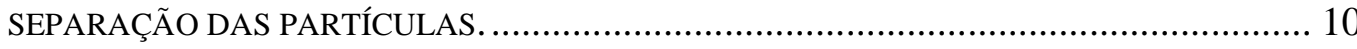

FIGURA 3: EFEITO DA ADSORÇÃO DE UM POLÍMERO SOBRE A DUPLA CAMADA ELÉTRICA. 11

FIGURA 4: ILUSTRAÇÃO DOS MECANISMOS DE ESTABILIZAÇÃO: A)ELETROSTÁTICO;

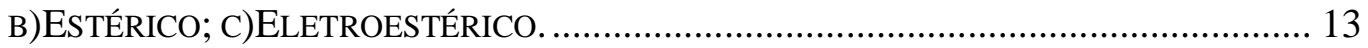

FIGURA 5: REPRESENTAÇÃO ESQUEMÁTICA DA ESTRUTURA DO ÁCIDO POLIACRÍLICO (A) E INTERAÇÕES ENTRE A SUPERFÍCIE DA ALUMINA E O POLÍMERO CARBOXÍLICO(B) .... 14

FIGURA 6: MODELO DE ISAAC NEWTON PARA DESCREVER A VISCOSIDADE: DUAS PLACAS PARALELAS DE ÁREA “A”, SEPARADAS POR UMA DISTÂNCIA INFINITESIMAL “DX”, MOVENDO-SE COM VELOCIDADES DISTINTAS V1 E V2, EM UMA MESMA DIREÇÃO, SOB APLICAÇÃO DE UMA FORÇA. 16

FIGURA 7: COMPORTAMENTO REOLÓGICO EM FUNÇÃO DA TAXA DE CISALHAMENTO APLICADA.

FigURA 8: HiSTOGRAMA UTILIZADO PARA A REPRESENTAÇÃO DE TAMANHO DE PARTÍCULAS PARA SISTEMAS POLIDISPERSOS.

FIGURA 10: REPRESENTAÇÃO ESQUEMÁTICA DA REAÇÃO DE O-CARBOXIMETILAÇÃO DA QUITOSANA. 25

FIGURA 11: REPRESENTAÇÃO ESQUEMÁTICA DE PARTE DA ESTRUTURA DA NCARBOXIMETILQUitosAnA. 26

FIGURA 12: REPRESENTAÇÃO ESQUEMÁTICA DA ESTRUTURA DA QUITOSANA, APRESENTANDO A NUMERAÇÃO UTILIZADA PARA A DETERMINAÇÃO DO GRAU MÉDIO DE ACETILAÇÃO.34

FIGURA 13:CURVA DE TITULAÇÃO CONDUTIMÉTRICAS PARA A QUITOSANA. 41

FIGURA 14: CURVA DE TITULAÇÃO POTENCIOMÉTRICA PARA A QUITOSANA. 42

FIGURA 15: DERIVADA PRIMEIRA DA CURVA DE TITULAÇÃO POTENCIOMÉTRICA DA QUITOSANA. 
FIGURA 16: ESPECTRO NA REGIÃO DO INFRAVERMELHO PARA A AMOSTRA DE QUITOSANA.44

FIGURA 17: ESPECTRO NA REGIÃO DO INFRAVERMELHO PARA AMOSTRAS DE CARBOXIMETILQUITOSANA: A)CMQ1, B) CMQ2 .............................................. 45

FIGURA 18: ESPECTROS NA REGIÃO DO INFRAVERMELHO DAS AMOSTRAS Q E CMQ1(A) E DETALHAMENTO DA REGIÃO ENTRE 500 E $2000 \mathrm{CM}^{-1}$ (B)....................................... 46

FIGURA 19: CURVA DE VISCOSIDADE REDUZIDA VERSUS CONCENTRAÇÃO DA AMOSTRA DE QUITOSANA EM SOLUÇÃO TAMPÃO 0,3M ÁCIDO ACÉTICO/0,2M ACETATO DE SÓDIO $(\mathrm{PH} 4,5), 25^{\circ} \mathrm{C}$ 48

Figura 20: EsPeCTRO DE RESSONÂNCIA MAGNÉTICA NuClEAR $\left(\mathrm{RMN}^{1} \mathrm{H}\right)$ DA QUITOSANA (Q), OBTIDO UTILIZANDO $\mathrm{D}_{2} \mathrm{O}$ COMO SOLVENTE, $\mathrm{NS}=16,80^{\circ} \mathrm{C}$ 50

Figura 21: EsPeCtro dE RESSONÂNCIA MAGNÉTICA NuCLEAR $\left(\operatorname{RMN}^{1} \mathrm{H}\right)$ DE CARBOXIMETILQUiTOSANA CMQ4 EM D $2 \mathrm{O} / \mathrm{HCl}$ (1:100 EM VOLUME), $80^{\circ} \mathrm{C}$. 51

FIGURA 22: ESPECTRO NA REGIÃO DO INFRAVERMELHO PARA CARBOXIMETILQUITOSANA (CMQ1) NA FORMA ÁCIDA E COMO SAL DE SÓDIO. 52

FIGURA 23: CURVA DE GRAU MÉDIO DE SUBSTITUIÇÃO VERSUS QUANTIDADE DE ÁCIDO MONOCLOROACÉTICO UTILIZADO.

FIGURA 24: CURVAS TERMOGRAVIMÉTRICAS PARA QUITOSANA (AMOSTRA Q) EM ATMOSFERA DE $\mathrm{N}_{2} 20$ MOL.MIN ${ }^{-1}$, RAZÃO DE AQUECIMENTO DE $20^{\circ} \mathrm{C} . M I N^{-1}{ }^{-1}$ 54

FIGURA 25: CURVAS TERMOGRAVIMÉTRICAS DAS AMOSTRAS CARBOXIMETILIDAS:(A)CMQ3 E (B)CMQ7, EM ATMOSFERA DE N 2 COM FLUXO DE GÁS DE 20ML.MIN ${ }^{-1}$ E RAZÃO DE AQUECIMENTO DE $20{ }^{\circ} \mathrm{C} \cdot \mathrm{MIN}^{-1}$ 55

FIGURA 26: VISCOSIDADE DA SUSPENSÃO AQUOSA DE ALUMINA EM FUNÇÃO DO PH; TEMPERATURA AMBIENTE 56

FIGURA 27: VISCOSIDADE DA SUSPENSÃO DE ALUMINA EM FUNÇÃO DA MASSA DE ADITIVO: A)CMQ3, B)CMQ4, C)CMQ5 E D)CMQ6, (E) Q. PH 5,5, TEMPERATURA AMBIENTE.58 FIGURA 28: VISCOSIDADE DA SUSPENSÃO DE ALUMINA EM FUNÇÃO DO PH, PARA A ADIÇÃO DE: (A) CMQ3, (B) CMQ4, (C) CMQ5, (D) CMQ6, (E) CMQ7, (F) CMQ1 E (G) Q, TEMPERATURA AMBIENTE 
FIGURA 29: REPRESENTAÇÃO ESQUEMÁTICA DAS POSSÍVEIS INTERAÇÕES ENTRE A SUPERFÍCIE DA ALUMINA E CARBOXIMETILQUITOSANA (CMQ).

FIGURA 30: POTENCIAL ZETA DA SUSPENSÃO AQUOSA DE ALUMINA EM FUNÇÃO DO PH; TEMPERATURA AMBIENTE

FIGURA 31: POTENCIAL ZETA DA SUSPENSÃO DE ALUMINA EM FUNÇÃO DA MASSA DE ADITIVo: CMQ3 (GS=0,5), CMQ4 (GS=0,8) E CMQ6 (GS=1,0). PH= 5,5, TEMPERATURA AMBIENTE 64

FIGURA 32: POTENCIAL ZETA DA SUSPENSÃO DE ALUMINA EM FUNÇÃO DO PH, PARA A ADIÇÃO DE: (A) CMQ3, (B)CMQ4, (C)CMQ5, (D)CMQ6, (E)CMQ7,(F)CMQ1 E (G)Q; TEMPERATURA AMBIENTE 66

FIGURA 33: DiÂMETRO MÉDIO DE PARTíCULA, EM FUNÇÃO DO PH E SEM A ADIÇÃO DE ESTABILIZANTES, PARA A SUSPENSÃO DE ALUMINA . TEMPERATURA AMBIENTE. .... 68

FIGURA 34: DiÂMETRO DE PARTÍCULA DA SUSPENSÃO DE ALUMINA EM FUNÇÃO DA MASSA DE ADITIVO: (A)CMQ3, (B)CMQ4, (C)CMQ6. TEMPERATURA AMBIENTE 69

FIGURA 35: DiÂMETRO MÉDIO DE PARTÍCULA DA SUSPENSÃO DE ALUMINA, EM FUNÇÃO DO PH, PARA A ADIÇÃO DE 15 MG DE: (A)CMQ3, (B)CMQ4, (C)CMQ5, (D)CMQ6, (E)CMQ7, (F)CMQ1 E (G)Q. TEMPERATURA AMBIENTE.

FIGURA 36: DiSTRIBUIÇÃO DE DIÂMETRO DE PARTÍCULA DA ALUMINA, EM FUNÇÃO DA INTENSIDADE DO SINAL. TEMPERATURA AMBIENTE.

FIGURA 37: DISTRIBUIÇÃO DO DIÂMETRO DE PARTíCULA, EM FUNÇÃO DO SINAL PARA A SUSPENSÃO DE ALUMINA A PH: (A)3,0, (B)5,5 E (C)10,0. TEMPERATURA AMBIENTE.73 


\section{LISTA DE TABELAS}

TABELA 1: SigLAS UTILIZADAS PARA AS AMOSTRAS AVALIADAS .................................... 38

TABELA 2: GANHO DE MASSA APÓS A REAÇÃO DE CARBOXIMETILAÇÃO ........................... 39

TABELA 3: DIMINUIÇÃO DA MASSA DE CARBOXIMETILQUITOSANA DEVIDO A PURIFICAÇÃO 40

TABELA 4: VALORES DE GRAU MÉDIO DE ACETILAÇÃO (GA), DE QUITOSANA DETERMINADO POR TITULAÇÃO CONDUTIMÉTRICAS E POTENCIOMÉTRICAS 43

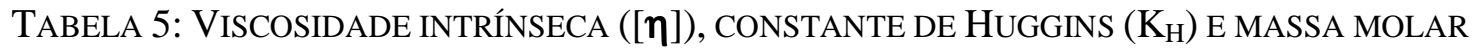
MÉDIA $\left(\mathrm{M}_{\mathrm{V}}\right)$ 49

TABELA 6: GRAU MÉDIO DE SUBSTITUIÇÃO (GS), OBTIDO POR ESPECTROSCOPIA NA REGIÃO DE INFRAVERMELHO 53 


\section{RESUMO}

Suspensões coloidais encontram um grande interesse prático e apresentam aplicações na área de material cerâmico. No processamento deste material, a qualidade do produto final depende das propriedades iniciais da suspensão. Portanto, a desaglomeração e dispersão do pó cerâmico são cruciais para que os defeitos sejam minimizados. Para isto, estabilizantes eficientes devem ser utilizados. A carboximetilquitosana (CMQ) é a uma cadeia macromolecular, que apresenta grupos funcionais (carboximetila e amino) que podem adquirir cargas quando dissolvidos em meio aquoso e, por isso, pode ser usada no controle de propriedades de suspensões em que a presença de grupos com cargas seja importante para os mecanismos de estabilização. Neste trabalho, a CMQ foi preparada pela reação entre quitosana e diferentes proporções de ácido monocloroacético. A reação foi realizada em dois meios, um em que ocorreu previamente a dissolução da quitosana em um sistema de solventes (dimetilacetamida/cloreto de lítio) e outro em meio heterogêneo, no qual o material permaneceu em suspensão. A carboximetilação com prévia dissolução da quitosana pode levar a uma distribuição mais homogênea dos grupos carboximetila, quando comparado à preparação em meio heterogêneo, o que poderá influenciar na eficiência da CMQ como estabilizante. As amostras de CMQ foram caracterizadas pelas técnicas de espectroscopia na região de infravermelho (IV), ressonância magnética nuclear (RMN) e análise termogravimétrica (TGA). A técnica de IV, aplicada também para as amostras na forma ácida, permitiu a determinação do grau de substituição médio $(\overline{G S})$, sendo encontrado valores que variaram de 0,6 a 1,1. A eficiência da CMQ como dispersante foi avaliada por meio de medidas viscosimétricas, de potencial zeta e diâmetro médio de partícula. Em geral, houve uma diminuição da viscosidade da suspensão de alumina com a adição da CMQ, com certo destaque para as amostras com $\overline{G S}$ em torno de 1,0. As medidas de potencial zeta mostraram um aumento da magnitude das cargas superficiais, quando na presença de CMQ, o que proporciona repulsão eletrostática entre as partículas. As medidas de diâmetro de partícula mostraram que, além da diminuição do valor médio na região do ponto de carga zero (pcz), em que a agregação é máxima, ocorreu uma diminuição na distribuição dos diâmetros das partículas, em todos os pHs considerados. Estes resultados confirmam a eficiência das amostras de CMQ como estabilizantes para suspensões aquosas de alumina. 


\begin{abstract}
Colloidal suspensions are of great practical interest, including applications in ceramic materials. In colloidal ceramic processing, the quality of the final product will depend on the properties of the initial powder suspension. Thus, an efficient deagglomeration and dispersion of the ceramic powder in a solvent is crucial for minimizing defects. This requires efficient dispersants. Carboxymethylchitosan (CMCh) corresponds to macromolecular chains containing groups carboxymethyl and amino, that can acquire charges when dissolved in water. Then, it can be used for the control of the properties of surface, when the presence of charged groups is important to the mechanisms of particles dispersion. In this work, carboxymethylchitosan was prepared reacting chitosan and different amount of monochloroacetic acid, in two different media. In the first one, chitosan was previously dissolved in a solvent system (dimethylacetamide/ lithium Chloride) and in the second one, corresponding to heterogeneous media, the reactants and products remained suspended during the whole process. The reaction with previous dissolution of chitosan may generate a more homogeneous distribution of carboxymethyl groups, which in turn can influence the CMCh efficiency as dispersant. The CMCh sample was characterized by infrared spectroscopy (IR), nuclear magnetic resonance (NMR) and thermogravimetric analyses (TGA). The obtainment of IR spectra considering the samples of $\mathrm{CMCh}$ in their acid form, also allowed determining the average degree of substitution (DS), that ranged from 0.6 to 1.1. These samples were used as dispersants for aqueous alumina suspensions. In this work the efficiency of the carboxymethylchitosans as stabilizing agents was analyzed considering rheological, zeta potential and average particle size measurements. The addition of $\mathrm{CMCh}$, mainly that with $\mathrm{DS}$ near 1.0 , led to a suspension with lower viscosity. Zeta potential measurements show that the addition of $\mathrm{CMCh}$ results in an increase in the absolute value of zeta potential at the point of zero charge (pzc), what promote the electrostatic repulsion between the particles. The presence of CMCh led also to a suspension with lower average diameter of particles and narrow particle size distribution in all $\mathrm{pH}$ values considered in the present work. The results showed that the charged macromolecules $(\mathrm{CMCh})$ obtained from a renewable source (chitosan), present a good performance as deflocculating agents of alumina suspensions.
\end{abstract}




\section{INTRODUÇÃO}

\subsection{Materiais cerâmicos}

As cerâmicas derivadas de matérias primas naturais, conhecidas como cerâmicas tradicionais, são largamente utilizadas há séculos, sendo que sua aplicação inicial correspondeu à produção de utensílios domésticos. Atualmente, ao lado deste tipo de material, uma extraordinária variedade de cerâmicas especiais surgiu, as quais são consideradas tanto nas áreas de pesquisa, quanto na industrial. Existem cinco grupos principais, que representam as diferentes aplicações dos materiais cerâmicos: cerâmica para ótica, eletrônica, nuclear, aplicações estruturais e biocerâmicas. (YOKOSAWA, 1996; THONGMEE; WATCHARAPSON; JIANSIRISOMBOON, 2008)

A fundamentação contemporânea da indústria cerâmica é baseada nas propriedades que são críticas para determinada aplicação, na estimativa da qualidade do produto e a sua adequação a um uso particular. Esta abordagem é fundamentada no conceito da interdependência entre composição, estrutura e tecnologia, nas principais propriedades dos materiais.(SHMURADKO et al., 2007)

Os materiais cerâmicos têm encontrado grande variedade de aplicações devido às suas características, como alta resistência à corrosão e ao desgaste, quando comparado aos materiais metálicos. Foram desenvolvidas técnicas de modelagem para o processamento coloidal, como, modelagem por gel, modelagem por coagulação, entre outras. Todas estas técnicas têm em comum o fato de serem empregadas suspensões dispersas, com alto teor em sólido (SINGH, 2006). Portanto, a preparação de suspensões aquosas cerâmicas concentradas e com viscosidade moderada, o que indica dispersão, tornou-se um problema central no processamento cerâmico, especialmente no controle das propriedades do produto final. (WANG et al, 2007).

Tipicamente, quando o pó cerâmico é adicionado a um solvente como a água, na etapa inicial do processamento cerâmico, a presença de forças atrativas de van der Waals resulta na agregação das partículas, que pode levar a floculação. Este efeito torna-se mais significativo quanto maior for a concentração da suspensão, pois a distância entre as 
partículas se torna cada vez menor, e a probabilidade de colisões no meio aumenta consideravelmente (GOCMEZ, 2006). Portanto, é essencial o conhecimento das propriedades de suspensões concentradas, o que viabiliza que se interfira na interação entre as partículas para manter a força repulsiva entre elas (CRUZ et al, 2005; LIU; GAO, 2003). Qualquer defeito presente na suspensão estará presente no corpo a verde, que corresponde à suspensão cerâmica antes da etapa de queima, e, conseqüentemente, no produto final.

Usualmente, utiliza-se compostos poliméricos no processamento coloidal de pós cerâmicos, com o objetivo de melhorar características das suspensões, como homogeneidade de concentração do pó, reologia e estado de dispersão. (BAKLOUTIA et al, 2003).

Nestes sistemas coloidais, existem ainda as forças eletrostáticas, que se originam da diferença de solubilidade de íons com cargas opostas, o que gera um potencial eletrostático. Quando $\mathrm{H}_{3} \mathrm{O}^{+}$e $\mathrm{OH}^{-}$são os íons determinantes de potencial, os sítios positivos e negativos do material podem ser controlados através do controle do $\mathrm{pH}$ do meio.

Para o óxido de alumínio, também conhecido como alumina, utilizado no presente trabalho, que é um material cerâmico considerado como estrutural, pode-se propor, de forma simplificada, que a carga na superfície do material varia da de acordo com as equações 1 e 2, dependendo do meio:

$$
\begin{aligned}
& \text { meio ácido: } \mathrm{AlOH}+\mathrm{H}_{3} \mathrm{O}^{+} \rightarrow \mathrm{AlOH}_{2}^{+}+\mathrm{H}_{2} \mathrm{O} \\
& \text { meio alcalino: } \mathrm{AlOH}+\mathrm{OH}^{-} \rightarrow \mathrm{AlO}^{-}+\mathrm{H}_{2} \mathrm{O}
\end{aligned}
$$

Pode-se, ainda, induzir uma carga sobre a superfície do material através da adsorção de espécies com cargas, como é o caso de um polieletrólito, que corresponde a uma cadeia macromolecular que apresenta grupos com cargas (MILAS, 1991; CERRUTTI, 2005).

\subsection{O Estado Coloidal}

Sistemas coloidais são fluidos complexos, compostos por duas fases, conhecidas pelos termos fase dispersa (aquela que é constituída pelas partículas) e meio de dispersão 
(fase pela qual as partículas se distribuem). Um sistema será dito coloidal se um ou mais de seus componentes apresentarem dimensões dentro do intervalo de $1 \mathrm{~nm}$ a $1 \mu \mathrm{m}$ (SHAW, 1975). Portanto, um sistema coloidal pode apresentar espécies com dimensões variando dentro de um intervalo razoável, abrangendo uma grande diversidade de sistemas, como, sangue, cosméticos e detergentes (VASCONSELOS; PEREIRA; FONSECA, 2005).

A característica mais importante de uma mistura coloidal é que o comportamento macroscópico é determinado mais pela natureza de forças entre as partículas na superfície (microscópicas), que pela presença de qualquer outra força externa, tal como a sedimentação devido à gravidade. (YOKOSAWA, 1996)

Os termos liófilo (atração por líquidos) e liófobo (aversão a líquidos) são utilizados para distinguir sistemas coloidais monofásicos e bifásicos. Se o solvente for a água, os colóides são classificados como hidrofílicos ou hidrofóbicos. (HIEMENZ,1986)

Os colóides são ditos liofílicos quando o sistema coloidal é obtido simplesmente pela adição de um solvente adequado ao pó cerâmico. Inicialmente, o pó irá absorver o líquido, aumentando seu volume e formando uma suspensão coloidal homogênea. Já os colóides liofóbicos são dispersos apenas através de uma agitação vigorosa, ou por outra fonte de energia. Na prática, esta distinção entre liófilíco e liofóbico não é sempre fácil, pois existem sistemas que apresentam tanto características de um quanto de outro.

Uma característica importante dos colóides liofóbicos é a instabilidade dos mesmos frente a processos de agregação, no qual a formação de uma única partícula maior e porosa se dá pela união de diversas partículas primárias (PANDOLFELLI, 2000). A característica central da agregação é o fato que a área superficial total é reduzida e os agregados formados são irreversíveis, ou seja, não podem retornar ao estado coloidal inicial (YOKOSAWA, 2001).

A floculação é um processo distinto da agregação, pois as partículas formam flocos, menos firme e mais abertos que os agregados, mas não se fundem para formar uma nova partícula. Na floculação, portanto, não existe a diminuição da área superficial, embora certos sítios superficiais possam estar mais bloqueados em alguns pontos. Outro aspecto importante é que a floculação pode ser revertida e as partículas podem retornar ao estado disperso apenas com a aplicação de uma força externa não muito vigorosa (HIEMENZ,1986; YOKOSAWA, 2001). 


\subsection{Interações partícula-partícula.}

A preparação e aplicação de suspensões aquosas cerâmicas estabilizadas são de grande importância no processamento cerâmico, especialmente para o controle das propriedades do produto final (WANG et al, 2006). Portanto, é essencial o estudo das interações entre as partículas, já que as propriedades de uma mistura coloidal são governadas pelas forças atuantes entre as partículas individuais e consequentemente, as interações partícula-partícula são as responsáveis pela estabilidade ou não de um sistema coloidal.

\subsubsection{Forças de van der Waals.}

A existência de forças atrativas de longo alcance entre átomos pode ser observada pelos desvios das leis dos gases perfeitos de Boyle e Charles. Entretanto, foi a partir de 1873, quando a equação do estado gasoso (3) foi proposta por van der Waals, que as propriedades deste estado e o seu comportamento estimularam fundamentações teóricas para que a origem destas forças fosse entendida. (HUNTER,1987)

$$
\begin{aligned}
& {\left[\mathbf{P}+\left(\mathbf{n}^{2} \mathbf{a} / \mathbf{V}^{2}\right)\right](\mathbf{V}-\mathbf{n b})=\mathbf{n R T} \quad(\mathbf{3})} \\
& \text { na qual: } \mathbf{P}=\text { pressão do gás } \\
& \mathrm{V}=\text { volume ocupado pelo gás; } \\
& \mathrm{n}=\text { número de mol do gás; } \\
& \mathrm{R}=\text { constante universal dos gases; } \\
& \mathrm{T}=\text { temperatura } \\
& \mathrm{a}=\text { constante relacionada a atração entre as moléculas gasosas; } \\
& \mathrm{b}=\text { constante relacionada ao volume ocupado por uma molécula. }
\end{aligned}
$$

As forças atrativas de van der Waals, que estão presentes em todas as interações intermoleculares, ocorrem também entre partículas coloidais.

A existência da força de van der Waals, como definida normalmente em físicoquímica, é resultante da interação entre um dipolo momentâneo de uma molécula e o dipolo 
induzido por ela em uma molécula vizinha. A teoria de London para as forças de van der Waals não requer a existência de momentos dipolares permanentes e, demonstra a universalidade dessa força atrativa. (HUNTER,1987)

Para átomos ou moléculas, as forças atrativas de van der Waals atuam em um intervalo de distância de um nanômetro, ou menos. Entretanto, quando se trata de uma partícula coloidal, estas forças podem atuar em distâncias maiores do que aquelas para átomo e moléculas. Este tipo de interação é chamado de "forças de van der Waals de longo alcance" ou força de Hamaker (HUNTER,1987), e existe devido ao fato de que quando duas partículas coloidais se aproximam, os átomos de uma partícula conseguem interagir com todos os átomos da outra partícula, sendo estes efeitos aditivos para a magnitude das forças de interação partícula-partícula.

\subsubsection{Movimento Browniano}

As partículas coloidais são significativamente maiores que as moléculas de solvente, mas pequenas o suficiente para apresentar o movimento browniano. (VASCONSELOS; PEREIRA; FONSECA, 2005)

O movimento térmico se manifesta em escala microscópica nas soluções através do movimento browniano, que corresponde a um movimento tridimensional ao acaso, que resulta do bombardeamento constante do solvente nas partículas. O movimento das partículas individuais muda continuamente de direção, como conseqüência das colisões ao acaso das moléculas do meio de suspensão, tanto com outras partículas como com as paredes do recipiente.

O momento da colisão é de grande importância, já que a estabilidade das suspensões coloidais é diretamente dependente do modo como as partículas interagem durante esta fração de tempo. Uma possibilidade corresponde a formação de aglomerados de partículas e, em uma escala microscópica, pode ocorrer flutuações de concentração ao longo do sistema coloidal. (SHAW, 1975; MEGIATTO, 2001) 


\subsubsection{Dupla Camada Elétrica}

Quando duas fases são colocadas em contato, existe a tendência de alguns constituintes com cargas (elétrons ou íons) serem atraídos em diferentes graus na direção das duas fases, orientando-se então seletivamente, de acordo com os dipolos moleculares das fases (HUNTER, 1981). Portanto, quando íons estão presentes em um sistema que contem uma interface, existirá uma variação na densidade de íons próximos à interface. A região fronteiriça será identificada como interface e define o excesso de carga na superfície. Supondo que fosse possível separar completamente as duas fases, a partir da interface cada uma dessas fases separada teria carga de mesma magnitude, mas opostas. Estas duas porções carregadas e separadas correspondem à dupla camada elétrica (DCE). (HIEMENZ,1986). A teoria da dupla camada elétrica, portanto, trata da distribuição de íons e, conseqüentemente, da intensidade dos potenciais elétricos que ocorrem na superfície com carga.

Qualquer região fronteiriça entre duas fases é caracterizada pela presença de forças anisotrópicas, que são as responsáveis pelos fenômenos interfaciais (GONZALES; TICIANELLI,1998). Para um sistema eletrolítico, esta região fronteiriça é chamada de dupla camada elétrica, já mencionada, e as forças anisotrópicas provocam uma distribuição desigual das cargas elétricas, já que uma camada de íons de carga oposta (contra-íon) irá se adsorver sobre a superfície carregada da partícula, deixando o meio circundante eletricamente neutro. A região mais distante da superfície da partícula é caracterizada pela distribuição difusa dos co-íons. Uma representação esquemática da dupla camada elétrica é mostrada na figura 1 . 


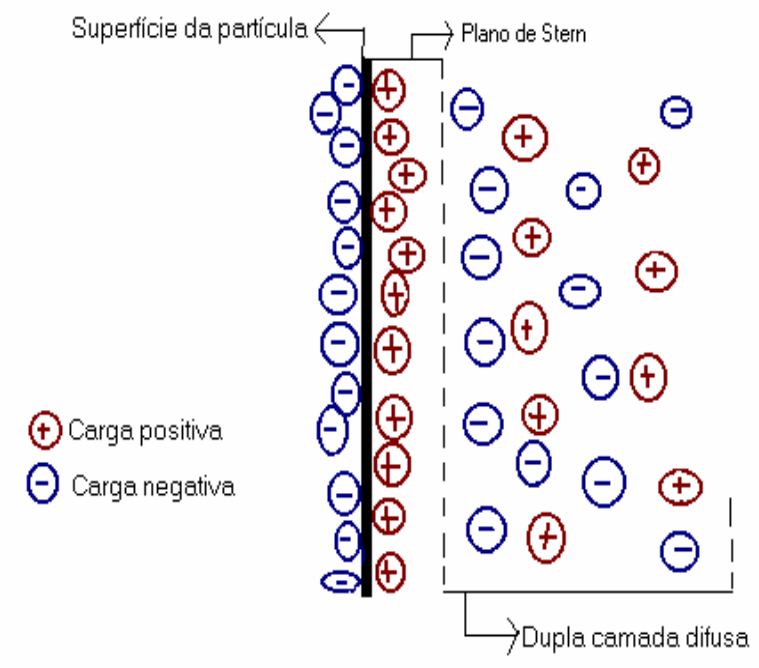

Figura 1: Representação esquemática da dupla camada elétrica. (EVERETT, 1989)

O modelo mais simples para se estudar a dupla camada considera a interface como um capacitor de placas paralelas e foi elaborado por Guy e Chapman. O modelo de GuyChapman apresenta um bom resultado quantitativo e, faz as seguintes considerações:

- A superfície é supostamente plana, de extensão infinita e com cargas distribuídas de maneira uniforme;

- Os íons da parte difusa da dupla camada são considerados como cargas puntiformes, distribuídas segundo a distribuição de Boltzmann;

- O solvente influencia a dupla camada somente através da sua constante dielétrica, que tem o mesmo valor através de toda parte difusa. (SHAW, 1975)

O comportamento de muitos sistemas pode ser previsto pela teoria de GuyChapman, que está em concordância com alguns resultados experimentais. Por exemplo, por meio desta teoria, pode-se afirmar que a densidade de carga superficial de uma partícula aumenta com o aumento da concentração de sal, enquanto a magnitude do potencial de superfície diminui com o aumento da concentração de sal. Tal fato foi 
experimentalmente confirmado pela concordância existente entre a determinação experimental da densidade de carga superficial de uma borracha natural, feita pro meio de titulação, e a determinação teórica, feita por meio de uma equação. (BUSCAL, 1985)

Como a interação entre partículas carregadas é governada pela sobreposição de suas camadas difusas, a teoria de dupla camada elétrica se torna de grande importância, sendo o potencial de interesse aquele da interface do plano de Stern e da dupla camada difusa. Entretanto, o potencial de Stern ( $\left.\Psi_{\mathrm{s}}\right)$ não pode ser medido experimentalmente, por isso, utiliza-se a medida do potencial zeta $(\xi$,$) que corresponde ao plano de cisalhamento$ próximo ao plano de Stern. O potencial zeta será discutido na seqüência deste texto.

\subsection{Teoria Derjaguin - Landau e Verwey - Overbeek (DLVO)}

A estabilidade coloidal é relacionada à existência de uma barreira de energia potencial repulsiva entre as partículas coloidais, que impede a aproximação destas. (SONG; SHANG, 2007). Derjaguin - Landau e Verwey - Overbeek (DLVO) desenvolveram, independentemente, uma teoria quantitativa na qual a estabilidade de sistemas coloidais é tratada em termos das variações de energia que ocorrem quando as partículas se aproximam umas das outras. Segundo a teoria DLVO, a barreira energética varia como resultado da repulsão entre a dupla camada elétrica e da força atrativas de van der Waals.

Em dispersões homogêneas de partículas, a energia potencial da dupla camada elétrica entre duas esferas $\left(V_{R}\right)$ é expressa pela equação 4 :

$$
V_{R}=\frac{1}{2} \varepsilon a \psi^{2} \ln [1+\exp (-\kappa h)]
$$

na qual: $\varepsilon=$ constante dielétrica absoluta do meio;

$\mathrm{a}=$ raio da partícual;

$\psi=$ plano externo de Helmholtz (OHP);

$\kappa=$ comprimento recíproco de Debye-Huckel;

$\mathrm{h}=$ menor separação entre as partículas. 
A energia potencial das interações de van der Waals entre duas esferas $\left(\mathrm{V}_{\mathrm{A}}\right)$ pode ser calculado pela equação 5:

$$
V_{A}=\frac{a A_{131}}{2 h}
$$

na qual: $\mathrm{A}_{131}=$ constante de Hamaker das partículas (1) no meio (3);

$\mathrm{h}=$ menor separação entre duas partículas.

De acordo com as equações 4 e 5, para dispersões coloidais aquosas, nas quais a interação de van der Waals entre duas partículas é constante, a desestabilização devido à agregação é sensível ao potencial zeta das partículas. Quanto menor for o valor absoluto de potencial zeta, mais a agregação será favorecida. (SONG; ZHANG, 2007)

A figura 2 mostra o caráter geral da curva de energia potencial de interação versus a distância de separação das partículas, segundo a teoria DLVO. A energia de repulsão é uma função exponencial da distância que separa as partículas, com um alcance da ordem da espessura da dupla camada elétrica, e a energia de atração decresce inversamente com o aumento da distância entre as partículas. Portanto, fica claro que quando a distância entre as partículas diminui, a magnitude da atração aumenta. Por outro lado, como mencionado anteriormente, a energia repulsiva diminui exponencialmente com o aumento da distância entre as partículas, logo, mais rapidamente que a atrativa. Então, a pequenas ou grandes distâncias entre partículas, predominará a atração de van der Waals. A distâncias intermediárias, que dependem do potencial da dupla camada, poderá predominar a repulsão das duplas camadas elétricas. 


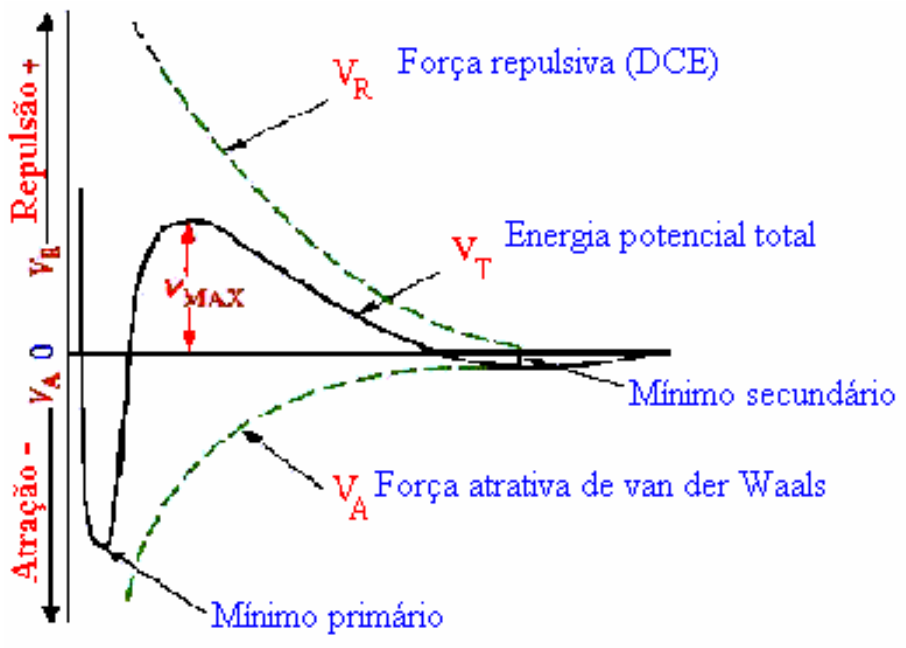

Figura 2: Energia potencial de interação partícula-partícula em função da separação das partículas. (SHAW, 1975)

Observa-se a existência de um "Mínimo Primário" de potencial (Figura 2), no qual a agregação ocorre de maneira irreversível. Já em distâncias de separação maiores existe o potencial do "Mínimo Secundário", no qual há a possibilidade de agregação fraca ou reversível, nesse caso mais corretamente chamada de associação.

\subsection{Mecanismos de Estabilização}

Quando um polímero é adicionado a uma mistura coloidal, ocorrem mudanças nas forças atrativas que atuam a longas distâncias e, nos padrões da dupla camada elétrica em torno da partícula. A presença de um polímero adsorvido introduz novos fatores às condições de atração/repulsão, que não estavam presentes quando somente partículas coloidais estavam no meio.

As mudanças que podem ocorrer na dupla camada elétrica estão representadas de forma esquemática na figura 3 e podem ser resumidas como: 
- Mudanças de carga na superfície devido à mudanças na ionização de grupos da superfície;

- Deslocamento dos contra-íons adsorvidos, devido à adsorção de segmentos da cadeia polimérica;

- Deslocamento de dipolos orientados da água, devido à adsorção de segmentos de polímero;

- Mudanças na constante dielétrica e espessura da camada interna devido à presença de segmentos adsorvidos;

- Mudanças na dupla camada difusa. (YOKOSAWA, 1996; LUCKHAM, 1997)

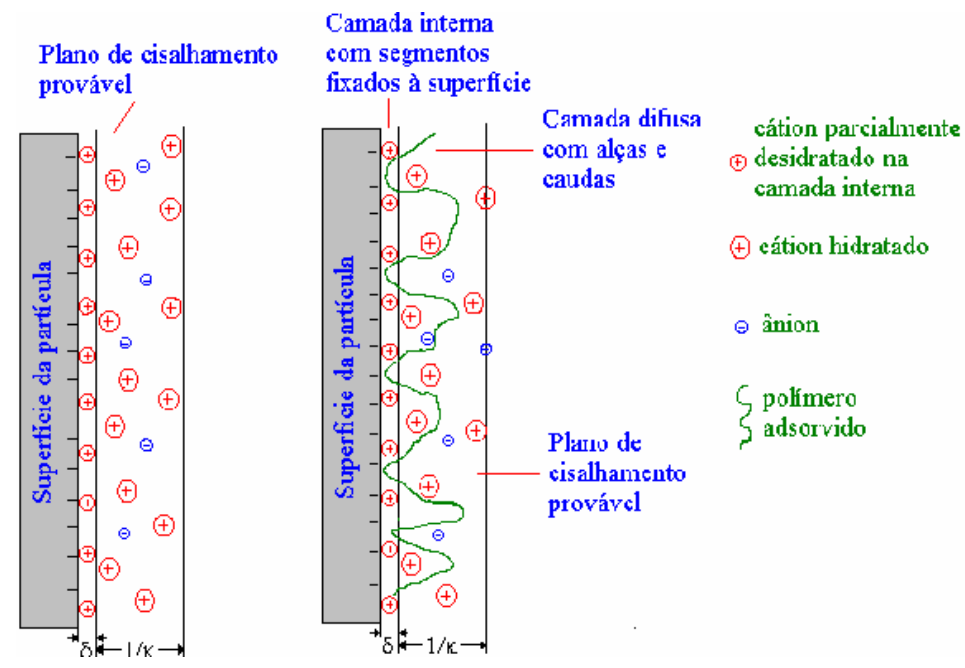

Figura 3: Efeito da adsorção de um polímero sobre a dupla camada elétrica. (LUCKHAM; 1997)

Quando a estabilização ocorre através da adsorção de um polímero, como descrito anteriormente, o efeito obtido é chamado de estabilização estérica.

A adsorção de um polímero pode ocorrer devido a uma interação coulumbica, ligação hidrogênio, interações de van der Waals. Para que esta adsorção leve à estabilização, de modo que quando as partículas revestidas pelas cadeias poliméricas se aproximem ocorra a repulsão, deve haver uma energia livre positiva envolvida na aproximação. Polímeros que apresentam um segmento que interage fortemente com a 
superfície a ser estabilizada e, outro segmento que possa se mover livremente no solvente podem ser bons agentes de estabilização estérica. Se o meio de dispersão for um bom solvente para estes segmentos, a interação é desfavorecida e os segmentos ficam estendidos para o meio da solução. (PALMQVIST et al, 2006)

Quando partículas coloidais com polímero adsorvido se aproximam, existe a tendência das camadas poliméricas se interpenetrarem, causando dois efeitos: 1) efeito osmótico devido ao aumento na concentração total das espécies adsorvidas entre as partículas; 2) efeito entrópico ou restrição de volume devido à perda de graus de liberdade resultante da interação das cadeias poliméricas.

Em ambos, ocorrerá um decréscimo na entropia, o que é desfavorável. O efeito osmótico também pode ser acompanhado por um fator entálpico, pois se é forçada a proximidade entre as cadeias adsorvidas, promovendo a interpenetração entre as mesmas, diminui a interação polímero-solvente e aumenta a interação polímero-polímero o que é desfavorável devido a dessolvatação das cadeias poliméricas mais próximas. Assim, para recuperar a perda de entropia, as partículas devem se distanciar para permitir maior movimentação às mesmas, enquanto que, o solvente se move para solvatar novamente as cadeias. Como resultado, se tem uma barreira energética que dificulta a aproximação das partículas, gerando um mecanismo efetivo para a estabilização (EVERETT, 1989)

A adsorção do polímero ainda depende de uma série de características do próprio polímero, que incluem valor da massa molecular média, comprimento médio da cadeia e conformações assumidas no meio, entre outros (YAN, 2004). Estes parâmetros mencionados são de importância destacada, já que se a partícula não estiver totalmente recoberta pelo polímero, poderão ocorrer interações entre partes da cadeia polimérica com outra partícula, formando o que se chama de "pontes", podendo resultar em floculação (WIŚNIEWSKA; 2007). Portanto, o polímero passaria a agir como um floculante, apresentando efeito oposto ao desejado, quando o que se pretende é a estabilização do sistema coloidal.

Existem outros dois mecanismos pelos quais uma mistura coloidal pode ser estabilizada: estabilização eletrostática e estabilização eletroestérica.

A estabilização eletrostática é conseguida quando a interação entre a dupla camada elétrica das partículas próximas supera a magnitude das forças atrativas de van der Waals, 
ocorrendo então repulsão e prevenindo a agregação(ORTEGA et al. 1999). Para suspensões de óxidos metálicos, como a alumina, existe uma faixa de $\mathrm{pH}$, na qual ocorre a estabilização ótima sem a adição de estabilizantes, devido unicamente à repulsão eletrostática das superfícies carregadas. (SINGH et al, 2005)

A estabilização eletroestérica é obtida pela adsorção de polieletrólito nas partículas. Um polieletrólito é caracterizado por apresentar uma cadeia extensa de átomos, como as dos polímeros, apresentando também grupos com cargas ao longo dessa cadeia (VASCONSELOS; PEREIRA; FONSECA, 2005), sendo que estas cargas podem surgir devido a processos de ionização, que depende do $\mathrm{pH}$ do meio.

A estabilização eletroestérica é uma combinação dos dois mecanismos anteriores, ou seja, as partículas são mantidas afastadas devido a repulsão eletrostática e ao impedimento estérico. Esquematicamente, os diferentes mecanismos de estabilização são mostrados na figura 4

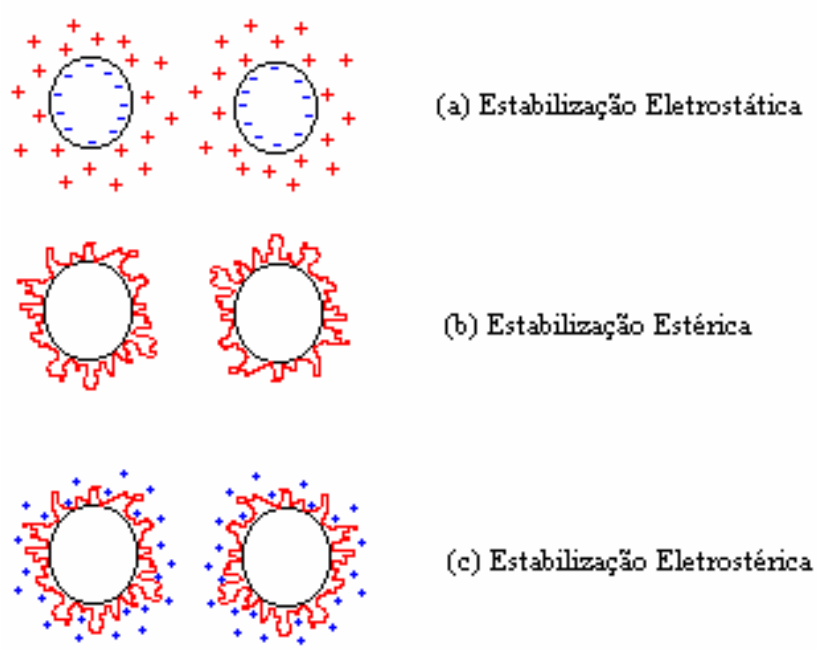

Figura 4: Ilustração dos mecanismos de estabilização: a) Eletrostático; b) Estérico; c) Eletroestérico. (PANDOLFELLI, 2000)

O ácido poliacrílico, é um estabilizante largamente utilizado para suspensões aquosas de alumina, e oferece estabilização deste tipo, já que existe alta densidade de grupos carboxílicos (e carboxilatos, dependendo do $\mathrm{pH}$ do meio) na cadeia linear do polímero. Algumas interações entre os grupos carboxilato e carboxílicos e a superfície da 
alumina, considerando diferentes espécies que podem estar presentes são mostrados na figura 5, juntamente com a representação esquemática do ácido poliacrílico.<smiles>CCCCC(CC(C)CC)C(=O)O</smiles>

(a)

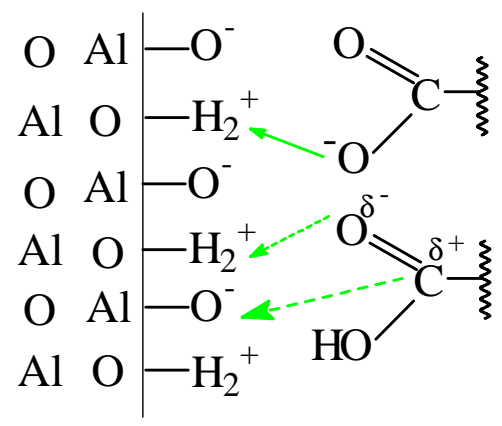

(b)

Figura 5: Representação esquemática da estrutura do ácido poliacrílico (a) e Interações entre a superfície da alumina e o polímero carboxílico(b). (YOKOSAWA, 2001)

No presente trabalho, estudos foram desenvolvidos considerando a ação de uma macromolécula polieletrolíticas sobre a estabilidade de suspensões de alumina.

\subsection{Potencial Zeta}

Como mencionado anteriormente, quando duas fases são colocadas em contato, geralmente desenvolvem uma diferença de potencial e, conseqüentemente, espécies carregadas irão se distribuir de maneira não uniforme na interface. Quando uma dessas fases é obrigada a se mover tangencialmente à segunda fase, ocorrem fenômenos chamados de efeitos eletrocinéticos.

Em quase todos os fenômenos eletrocinéticos, um fluído se move com relação a uma superfície sólida. $\mathrm{O}$ grande interesse corresponde à determinação da relação entre a velocidade do fluido e a determinação do campo elétrico na região interfacial. Um conceito de grande importância introduzido no estudo dos efeitos eletrocinéticos é aquele de superfície de corte, que corresponde à uma superfície imaginária, que está junto à superfície do sólido e, dentro da qual o fluído é estacionário. 
A análise de forças a que sólidos ou líquidos são submetidos, pode ser realizada em termos da carga ou potencial eletrostático. No último caso, calcula-se a média de potencial na superfície de corte, sendo o resultado chamado de potencial eletrocinético, ou potencial zeta, que é universalmente conhecido pela letra grega zeta ( $\xi$ ) (HUNTER, 1981).

A medida do potencial zeta leva à determinação da carga eletrostática superficial de pequenas partículas sólidas dispersas no meio. A magnitude desta carga determina a estabilidade do colóide, pois, se a determinação do potencial zeta mostrar um valor alto, significa que a densidade de cargas de um mesmo sinal sobre as partículas é alta, tendo como consequiência a repulsão mútua entre elas. Se as partículas apresentarem carga resultante próxima de zero, o movimento browniano é bastante pronunciado no colóide, normalmente tendo como efeito final a aglomeração das partículas, levando a instabilidade do sistema.

Muitas outras propriedades importantes dos sistemas coloidais são determinadas direta ou indiretamente pelo potencial zeta, por exemplo, a adsorção de íons e moléculas polares, que são fortemente influenciadas pelo potencial da superfície.

Como mencionado anteriormente, as propriedades dos óxidos em suspensões aquosas são dominadas pelo efeito do $\mathrm{pH}$, sendo que em meio alcalino esses compostos apresentarão majoritariamente carga negativa, e em meio ácido positiva. Existe uma faixa de $\mathrm{pH}$ na qual o número de cargas positivas e negativas é igual, sendo conhecido como $\mathbf{p H}$ de ponto de carga zero (pHpzc). Neste $\mathrm{pH}$, a resultante da carga na superfície das partículas é nula e, portanto, favorece a interação eletrostática entre as partículas com cargas opostas, o que promove a desestabilização do sistema (GAYDARDZHIEV; JANECZKO, 2006). Na literatura, encontra-se que o pHpzc pode ocorrer no intervalo de pH entre 6 e 9, dependendo das características da alumina utilizada (MEGIATTO, 2001; PANDOLFELLI, 2000).

O potencial zeta é uma técnica de grande importância na determinação do $\mathrm{pH}$ no qual ocorre o ponto isoelétrico, ou ponto de carga zero, já que suas medidas são rápidas e não tediosas, como é, normalmente, a determinação de isotermas de adsorção. (GREENWOOD; 2003).

No presente trabalho, uma das avaliações referente a estabilidade de suspensões de alumina foi feita via medidas de potencial zeta. 


\subsection{Reologia}

A reologia corresponde ao estudo da relação entre a tensão aplicada a um determinado material e a deformação resultante. (SHAW; 1975)

A viscosidade é a variável mais importante no conhecimento do comportamento reológico de uma suspensão. Pode ser definida como a resistência que um fluido oferece à deformação por agitação ou cisalhamento.

A equação $\mathbf{F} / \mathbf{A}=\boldsymbol{\eta} \mathbf{d v} / \mathbf{d} \mathbf{x}$

na qual: $\mathrm{F}=$ força aplicada;

$\mathrm{A}=$ área das placas paralelas;

$\eta=$ viscosidade;

$\mathrm{dv}=$ velocidade infinitesimal de movimento das placas;

$\mathrm{dx}=$ separação infinitesimal das placas.

foi proposta por Isaac Newton e descreve o escoamento de um fluido sob cisalhamento constante, que corresponde ao modelo mostrado na figura 6 .

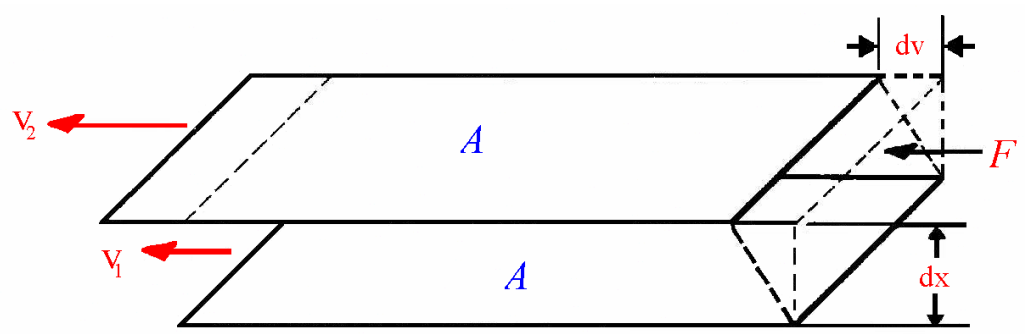

Figura 6: Modelo de Isaac Newton para descrever a viscosidade: duas placas paralelas de área “A”, separadas por uma distância infinitesimal "dx", movendo-se com velocidades distintas V1 e V2, em uma mesma direção, sob aplicação de uma força. (JONES; 1993) 
A viscosidade de um sistema coloidal é maior que a de um líquido puro. Isso acontece porque a presença das partículas no meio provoca uma perturbação das linhas de fluxo, tornando maior a energia necessária para que o deslizamento relativo entre camadas infinitesimais do fluido ocorra. A verificação macroscópica desse fato é o aumento da viscosidade (HUNTER, 1981).

Um líquido pode se comportar de diferentes maneiras ao longo do tempo e também em função da taxa de cisalhamento, no que diz respeito a viscosidade. Se o líquido for ideal, apresentará um comportamento newtoniano e sua viscosidade será independente da velocidade de cisalhamento. As suspensões coloidais, entretanto, apresentam a viscosidade variável e dependente da taxa de cisalhamento, sendo, portanto chamadas de fluidos não newtonianos. Dentro desta classe, estão os comportamentos pseudoplástico, no qual ocorre um decréscimo da viscosidade aparente com o aumento da tensão ou da taxa de cisalhamento e, o comportamento dilatante, no qual ocorre o aumento da viscosidade com o aumento da tensão ou da taxa de cisalhamento (SHAW, 1975). Estes comportamentos são ilustrados na figura 7 .

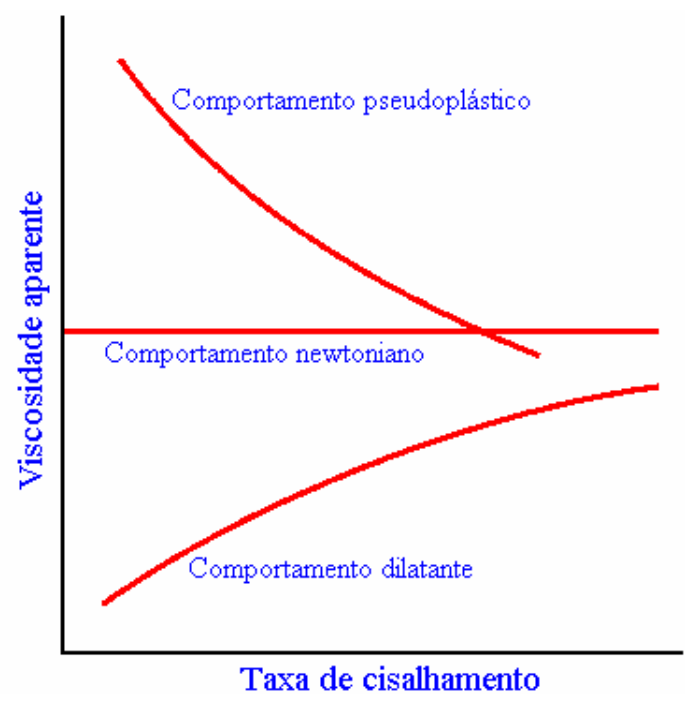

Figura 7: Comportamento reológico em função da taxa de cisalhamento aplicada. (MUTSUDDY, 1994).

O comportamento pseudoplástico é resultante do fato de que as forças de van der Waals geram aglomerados de partículas fracamente ligadas, que são desfeitos pela tensão 
aplicada à amostra. Já o comportamento dilatante, é observado quando em suspensões muito concentradas de sólidos, a velocidade de cisalhamento quebra o empacotamento existente, liberando o líquido que estava preso entre as partículas sólidas, permitindo que estas se movam, caracterizando o fluxo. Sob altas taxas de cisalhamento, ocorre um aumento no movimento das partículas, ou seja, do fluxo e um aumento da viscosidade é observado (YOKOSAWA, 1996, 2001)

Existem também os fluidos nos quais a viscosidade será dependente do tempo, analogamente àqueles nos quais a viscosidade dependia da taxa de cisalhamento. $\mathrm{O}$ aumento da viscosidade em função do tempo é o fenômeno chamado de reopexia. Já o decréscimo da viscosidade como função do tempo é chamado tixotropia.

Em um sistema coloidal, considera-se que as partículas do sistema tenham o comportamento de uma esfera e que apresentam uma distribuição pequena de diâmetros, entretanto, não monodispersas. De acordo com a teoria de Kriegeer e Dougherty, para esferas rígidas, a viscosidade $(\eta)$ é relacionada ao volume $(\phi)$ pela equação 7 :

$$
\eta=\eta_{s}-\left(1-\frac{\phi}{\phi_{m}}\right)^{-[\eta]} . \phi_{m}
$$

na qual: $\eta_{\mathrm{s}}$ é a viscosidade do meio líquido;

[ $\rceil$ e é a viscosidade intrínseca;

$\phi_{\mathrm{m}}$ é o volume fracional da esfera empacotada.

A equação 7 mostra que o aumento de $\phi_{\mathrm{m}}$ da suspensão produz um efeito duplo na melhora das propriedades reológicas da suspensão e da estabilidade. De fato, a agregação das partículas é o principal fator que afeta a viscosidade e a estabilização da suspensão. Portanto, é indispensável a adição de estabilizantes para que ocorra a quebra do agregado e, desta forma, a fluidez e a possibilidade de moldagem da suspensão cerâmica aumentem. (WANG et al, 2006)

No presente trabalho, medidas de viscosidade foram realizadas, com o objetivo de avaliar a estabilidade de suspensões aquosas de alumina em condições de pH diversificadas. 


\subsection{Diâmetro de Partícula}

Outro parâmetro que é importante para se investigar em dispersões coloidais (especialmente aerossóis e sólidos dispersos em líquidos) é o tamanho médio e a forma das partículas, já que a maioria das outras propriedades do sistema é influenciada, em alguma extensão, por estes fatores. (HUNTER,1987). Dependendo da aplicação a que se destina a suspensão, pode ser necessário obter partículas maiores ou menores. Partículas menores, por exemplo, podem se ajustar melhor aos moldes resultando em melhor empacotamento no corpo a verde e maiores densidades no produto final. (STAIGER, 2002) Portanto, além do conhecimento dos mecanismos de estabilização e do comportamento reológico, as medidas para se determinar o tamanho de partícula e as propriedades eletrocinéticas têm recebido grande atenção (YOKOSAWA; FROLLINI, 2002).

Um problema recorrente corresponde a descrição do tamanho médio de partícula em sistemas que são heterodispersos ou polidispersos (isto é, que contem muitos tamanhos diferentes de partículas). Para resolver este problema, utiliza-se a separação das magnitudes de tamanho entre classes, registrando o número de partículas em cada classe. Os resultados podem ser plotados como um histograma ou uma curva suavizada, como mostra a figura 8.

Existem muitos métodos para avaliar a distribuição de tamanho de partícula, mas um que vem encontrando grande aplicação para o estudo de suspensões diluídas, recorre a utilização de sondas óticas. Por exemplo, para este fim, a técnica que emprega os princípios da espectroscopia de correlação de fótons (Photon Correlation Spectroscopy - PCS), também conhecida como espalhamento de luz quasi-elástico (Quasi-Elastic Light Scattering - QELS) ou espalhamento de luz dinâminco (Dinamic Light Scattering - DLS), tem sido utilizada (YOKOSAWA, 2001). 


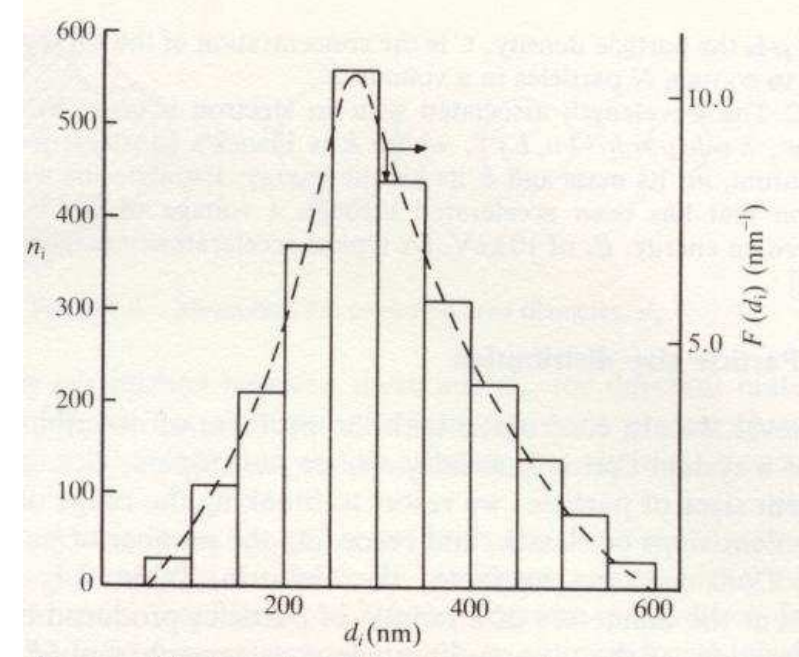

Figura 8: Histograma utilizado para a representação de tamanho de partículas para sistemas polidispersos. (HUNTER, 1987)

Dentre as técnicas disponíveis para a medida do tamanho de partícula, o espalhamento de luz oferece muitas vantagens: rapidez, versatilidade, pequeno volume de amostra, técnica não destrutiva, e medidas de tempo independente da densidade de partícula. Para partículas com tamanho inferior ao mícron, esta técnica é, algumas vezes, a única viável.

Ao longo dos anos, muitas princípio de espalhamento de luz foram utilizados para determinar o tamanho partícula. Dentre estes:

- Mudanças na intensidade média da luz, como função do ângulo;

- Mudanças na polarização;

- Mudanças no comprimento de onda;

- Flutuações na intensidade média.

Este último fenômeno é a base do QELS. Esta técnica utiliza um feixe de luz monocromática (laser) e, se baseia no fato de que partículas em dispersões coloidais estão continuamente em movimento. Como conseqüência, a luz espalhada apresentará um espectro de frequiência, que depende das flutuações e do movimento das partículas. A variação na freqüência da luz espalhada é sentida por um “correlator de fótons”, que 
permite a correlação de tempo entre as flutuações na intensidade da luz a ser analisada. (EVERETT;1989)

O diâmetro, d, de uma partícula esférica pode ser determinado a partir do coeficiente de difusão, por meio da equação Stokes-Einsten (8):

$\mathrm{D}=\mathrm{kT} / \mathbf{3} \pi \eta \mathbf{d}$

Sendo: $\mathrm{D}=$ coeficiente difusional;

$\mathrm{k}=$ constante de Boltzman;

$\mathrm{T}=$ temperatura absoluta;

$\eta=$ viscosidade do meio líquido.

Esta técnica foi utilizada no presente trabalho para avaliar variações no tamanho médio das partículas em suspensão, em função de condições de pH diversificadas.

\subsection{Polissacarídeos polieletrolíticos}

A dispersão de suspensões coloidais de alumina foi extensivamente estudada. Uma grande variedade de dispersantes mostrou grande eficiência, como policarboxilato de amônia (SINGH et al. 2005), poliacrilato de amônia (ORTEGA et.al., 2008), citrato de amônio (SINGH; BHATTTACHARJEE; BESRA, 2002; DHARA; BHARGAVA 2005), albumina (SINGH; BHATTTACHARJEE; BESRA, 2002), ácido polimetacrílico (SHIN; SU; SHEN, 2006) aquil-sulfato de sódio (SONG; ZHANG, 2007). Os copolímeros, como poli(ácido acrílico-b-etileno), poli(etileno-co-propileno), entre outros, também foram extensivamente utilizados e mostraram boa eficiência (BOUHAMED; BOUFI, MAGNIN, 2007; BAKLOUT et al, 2003; SAKAR-DELIORMANLI et al, 2004; RONDHAMEI et al, 2004). Analisando a literatura, percebe-se que os polieletrólitos são os dispersantes mais largamente utilizados no estudo de estabilidade de suspensões cerâmicas. (RAICHUR, 2007).

Atualmente, com a crescente preocupação com o impacto ambiental que certos processos podem causar, novos dispersantes que sejam biodegradáveis e se enquadrem nas 
regulamentações ambientais, devem ser desenvolvidos. Dentre os novos materiais que estão sendo pesquisados com esta finalidade, encontram-se os polissacarídeos (CHEN; LIU; WANG,2006), como a quitina e a quitosana (ZHU et al 2006). Alguns polissacarídeos podem apresentar comportamento polieletrólitoco pois, em solvente polar adequado, dependendo do $\mathrm{pH}$, podem ter grupos com cargas positivas como na quitosana, negativas, como em carboximetilcelulose, ou cargas positivas e negativas, como no caso da carboximetilquitosana (MILAS, 1991).

Devido às atividades agrícolas e pesqueira, no Brasil grandes quantidades de celulose e quitina estão disponíveis como rejeitos. Tal fato tem motivado a exploração e uso destes rejeitos (GUO, et al 2006; LI; SHIE; LO, 2006; RABEA, 2003). Um exemplo corresponde a obtenção da carboximetilquitosana, a partir da quitosana, para sua utilização como estabilizantes de suspensões aquosas de alumina, como foi considerado no presente trabalho.

\subsection{Quitosana}

A quitosana, considerada um biopolímero, é biodegradável, não-tóxica, constituído por unidades de 2-acetamida- 2-desoxi-D-glicopiranose unidas por ligações $\beta(1 \rightarrow 4)$. A quitosana pode ser definida como um copolímero de 2-amino-2-desoxi-D-glicopiranose e 2-acetamida-2-desoxi-D-glicopiranose, de composição variável em função do grau residual de acetilação, cujas unidades também são unidas por ligações $\beta(1 \rightarrow 4)$. A quitosana é um derivado da quitina, obtida pela desacetilação desta última (figura 9). (SARAVANAN et al, 2006).

Há um crescente interesse sobre propriedades da quitosana e possibilidades de aplicações aplicações, como nas áreas farmacêutica, de biomateriais, cosmética, processamento de alimentos. Recentemente, a quitosanas começou a ser utilizada como dispersante para suspensões de $\mathrm{SnO}_{2}$. (CASTRO; GOUVÊA, 2003) 


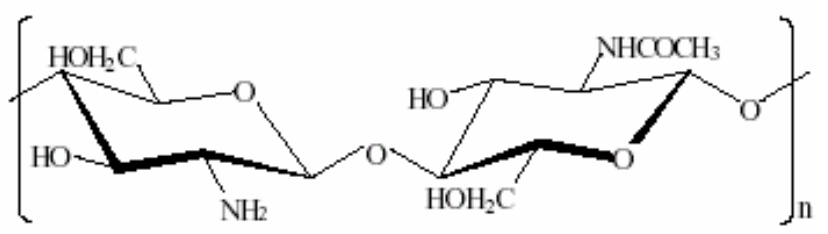

(a)

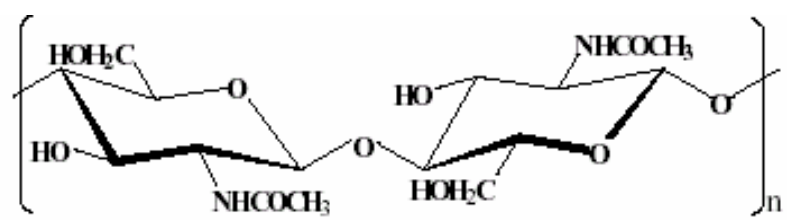

(b)

Figura 9: Representação esquemática da estrutura idealizada da (a)quitina e (b) quitosana; sendo n igual ao grau de polimerização. [Abreu, 2006]

Os termos quitina e quitosana são amplamente usados, mas nenhum dos dois representa uma estrutura química única (SIGNINI, 2006). Geralmente a quitina não existe na natureza como substância simples, pois ocorre complexada com outras substâncias e, por isso, dependendo da fonte de quitina e do método de hidrólise utilizado, a quitosana pode apresentar grandes variações em sua massa molecular média e no grau médio de acetilação (LI, 2006). Usualmente, denomina-se quitosana quando a cadeia do polissacarídeo apresenta grau médio de acetilação $(\overline{G A})$ menor do que $50 \%$.

$\mathrm{Na}$ literatura, os valores de pKa descritos para a quitosana variam de 6,3 a 7,0 (SIGNINI, 1998). A quitosana é uma polibase e, como tanto forma sais quando reage com ácidos originando polieletrólitos cujas solubilidade dependente da natureza do ânion (contra-íons) envolvido. Massa molar média e grau médio de acetilação são fatores que também interferem na solubilidade da quitosana. Por exemplo, o valor médio do grau de acetilação controla a solubilidade em água, já que a solubilidade da quitosana depende das interações entre os grupos amino, resultantes da desacetilação dos grupos acetamidas da quitina, e o solvente. 


\subsection{Carboximetilquitosana}

Como mencionado anteriormente, os grupos amino da quitosana são protonados em extensão razoável quando $\mathrm{pH} \approx \mathrm{pKa} \approx 6,5$ (ABREU, 2006), o que permite a solubilização da quitosana apenas em soluções diluídas de ácido. Portanto, para que se supere o fato da quitosana ser solúvel apenas em soluções com pHs inferiores a 6,5, vários derivados de quitosana têm sido sintetizados, sendo a carboximetilquitosana (CMQ) de grande relevância (GUO, 2006). Modificações químicas na estrutura da quitosana, tais como as resultantes de reação de carboximetilação, permitem a obtenção de derivados solúveis em ampla faixa de $\mathrm{pH}$ (CHEN, 2003).

Dentre os derivados solúveis em água da quitosana obtidos até o momento, a carboximetilquitosana, que apresenta grupos éter, é o único que apresenta tanto os grupos $\mathrm{COOH}$, como os grupos $-\mathrm{NH}_{2}$. (CHEN; PARK, 2003). A carboximetilquitosana apresenta grande importância devido às suas características como atividade antifúngica, baixa toxicidade e propriedades de membrana, que permite sua aplicação para liberação de fármacos. (LIU, 2007)

A figura 10 mostra, de forma esquemática, a reação de carboximetilação de quitosana, considerando a hidroxila como sítio reativo, ou seja, a O-carboximetilação. 

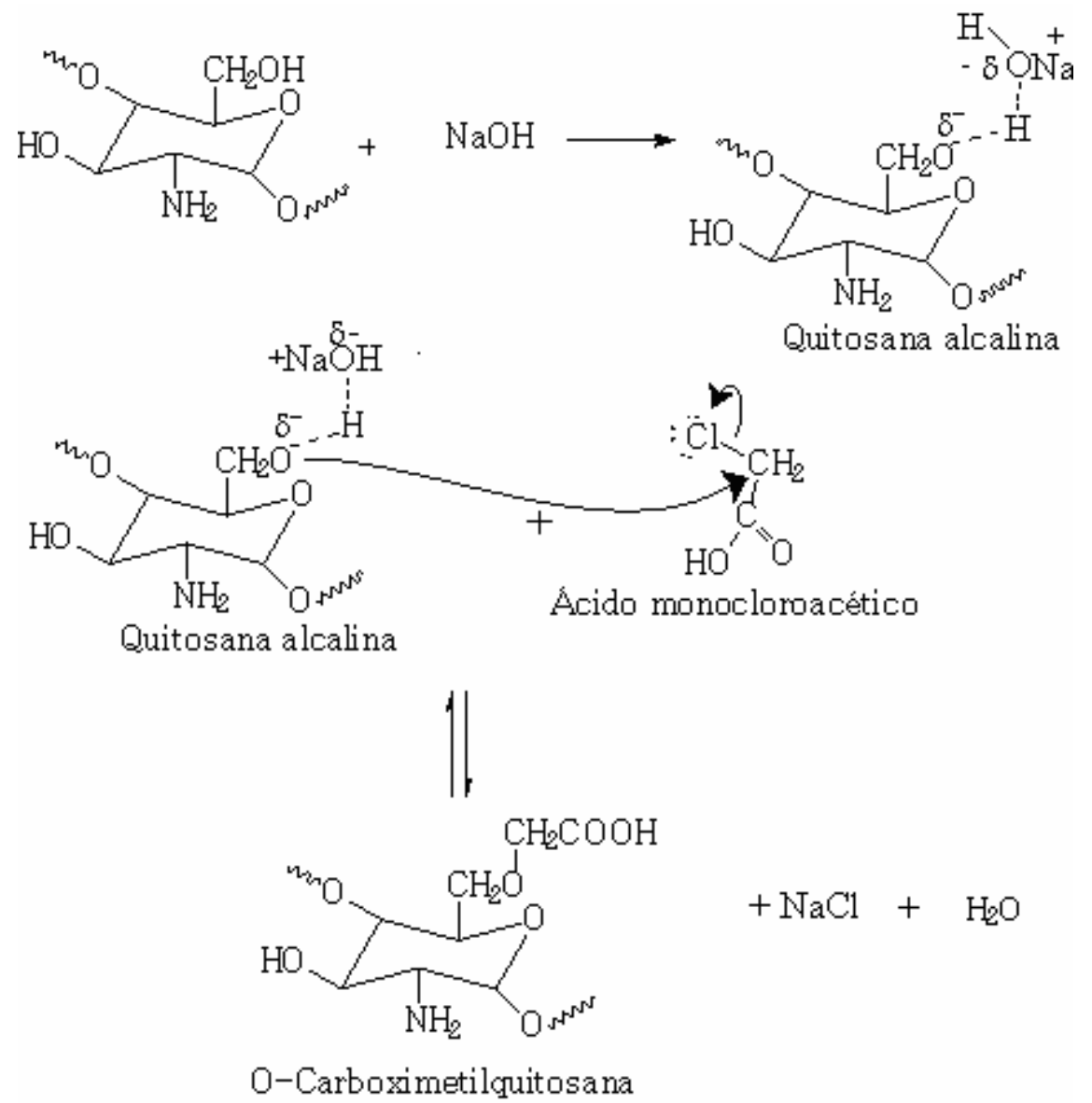

Figura 10: Representação esquemática da reação de O-carboximetilação da quitosana.

(ABREU,2006)

A O-Carboximetilquitosana se comporta como um polieletrólito fraco e pode sofrer agregação em soluções aquosas neutras, já que neste meio, os grupos amino não são protonados e a maior parte dos grupos carboxílicos não está dissociado, o que não permite uma interação eficiente com as moléculas de água, que são altamente polares.(ZHU et al., 2006), o que favorece a interação entre as cadeias poliméricas. Portanto, a ligação hidrogênio intermolecular da O-Carboximetilquitosana é a principal força responsável pela agregação em solução.

A carboximetilação da quitosana também pode ocorrer tendo o grupo amino como sítio reativo, gerando a N-Carboximetilquitosana (Figura 11). Sua preparação seletiva, ou seja, sem que ocorra a O-carboximetilação é feita por meio da reação entre os grupos aminos livres da quitosana e o ácido glioxílico. O ácido glioxílico [HOC-COOH] apresenta 
também em sua estrutura o grupo funcional aldeído e por isso ele é utilizado na síntese da N-CMQ, já que este grupo reage seletivamente com o grupo amino da quitosana, gerando uma imina (base de Schiff), que então é reduzida a N-CMQ (BAUMANN; FAUST, 2001). Esta reação tem como produto final uma variedade de N-CMQ com grupos acetil, carboximetil e amino, que podem ser controlados pelas proporções de quitosana e ácido glioxílico utilizadas. (MIRANDA et al., 2006)

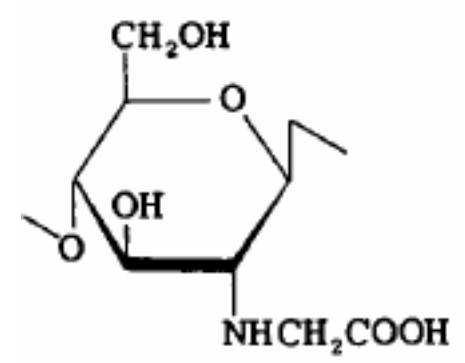

Figura 11: Representação esquemática de parte da estrutura da $\mathrm{N}$-Carboximetilquitosana.

(MUZZARELLI, 1998)

Para explicar a obtenção de derivados solúveis com diferentes posições dos grupos caboximetil deve-se considerar as diferentes reatividades do grupos $-\mathrm{OH}$ e $-\mathrm{NH}_{2}$. $\mathrm{O}$ grupo $-\mathrm{OH}$ alcoólico é um nucleófilo mais fraco que o $-\mathrm{NH}_{2} \mathrm{e}$, portanto, para que a reação que dá origem a O-CMQ ocorra em extensão razoável, é necessário que estes grupos sejam ativados com o uso de um álcali, mais comumente o hidróxido de sódio $(\mathrm{NaOH})$ (Figura 10). Deve-se considerar ainda que o grupo $-\mathrm{NH}_{2}$ quando protonado $\left(\mathrm{NH}_{3}{ }^{+}\right)$torna-se desativado como nucleófilo.(SOLOMONS; FRYHLE, 2006; BAUMANN; FAUST, 2001) Portanto, quando ocorre a reação entre a quitosana e o ácido monocloroacético, na presença de $\mathrm{NaOH}$, normalmente o produto obtido é preferencialmente o O-susbstituído, sendo o produto N,O-substituído obtido em menor quantidade (BAUMANN; FAUST, 2001).

No presente trabalho, foram preparadas e caracterizadas carboximetilquitosanas com diferentes graus de substituição, as quais foram posteriormente avaliadas como agentes de estabilização de suspensões de alumina. As reações foram realizadas em dois meios, em que a acessibilidade dos reagentes aos 
sítios reativos da quitosana é diferente, a fim de se avaliar se tal fato tem influência na ação do produto como agente de estabilização. 


\section{OBJETIVOS}

Este trabalho tem por objetivo a preparação e caracterização de polieletrólitos obtidos a partir da carboximetilação de macromolécula natural (carboximetilquitosana) com diferentes graus de substituição, em meio homogêneo, a fim de avaliar a atuação dos produtos obtidos como agentes de estabilização de suspensões aquosas de alumina, buscando-se alternativas aos polímeros sintéticos normalmente utilizados. 


\section{MATERIAIS E MÉTODOS}

\subsection{Quitosana e sua purificação}

Para a síntese de carboximetilquitosana foi utilizada quitosana comercial (Fluka/Biochemica, lote:22742).

A amostra de quitosana foi purificada na forma neutra, segundo a literatura (SEGNINI, 1998). 1,0g de quitosana foi adicionada, lentamente, a 300mL de ácido acético $1 \%$ e a suspensão resultante foi mantida sob agitação magnética por $24 \mathrm{~h}$ à temperatura ambiente. Após este período, a solução obtida foi filtrada sob pressão positiva através de membranas com porosidades de 5,0 e $0,8 \mathrm{~mm}$.

A seguir, a solução isenta de materiais insolúveis foi neutralizada com $\mathrm{NH}_{4} \mathrm{OH}$ concentrado para a precipitação da quitosana. Com a neutralização,as cadeias de quitosana são desprotonadas, o que diminui suas interações com o solvente aquoso e resulta em um precipitado gelatinoso. Na sequiência, o precipitado obtido foi separado do sobrenadante por filtração e lavado com água destilada até se atingir a neutralidade, sendo lavado em seguida com metanol e colocado em vidro de relógio, para secar a temperatura ambiente. Após a secagem, a quitosana foi triturada em moinho de facas e peneirada em peneira de diâmetro médio de $125 \mathrm{~mm}$. Esta amostra foi denominada $\mathbf{Q}$.

\subsection{Sintese de Carboximetilquitosana}

A preparação da $\mathrm{CMQ}$ foi realizada em dois meios diferentes. Em meio homogêneo, em que idealmente as cadeias de quitosana se encontram rodeadas por moléculas de solvente a distribuição dos grupos carboximetila no produto pode apresentar distribuição mais homogênea, já que todas as cadeias teriam os sítios reativos igualmente disponíveis. Entretanto, no presente trabalho, embora a quitosana seja inicialmente dissolvida, a adição de $\mathrm{NaOH}$, que é feita após a solubilização da quitosana, promove a precipitação da mesma. De qualquer forma, o grau de agregação destas cadeias deve ser diferente daquele em que a quitosana desde o início está suspensa no meio (reação em meio heterogêneo). Assim, a dissolução prévia da quitosana deve facilitar o acesso dos reagentes aos sítios reacionais. 
Já em meio heterogêneo, a reação inicia na superfície das partículas, provavelmente envolvendo primeiramente cadeias da região não cristalina, mais acessíveis para o reagente. Portanto, mesmo que apresentem mesmo grau médio de substituição, as amostras obtidas em diferentes meios poderão apresentar diferentes efeitos na estabilização de suspensões de aluminas.

A seguir serão descritos os procedimentos realizados para a obtenção da carboximetilquitosana.

\subsubsection{Síntese usando Dimetilacetamida/Cloreto de Lítio (DMAc/LiCl) como sistema de solvente}

A síntese foi adaptada a partir do procedimento para a obtenção carboximetilcelulose (RAMOS, 2005).

A quitosana $(2,00 \mathrm{~g})$ e o $\mathrm{LiCl}(5,00 \mathrm{~g}$, previamente secos) foram misturados, sob agitação mecânica, num balão de quatro bocas, equipado com: uma torneira de três saídas ligada a bomba de vácuo e a $\mathrm{N}_{2}$; um funil de adição, sem braço lateral de equalização, com a torneira fechada; um condensador de refluxo com a saída tampada; um agitador mecânico.

O sistema foi imerso em um banho de óleo, a pressão no balão foi reduzida e a temperatura do óleo (controlada por um controlador digital Flyever FE50RP, São Carlos, $\mathrm{SP}$ ) foi elevada até $110^{\circ} \mathrm{C}$ em $30 \mathrm{~min}$. Após permanecer nesta temperatura por mais $30 \mathrm{~min}$, o sistema foi isolado da bomba de vácuo, conservando-se a pressão interna reduzida. $\mathrm{O}$ funil de adição foi carregado com $100 \mathrm{~mL}$ de DMAc seco. Com o funil tampado, a torneira foi aberta e o solvente adicionado sob pressão reduzida .

O sistema foi conectado a uma linha de nitrogênio seco e, após equalização da pressão interna com $\mathrm{N}_{2}$, a tampa do condensador foi substituída por um tubo secante. $\mathrm{O}$ sistema foi aquecido a $150^{\circ} \mathrm{C}$ sob agitação. Após este período, o sistema foi resfriado lentamente, mantendo-se a agitação.

Após a solubilização, adicionou-se à solução $\mathrm{NaOH}$ (em proporções diversificadas, a fim de se observar a influência sobre as propriedades do produto obtido). Em seguida, a quantidade desejada de ácido monocloroacético foi adicionada, a temperatura foi elevada a $70^{\circ} \mathrm{C}$ e mantida por $4 \mathrm{~h}$, sob agitação mecânica. Após este período, a suspensão foi 
resfriada a temperatura ambiente e o produto precipitado em $350 \mathrm{~mL}$ de isopropanol. $\mathrm{O}$ precipitado foi filtrado, dissolvido em água destilada, neutralizado com ácido acético e reprecipitado em uma solução de etanol $90 \%$. O produto foi lavado em solução de etanol $90 \%$ e seco a temperatura ambiente até massa constante.

\subsubsection{Síntese em meio heterogêneo}

Somente uma amostra foi preparada neste meio, para efeito de comparação.

A síntese foi realizada conforme descrita por Caraschi (1997). Em um erlenmeyer de $125 \mathrm{~mL}$ foram suspensas $3 \mathrm{~g}$ de quitosana, previamente purificada, em $65 \mathrm{~mL}$ de álcool isopropílico. A suspensão foi mantida sob agitação magnética, a temperatura ambiente, por 20 min. Em seguida, adicionou-se, lentamente, 20,4g da solução aquosa 40\% de $\mathrm{NaOH}$ e, em seguida, foram adicionados $14,4 \mathrm{~g}$ da solução de ácido monocloroacético em isopropanol (1:1 em massa). A reação foi realizada por três horas, sob agitação magnética e temperatura ambiente.

Após a reação, o resíduo sólido foi filtrado e suspenso em 150mL de metanol 80\%, sendo em seguida neutralizado com ácido acético glacial. O resíduo sólido foi filtrado novamente, lavado várias vezes com etanol $80 \%$ e, por fim, com etanol absoluto, sendo em seguida seco à temperatura ambiente.

Após a secagem a carboximetilquitosana foi triturada em moinho de facas e peneirada em peneira de diâmetro médio de $125 \mathrm{~mm}$.

\subsection{Purificação das amostrar de carboximetilquitosana}

Em béquer de $2 \mathrm{~L}$ foram adicionados $1,5 \mathrm{~g}$ de carboximetilquitosana em $750 \mathrm{~mL}$ de água destilada. A suspensão foi mantida sob agitação magnética, por cerca de $16 \mathrm{~h}$ e, em seguida, a solução resultante foi filtrada sob pressão positiva através de membranas de poros de $5 \mathrm{~mm}$ e $0,8 \mathrm{~mm}$. Em seguida, foram adicionados $750 \mathrm{~mL}$ de solução de $\mathrm{NaCl}$ 0,2mol/L, a fim de aumentar a força iônica da solução, garantindo que as cadeias estejam estendidas e nenhuma impureza ficasse retida. A solução permaneceu sob agitação magnética durante cerca de 30min Em seguida, a carboximetilquitosana foi precipitada pela 
adição de etanol 95\%, em porções de $100 \mathrm{~mL}$, sob forte agitação magnética. O precipitado foi filtrado e lavado com etanol $75 \%, 80 \%, 90 \%$ (em volume) e seco a temperatura ambiente.

\subsection{Caracterização das amostras de Quitosana e Carboximetilquitosana}

\subsubsection{Análises condutimétricas e pontenciométricas (GE; LUO, 2005; RAYMOND et al.} ,2005)

As análises foram realizadas simultaneamente em uma cela de vidro encamisada, a qual permite a circulação de água e termostatização do sistema. Uma alíquota de $100 \mathrm{~mL}$ de solução foi adicionada à cela termostatizada, sendo em seguida feitas as titulações com solução aquosa padronizada de $\mathrm{NaOH} 0,1 \mathrm{~mol} / \mathrm{L}$. Todas as titulações foram realizadas empregando titulador automático Schott Titronic Universal com precisão de 0,05mL. Para as medidas de condutimetria foi utilizado o condutivímetro da Schott modelo Handylab LF 1 e para as medidas de $\mathrm{pH}$ foi utilizado o pHmetro Schott modelo modelo CG 843P.

A solução de quitosana foi feita pesando-se $0,24 \mathrm{~g}$ de quitosana, que foi previamente seca a $60{ }^{\circ} \mathrm{C}$ em estufa à vácuo por $6 \mathrm{~h}$. Esta massa foi dissolvidos em $50 \mathrm{~mL}$ de solução de $\mathrm{HCl} \quad 0,05 \mathrm{~mol} / \mathrm{L}$, permanecendo sob agitação magnética por aproximadamente $18 \mathrm{~h}$. Após esse período, foram adicionados $150 \mathrm{~mL}$ de água Milli-Q. O pH final da solução foi de aproximadamente 2,30.

O grau médio de acetilação de quitosana foi calculado utilizando as equações 9 e 10.

$$
\begin{gathered}
\% \mathbf{G D}=(\mathbf{M} \times[\mathrm{v3}-\mathrm{v} 2] \times[\text { Base }] / \mathrm{m}) \times 100 \\
\% \mathrm{GA}=100-\mathrm{GD} \%
\end{gathered}
$$

em que: \%GD = Grau médio de desacetilação;

$\% \mathrm{GA}=$ Grau médio de acetilação;

$\mathrm{M}=$ Massa molar média da unidade repetitiva de quitosana $(161,0 \mathrm{~g} / \mathrm{mol})$. 


\subsubsection{Espectroscopia na Região do Infravermelho}

Após a reação de carboximetilação da quitosana, as modificações estruturais foram verificadas por meio da espectroscopia na região do infravermelho.

As análises de espectroscopia na região do infravermelho foram realizadas em aparelho BOMEM modelo MB-102 com transformada de Fourier.

As amostras foram analisadas usando-se pastilhas, que foram feitas na proporção de 1:100 de amostra para $\mathrm{KBr}$.

Tanto o $\mathrm{KBr}$ como as amostras foram previamente secas em estufa a vácuo a $60^{\circ} \mathrm{C}$ por $24 \mathrm{~h}$ e depois trituradas em gral de ágata. As amostras trituradas com $\mathrm{KBr}$ foram novamente levadas à estufa à vácuo a $60^{\circ} \mathrm{C}$, por 24 h. Após este período, as amostras com $\mathrm{KBr}$ foram prensadas, sendo as pastilhas obtidas colocadas em estufa nas mesmas condições, sendo em seguida analisadas.

\subsubsection{Vicosimetria Capilar}

Para a determinação de viscosidade intrínseca de quitosana foram dissolvidos cerca de $50 \mathrm{mg}$ de quitosana purificada em $25 \mathrm{~mL}$ de uma solução tampão (0,3M ácido acético/0,2M acetato de sódio) de pH em torno de 4,5 (KASAAI, 2007). A solução permaneceu sob agitação constante à temperatura ambiente, por $16 \mathrm{~h}$.

A seguir, a solução foi aquecida em banho-maria a $80^{\circ} \mathrm{C}$ por dois minutos. Foi então resfriada a temperatura ambiente, sendo mais $25 \mathrm{~mL}$ de solução tampão adicionados, sendo a solução foi novamente aquecida a $80^{\circ} \mathrm{C}$, por mais dois minutos. A solução foi resfriada e filtrada em um filtro de pressão positiva, através de membrana de $0,45 \mathrm{~mm}$.

Alíquotas de $15 \mathrm{~mL}$ da solução resultante de quitosana foram retiradas e os tempos de escoamento determinados pelo viscosímetro AVS-350 acoplado ao sistema diluidor automático ViscoDoser AVS 20 (Schott Gerate), com o emprego do capilar número 531.01 (diâmetro interno, $\phi$, de $0,53 \mathrm{~mm}$ ). A solução foi seqüencialmente diluída no próprio capilar através da adição da solução tampão. Os valores de tempo de escoamento, empregados para as determinações de viscosidade intrínseca, correspondem a médias de três determinações independentes e que não apresentaram variação maior que $0,09 \%$. Todas as medidas foram realizadas a $25 \pm 0,010{ }^{\circ} \mathrm{C}$. 


\subsubsection{Espectroscopia de Ressonância Magnética Nuclear $\left(\mathrm{RMN}^{1} \mathrm{H}\right)$}

A técnica de $\mathrm{RMN}^{1} \mathrm{H}$, usando-se soluções, é um método eficiente para a determinação do grau médio de acetilação. A técnica é rápida, precisa, reprodutível e requer uma pequena quantidade de quitosana. (LAVERTU, et al., 2003)

$10 \mathrm{mg}$ de amostra foram adicionados a $1 \mathrm{~mL}$ de mistura $\mathrm{D}_{2} \mathrm{O} / \mathrm{HCl}(100 / 1 \mathrm{v} / \mathrm{v})$ e a suspensão mantida sob agitação magnética constante por $24 \mathrm{~h}$. A solução resultante foi transferida para um tubo apropriado, de $5 \mathrm{~mm}$ de diâmetro. Os espectros de quitosana e de carboximetilquitosana foram obtidos em espectrômetro BRUKER AC200 a $80^{\circ} \mathrm{C}$; o pulso utilizado foi de $8,2 \mathrm{mS}\left(90^{\circ}\right)$, acumulando 16 varreduras (NS = 16), sendo o tempo de relaxação de $1 \mathrm{~s}$, a potência de $20 \mathrm{~L}$ e o parâmetro $\mathrm{LB}$ foi de $0,2 \mathrm{~Hz}$.

A razão entre as áreas atribuídas aos hidrogênios da metila dos grupos acetamido e ao hidrogênio ligado ao carbono 2 do anel glicosídico (Figura 12) foi utilizada para determinação do grau médio de acetilação $(\overline{G A})$ da quitosansa (equação 11).

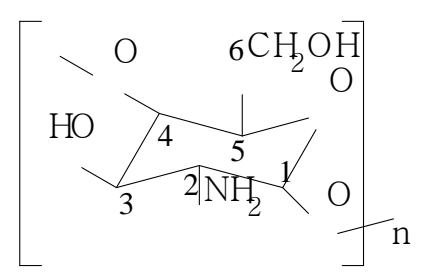

Figura 12: Representação esquemática da estrutura da quitosana, apresentando a numeração utilizada para a determinação do grau médio de acetilação.

$$
\% \overline{G A}=\left(\frac{A_{C H 3}}{3} / A_{H_{2}}\right) x 100
$$

na qual: $\mathrm{A}_{\mathrm{CH} 3}=$ área dos hidrogênios metílicos do grupo acetamida $\mathrm{A}_{\mathrm{H} 2}=$ área do hidrogênio ligado ao carbono $\mathrm{C}(2)$ do anel glicopiranosídico 


\subsubsection{Preparação de carboximetilquitosana na forma ácida}

Esta preparação foi realizada a fim de caracterizar os produtos obtidos após conversão das amostras carboximetiladas na forma sal de sódio para a forma ácida.

$500 \mathrm{mg}$ de carboximetilquitosana foram dissolvidos em $250 \mathrm{~mL}$ de água destilada, sendo que a suspensão foi mantida sob agitação cerca de 24 h. Em seguida, realizou-se diálise contra $\mathrm{HCl} 0,1 \mathrm{M}$, utilizando membranas para diálise da Viskase Corporation ${ }^{\circledR}$ de $21 \mathrm{~mm}$ de diâmetro e limite de exclusão de massa molecular de 12.000-16.000 Da.

As membranas de diálise foram preenchidas com a amostra e colocadas em um béquer de $2 \mathrm{~L}$ com $\mathrm{HCl} 0,1 \mathrm{M}$. A diálise se estendeu por 7 dias sendo que a cada $24 \mathrm{~h}$ a solução de $\mathrm{HCl}$ foi trocada. Este processo foi realizado a fim de trocar os contra íons $\mathrm{Na}^{+}$ por $\mathrm{H}^{+}$. Em seguida a solução foi colocada em uma placa de Petri de acrílico e mantida à temperatura ambiente por 5 dias. $\mathrm{O}$ filme de carboximetilquitosana foi destacado para a análise no equipamento BOMEM modelo MB-102, com transformada de Fourier.

\subsubsection{Análise Térmica: Termogravimetria}

Para avaliar a estabilidade térmica da quitosana e dos produtos obtidos, cerca de 6 mg de amostra na forma de pó foram pesadas e os experimentos foram feitos nas seguintes condições:

- Atmosfera de nitrogênio (fluxo=20mL. $\left.\mathrm{min}^{-1}\right)$;

- Aquecimento das amostras no intervalo de $25^{\circ} \mathrm{C}-700^{\circ} \mathrm{C}$;

- Taxa de aquecimento de $10^{\circ} \mathrm{C} \cdot \mathrm{min}^{-1}$.

O equipamento para utilizado para as análises termogravimétrica foi o aparelho SHIMADZU, modelo TGA50.

\subsection{Alumina}

A alumina utilizada no presente trabalho é denominada A17-NE, e foi gentilmente cedida por ALCOA Alumínio S.A.- Divisão de Produtos Químicos, (Poços de Caldas) 
apresentando área superficial de $6,86 \mathrm{~m}^{2} / \mathrm{g}$, e tamanho de partícula $0.6 \mu \mathrm{m}$, conforme informado por ALCOA.

\subsection{Avaliação da Estabilização de suspensões aquosas de Alumina}

\subsubsection{Medidas de Viscosidade}

A suspensão, conhecida como barbotina, utilizada para as medidas de viscosidade foi preparada pela adição de $500 \mathrm{~g}$ de alumina a $315 \mathrm{~mL}$ de água $(61 \%$ em massa), temperatura ambiente e agitação mecânica de $1 \mathrm{~h}$. Para o ajuste do $\mathrm{pH}$ da suspensão, foram utilizadas soluções de concentração $1 \mathrm{~mol} / \mathrm{L}$ de $\mathrm{NaOH}$ e $\mathrm{HCl}$.

As medidas foram realizadas no equipamento Brookfield Viscometer Model DVII, spindle 2 e velocidade de rotação de $3 \mathrm{rpm}$. Estas condições foram estabelecidas em trabalhos anteriores. (YOKOSSAWA, 1996; CERRUTTI, 2005)

A viscosidade foi avaliada em função da quantidade de estabilizante adicionada, mantendo-se o pH constante. Através da análise destes resultados, determinou-se a melhor quantidade de aditivo, para que medidas de viscosidade em função do $\mathrm{pH}$ fossem realizadas.

\subsubsection{Medidas de Potencial Zeta}

As medidas de potencial zeta foram realizadas com uma suspensão obtida pela adição de $2 \mathrm{~g}$ de alumina a $100 \mathrm{~mL}$ de água ( $2 \%$ em massa) a $25^{\circ} \mathrm{C}$. A concentração da suspensão utilizada para as medidas de potencial foi menor do que aquela utilizada para as medidas de viscosidade devido à limitações do equipamento.

As medidas de potencial zeta foram feitas, inicialmente, em função da massa de aditivo adicionada, em $\mathrm{pH}$ constante. Por meio dessas medidas, foi escolhida a massa que apresentava melhores resultados para que as medidas em função do $\mathrm{pH}$ fossem realizadas.

O equipamento utilizado foi Brookhaven Instrument Corporation, modo Zeta Pals. 


\subsubsection{Medidas de Diâmetro médio de Partícula}

As suspensões para as medidas de diâmetro de partícula foram feitas com $2 \%$ em massa ( $2 \mathrm{~g}$ de alumina adicionados a $100 \mathrm{~mL}$ de água) sendo, as medidas foram realizadas no equipamento modelo FOQELS - Particle Sizing software, da Brookhaven Instrument Corporation.

Assim como no caso das medidas de potencial zeta, as medidas de diâmetro médio de partícula foram realizadas com suspensões de baixa concentração devido à restrições do equipamento.

As massas utilizadas para as medidas em função do $\mathrm{pH}$ foram determinadas em medidas anteriores, que foram realizadas em função da massa de aditivo adicionada, em pH constante. 
As amostras de quitosana e seus derivados receberam as siglas que são mostradas na tabela 1.

Tabela 1: Siglas utilizadas para as amostras avaliadas

\begin{tabular}{|c|c|}
\hline Amostra & Descrição \\
\hline Q & Quitosana comercial (Fluka/Biochemica) \\
\hline CMQ1 & $\begin{array}{l}\text { Quitosana carboximetilada em meio heterogêneo } \\
\text { (razão Q: } \mathrm{NaOH} \text { : Ac. Monocloroacético: 1:10:5 mol) }\end{array}$ \\
\hline CMQ2 & $\begin{array}{l}\text { Quitosana carboximetilada em DMAc/LiCl (razão } \\
\text { Q: NaOH: Ac. Monocloroacético: 1:5:2,5 mol) }\end{array}$ \\
\hline CMQ3 & $\begin{array}{l}\text { Quitosana carboximetilada em DMAc/LiCl (razão } \\
\text { Q: NaOH: Ac. Monocloroacético: 1:5:5 mol) }\end{array}$ \\
\hline CMQ4 & $\begin{array}{l}\text { Quitosana carboximetilada em DMAc/LiCl (razão } \\
\text { Q: NaOH: Ac. Monocloroacético: 1:5:10 mol) }\end{array}$ \\
\hline CMQ5 & $\begin{array}{l}\text { Quitosana carboximetilada em DMAc/LiCl (razão } \\
\text { Q: NaOH: Ac. Monocloroacético: 1:5:13 mol) }\end{array}$ \\
\hline CMQ6 & $\begin{array}{l}\text { Quitosana carboximetilada em DMAc/LiCl (razão } \\
\text { Q: NaOH: Ac. Monocloroacético: 1:5:15 mol) }\end{array}$ \\
\hline CMQ7 & $\begin{array}{l}\text { Quitosana carboximetilada em DMAc/LiCl (razão } \\
\text { Q: NaOH: Ac. Monocloroacético: 1:5:17 mol) }\end{array}$ \\
\hline
\end{tabular}




\section{RESULTADOS}

\subsection{Preparação e Purificação das amostras}

Pode-se observar (tabela 2) que o aumento da quantidade de ácido monocloroacético usado na reação que produz a CMQ, provoca o aumento da massa de carboximetilquitosana recuperada após a reação. Entretanto, os ganhos de massa observados após a reação de carboximetilação não devem ser diretamente relacionados aos graus médios de carboximetilação das amostras, já que, paralelamente a caboximetilação, pode ocorrer a despolimerização de quitosana no meio alcalino, gerando cadeias de baixa massa molar, que podem, pelo menos em parte, permanecer solubilizada no meio, o que resulta em diminuição de massa do sólido isolado (ABREU, 2006).

Tabela 2: Ganho de massa após a reação de carboximetilação

\begin{tabular}{|c|c|}
\hline Amostra & 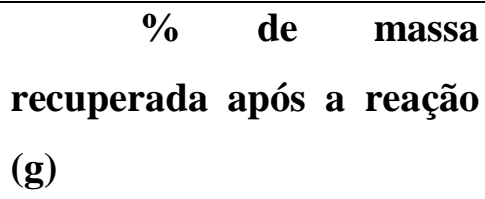 \\
\hline CMQ1 & $12,7 \%$ \\
\hline CMQ2 & $10,1 \%$ \\
\hline CMQ3 & $10,2 \%$ \\
\hline CMQ4 & $10,8 \%$ \\
\hline CMQ5 & $12,6 \%$ \\
\hline CMQ6 & $14,3 \%$ \\
\hline CMQ7 & $17,0 \%$ \\
\hline
\end{tabular}

A tabela 3 mostra a porcentagem de diminuição de massa de carboximetilquitosana devido ao procedimento de purificação. 
Tabela 3: Diminuição da massa de carboximetilquitosana devido a purificação

\begin{tabular}{||c||c||}
\hline Amostra & \multicolumn{1}{|c|}{ \% de diminuição da } \\
& $\begin{array}{l}\text { de } \\
\text { carboximetilquitosana } \\
\end{array}$ \\
\hline após a purificação (g) \\
\hline \hline CMQ1 & $2,6 \%$ \\
\hline \hline CMQ3 & $14,0 \%$ \\
\hline \hline CMQ4 & $3,6 \%$ \\
\hline \hline CMQ5 & $5,7 \%$ \\
\hline \hline CMQ6 & $5,2 \%$ \\
\hline \hline CMQ7 & $4,4 \%$ \\
\hline \hline
\end{tabular}

Observa-se que a massa recuperada após a purificação das amostras carboximetiladas aumentou, com o aumento da quantidade de ácido monocloroacético utilizada na reação, sugerindo que o emprego de maior excesso de ácido monocloroacético na reação aumenta a solubilidade das amostras em água, o que pode estar relacionado com aumento do GS, e resulta em rendimentos mais elevados na etapa de purificação.

\subsection{Análise Condutimétrica e Potenciométrica}

As análises condutimétrica e potenciométrica foram utilizadas para a determinação do grau de acetilação $(\overline{G A})$ da quitosana.

O grau médio de acetilação $(\overline{G A})$ da amostra de quitosana, que foi solubilizada em $\mathrm{HCl}$, foi determinada através dos dados obtidos com a curva de titulação condutimétrica (Figura 13). Como a amostra foi solubilizada em meio ácido ( $\mathrm{pH} 2,30$ ), assegura-se que todos os grupos $\mathrm{NH}_{2}$ da quitosana estão na forma $\mathrm{NH}_{3}{ }^{+}$, pois o pKa deste grupo é em torn de 6,5 (ABREU, 2006). Também pode-se afirmar que apenas os grupos $\mathrm{NH}_{3}{ }^{+}$serão titulados, pois nesse $\mathrm{pH}$ os grupos acetamido $\left[\mathrm{CONH}_{2}\right]$ não estão protonados, pois o valor do pKa do ácido conjugado deste grupo $\left[\mathrm{CONH}_{3}{ }^{+}\right]$consideravelmente menor pelo fato de 
os pares de elétrons não-compartilhados do nitrogênio não estarem tão disponíveis, devido à conjugação com a carbonila. Nesta curva (Figura 13) a forte inclinação na primeira parte corresponde à titulação do excesso de ácido forte presente $\left(\mathrm{H}_{3} \mathrm{O}^{+}\right)$e após sua neutralização, os sítios protonados $\left(\mathrm{NH}_{3}{ }^{+}\right)$existentes ao longo das cadeias de quitosana começam a ser neutralizados. Neste ponto, ocorre a primeira inflexão da curva (primeiro ponto de equivalência) e a condutância da solução, que decrescia com a adição de $\mathrm{NaOH}$, passa a aumentar. O segundo ponto de inflexão corresponde ao fim da neutralização dos sítios protonados de quitosana e, a partir desse ponto, o aumento da condutância da solução é muito mais acentuado, em relação à parte anterior da curva. A mudança de inclinações é devida não somente à ionização de $\mathrm{HCl}$ e $\mathrm{NaOH}$, mas principalmente às condutividades elevadas de $\mathrm{H}_{3} \mathrm{O}^{+}$e $\mathrm{OH}^{-}$comparadas à condutividade do polissacarídeo.

Os volumes de base gastos para atingir os dois pontos de equivalência foram determinados por extrapolação das partes lineares de variação de condutividade em função de volume do titulante e, como pode ser observado, os dois pontos de equivalência são claramente evidenciados pela mudança de inclinação da curva.

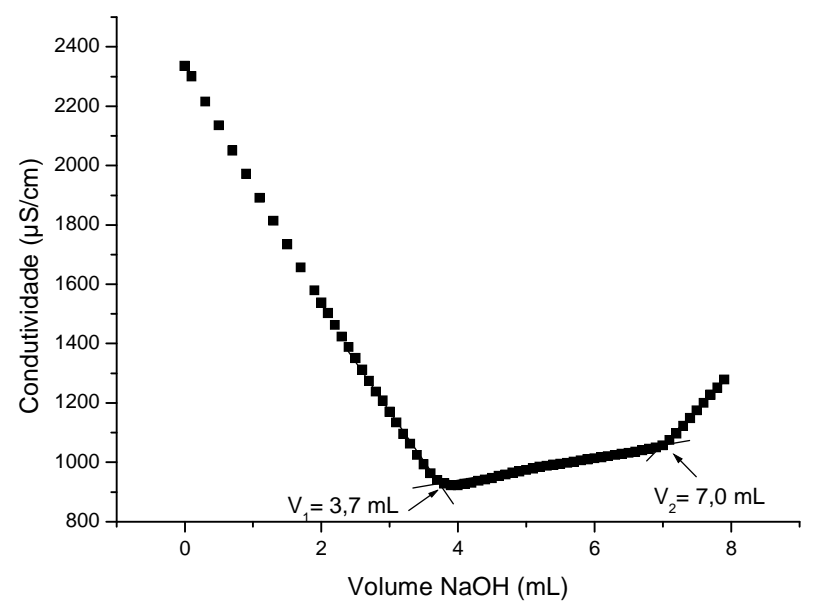

Figura 13:Curva de titulação condutimétricas para a quitosana.

Na titulação potenciométrica (Figura 14), o ponto de inflexão da curva de volume de base versus $\mathrm{pH}$ da solução, marca o ponto de equivalência. Para determinar esse ponto 
de inflexão com maior precisão, foram avaliados os pontos de máximo observados quando se aplica a derivada primeira (Figura 15) à curva.

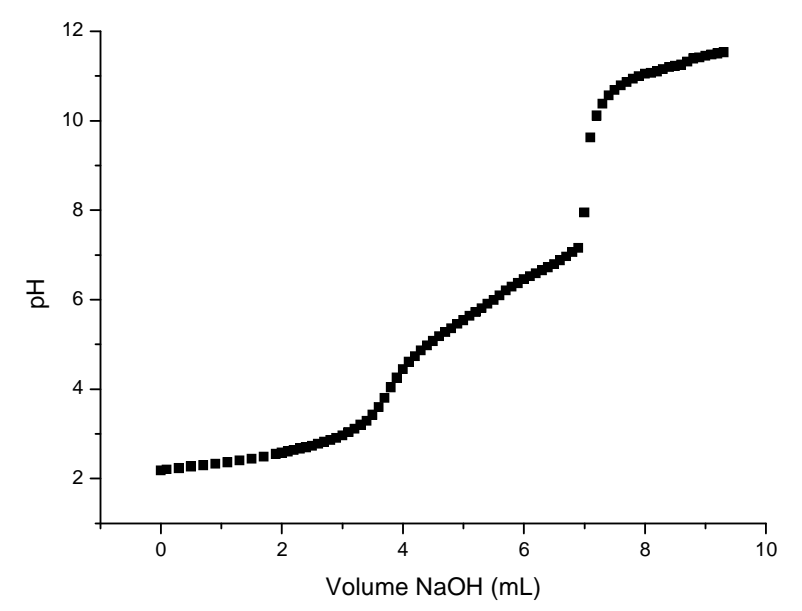

Figura 14: Curva de titulação potenciométrica para a quitosana.

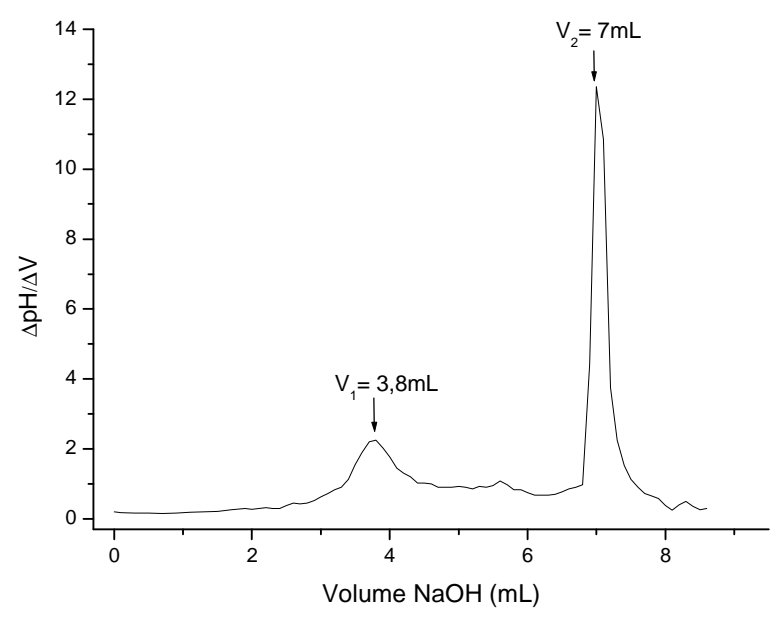

Figura 15: Derivada primeira da curva de titulação potenciométrica da quitosana.

As análises foram feitas em triplicata e, portanto, foram encontrados três valores de $\overline{G A}$, dos quais foi obtida uma média (tabela 4). As demais curvas encontram-se em anexo. 
Tabela 4: Valores de grau médio de acetilação (GA), de-quitosana determinado por titulação condutimétricas e potenciométricas

\begin{tabular}{|c|c|c|}
\hline \multirow[b]{2}{*}{ Determinação } & \multicolumn{2}{|c|}{ Amostra: Quitosana } \\
\hline & $\begin{array}{c}\overline{G A} \\
\text { (potenciometria) }\end{array}$ & $\begin{array}{c}\overline{G A} \\
\text { (condutimetria) }\end{array}$ \\
\hline 1 & $30,08 \pm 0,03$ & $28,05 \pm 0,03$ \\
\hline 2 & $30,12 \pm 0,03$ & $29,86 \pm 0,03$ \\
\hline 3 & $30,09 \pm 0,03$ & $29,12 \pm 0,03$ \\
\hline média & $30,09 \pm 0,09$ & $29,01 \pm 0,09$ \\
\hline
\end{tabular}

Como se pode observar, a determinação de $\overline{G A}$ pelos dois métodos apresentou boa concordância (tabela 4).

\subsection{Espectroscopia na região do infravermelho}

Analisando-se o espectro obtido para a quitosana (Figura 16), as seguintes bandas características podem ser observadas: banda larga de estiramento axial de $\mathrm{OH}$ em $\approx$ $3400 \mathrm{~cm}^{-1}$, a qual esta sobreposta a banda de estiramento de $\mathrm{N}-\mathrm{H}$; banda de deformação axial de $\mathrm{C}=\mathrm{O}$ em $1659 \mathrm{~cm}^{-1}$; de deformação angular de $\mathrm{N}-\mathrm{H}$ em $1590 \mathrm{~cm}^{-1}$; de deformação angular simétrica de $\mathrm{CH}_{3}$ em $1378 \mathrm{~cm}^{-1}$; de amida III em $1316 \mathrm{~cm}^{-1}$ e bandas de estiramento C-H em $3000 \mathrm{~cm}^{-1}$ e $2800 \mathrm{~cm}^{-1}$. (FUENTES et al., 2000) 


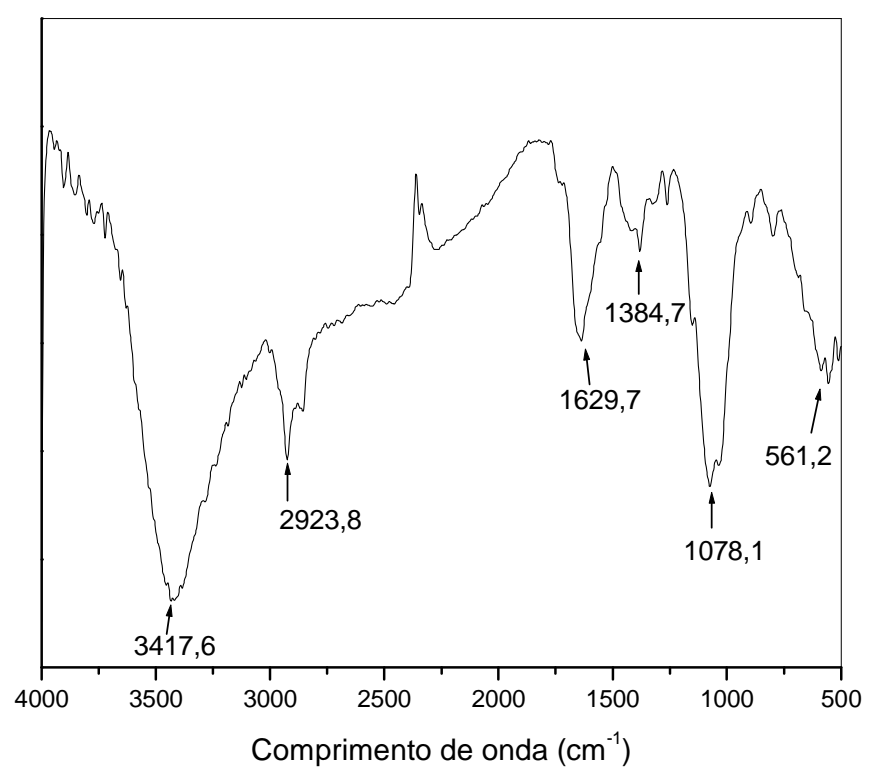

Figura 16: Espectro na região do infravermelho para a amostra de quitosana.

Após reação de carboximetilação, foram observadas algumas mudanças no espectro de infravermelho em relação a quitosana de partida. Foi observado, para o espectro de carboximetilquitosana, a ocorrência de uma banda intensa em torno de $1600 \mathrm{~cm}^{-1}$ e de uma banda menos intensa em torno de $1400 \mathrm{~cm}^{-1}$ (Figura 17), que podem ser atribuídas às deformações axiais simétricas e assimétricas de $\mathrm{COO}^{-}$respectivamente. 


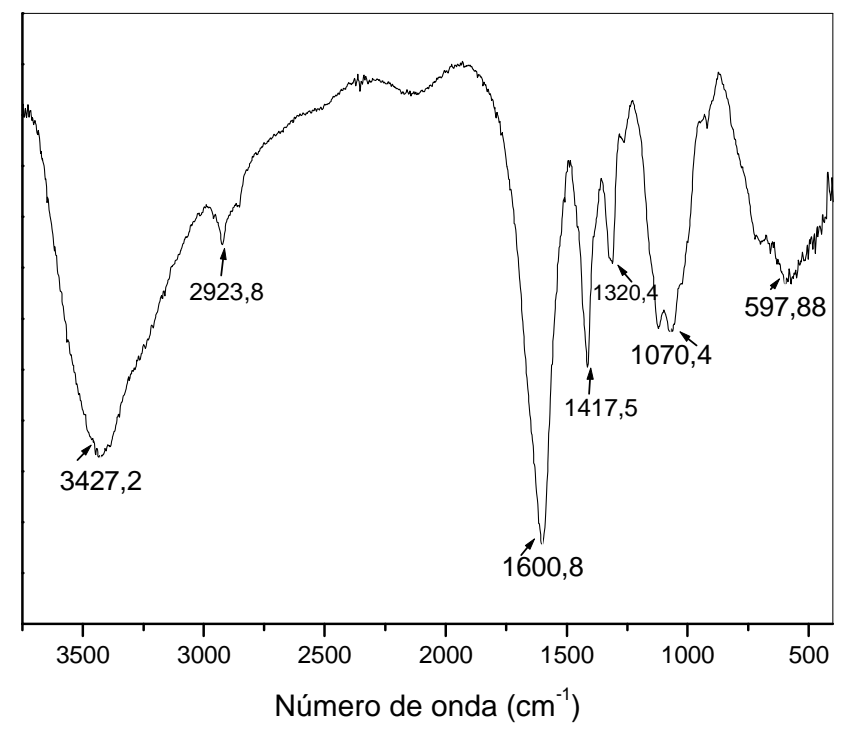

(a)

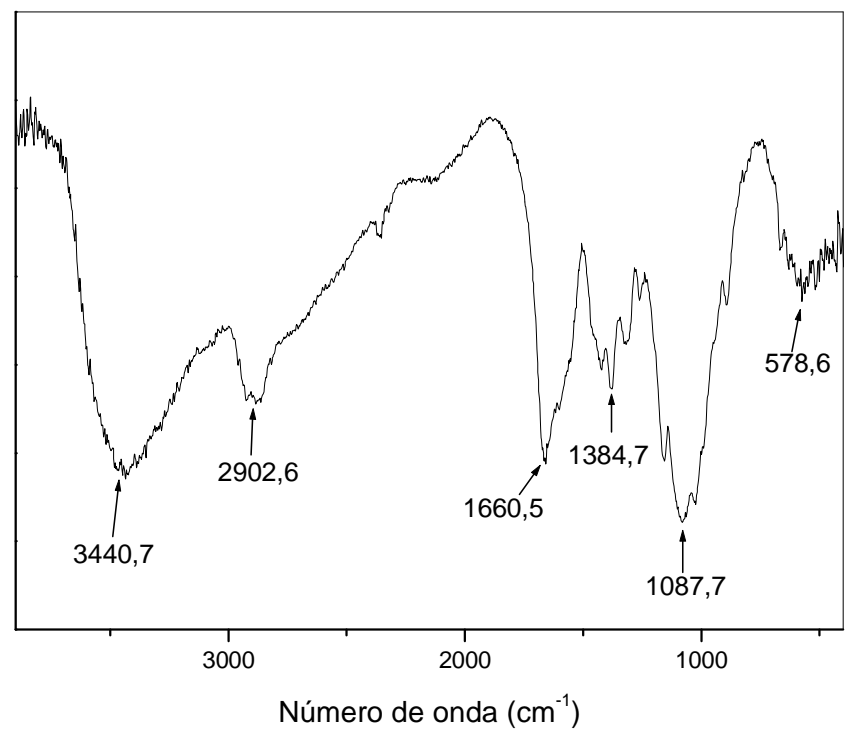

(b)

Figura 17: Espectros na região do infravermelho para amostras de carboximetilquitosana: a)CMQ1, b) CMQ2. 
A figura 18 mostra a comparação entre o espectro de quitosana e o espectro de CMQ1.

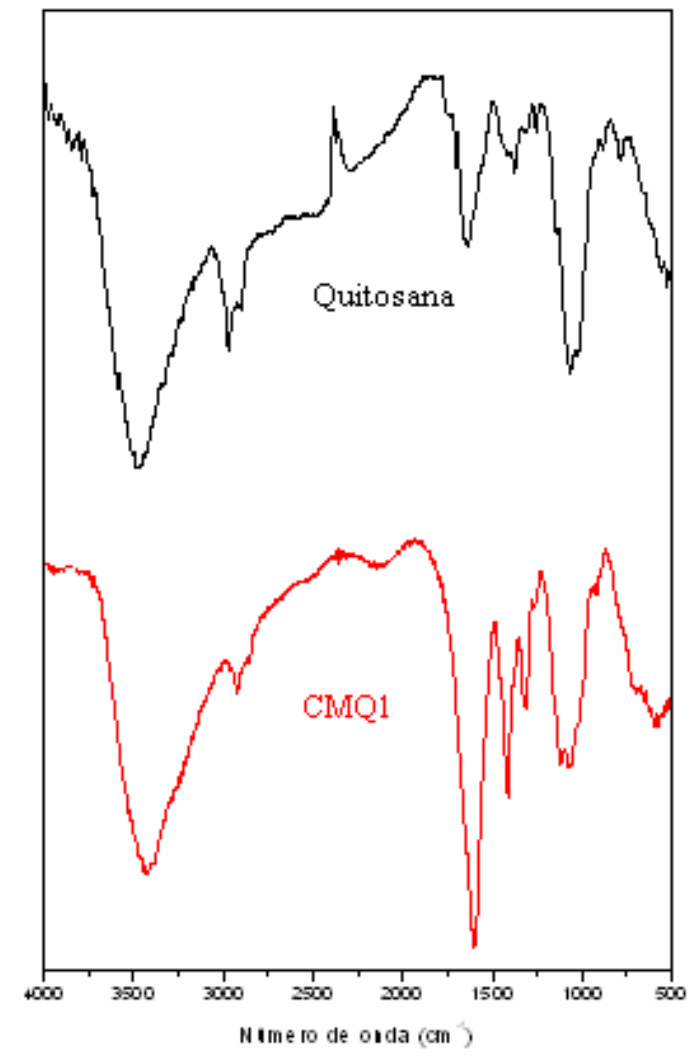

(a)

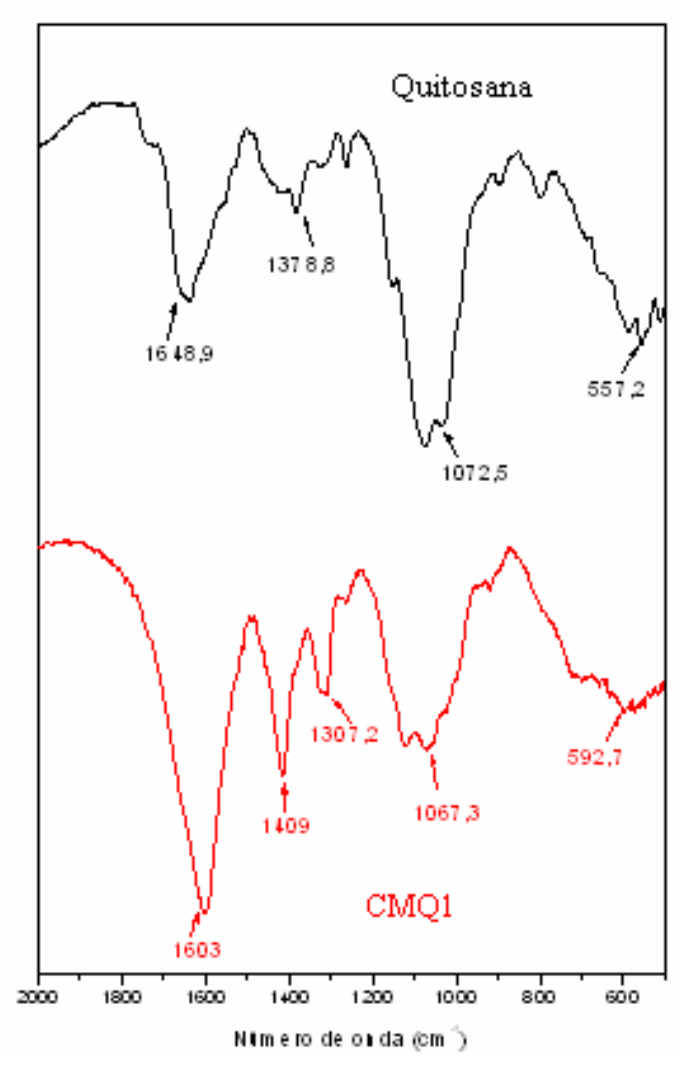

(b)

Figura 18: Espectros na região do infravermelho das amostras $Q$ e CMQ1(a) e detalhamento da região entre 500 e $2000 \mathrm{~cm}^{-1}$ (b).

Pode-se observar que após a reação de carboximetilação houve aumento na intensidade dos picos em torno de 1600 e $1400 \mathrm{~cm}^{-1}$, que caracterizam os grupos carboximetílicos.

Os espectros na região de infravermelho das outras amostras de CMQ se encontram em anexo. 


\section{$5.4 \quad$ Viscosidade}

A curva de viscosidade reduzida em função da concentração para a quitosana está mostrada na figura 19. Pode ser observado que os pontos estão perfeitamente alinhados ao longo da melhor reta $(r \geq 0,99)$, mostrando que as condições experimentais foram adequadas, principalmente no que diz respeito a manutenção da força iônica durante o procedimento de diluição da solução polimérica.

A viscosimetria permite também que se calcule a massa molar média viscosimétrica da quitosana, que é uma importante característica do polímero e da qual dependem muitas de suas aplicações. Para o cálculo da massa molar média viscosimétrica da quitosana foram utilizados os parâmetros $\mathrm{K}$ (equação 12) e a valores descritos na literatura para uma amostra com $\overline{G A}=29,5 \%$ (KASAAI, 2007), portanto próximo da quitosana considerada no presente trabalho, usando o tampão 0,3M HAc/0,2M NaAc como solvente (KASAAI, 2007) e a equação de Mark-Houwink (equação 12):

$$
[\eta]=K^{\prime} \mathbf{M}^{\mathbf{a}}
$$

na qual: $[\eta]=$ viscosidade intrínseca $(\mathrm{dL} / \mathrm{g})$;

K' e $\mathrm{a}=$ constantes para um dado solvente e temperatura;

$\mathrm{M}=$ massa molar viscosimétrica média. 


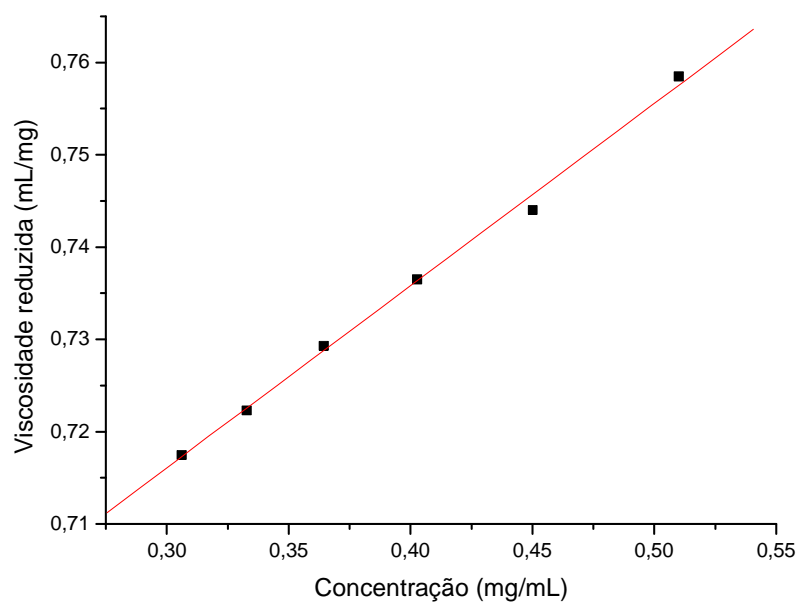

Figura 19: Curva de viscosidade reduzida versus concentração da amostra de quitosana em solução tampão 0,3M ácido acético/0,2M acetato de sódio $(\mathrm{pH} 4,5), 25^{\circ} \mathrm{C}$.

Considerando a relação de Huggins:

$$
\eta_{s p} / c=[\eta]+\mathrm{k}_{\mathrm{H}} \cdot[\eta]^{2} \cdot \mathrm{C}
$$

na qual: $\quad \eta_{s p}=$ viscosidade específica;

$$
\begin{aligned}
\eta_{s p} / c & =\text { viscosidade reduzida }(\mathrm{dL} / \mathrm{g}) ; \\
{[\eta] } & =\text { viscosidade intrínseca }(\mathrm{dL} / \mathrm{g}) ; \\
\mathrm{k}_{\mathrm{H}} & =\text { constante de Huggins; } \\
\mathrm{C} & =\text { concentração da solução }(\mathrm{g} / \mathrm{dL}) .
\end{aligned}
$$

Assim, a constante de Huggins $\left(\mathrm{K}_{\mathrm{H}}\right)$ pode ser determinada através da curva de viscosidade reduzida versus concentração da solução, conhecendo-se o coeficiente angular (b) da reta:

$$
\mathbf{b}=\mathbf{k}_{\mathbf{H}} \cdot[\eta]^{2}
$$


A tabela 5 mostra o valor de viscosidade intrínseca $([\eta])$, constante de Huggins $\left(\mathrm{k}_{\mathrm{H}}\right)$ (em solução tampão $0,3 \mathrm{M}$ ácido acético/ 0,2M acetato de sódio com $\mathrm{pH}=4,5$ ) e da massa molar média viscosimétrica $\left(\overline{M_{V}}\right)$ da amostra de quitosana purificada.

Tabela 5: Viscosidade intrínseca ([ $\eta])$, constante de Huggins $\left(K_{H}\right)$ e massa molar média

$$
\left(\overline{M_{v}}\right)
$$

\begin{tabular}{r|c|c|c} 
Amostra & {$[\eta](\mathbf{m L} / \mathbf{g})$} & $\mathbf{K}_{\mathbf{H}}$ & $\overline{\boldsymbol{M}_{\boldsymbol{v}}}(\mathbf{g} / \mathbf{m o l})$ \\
\hline quitosana & 657 & 0,45 & 156.739
\end{tabular}

Não foi possível fazer medidas de viscosidade das amostras carboximetiladas, pelo fato de que durante as medidas ocorre a formação de filme na parede do capilar e também a formação de bolhas. Estes problemas alteram a concentração da solução a ser analisada, tendo como conseqüência a mudança da viscosidade do meio, acarretando na imprecisão dos dados.

\subsection{Espectroscopia de Ressonância Magnética Nuclear $\left(R M N^{l} H\right)$}

A análise dos espectros de $\mathrm{RMN}^{1} \mathrm{H}$ da quitosana (Figura 20) e de carboximetilquitosanas (Figura 21) permitiu determinar o grau médio de acetilação, $\overline{G A}$, do primeiro polímero e, também foi possível observar as mudanças ocorridas na quitosana de partida após a carboximetilação. As amostras CMQ2 e CMQ1 não foram analisadas por RMN devido à questões relacionadas a disponibilidade de equipamento e outras dificuldades.

O grau médio de acetilação da quitosana, determinado por essa técnica foi $\% \overline{G A}=$ 25,00 , resultado próximo aos determinados através de análise condutimétrica $(\% \overline{G A}=$ $29,00)$ e potenciométrico $(30 \%)$.

Na figura 20 pode ser observado, em $\delta=1,90$, o sinal referente aos hidrogênios da metila do grupo acetamida. Entre $\delta=3,10$ e $\delta=2,90$ observa-se o sinal referente ao hidrogênio na posição $\mathrm{C} 2$ do anel glicosamino. Na região entre $\delta=3,30$ e $\delta=4,00$ ocorrem os 
sinais referentes aos hidrogênios localizados nos carbonos $\mathrm{C} 3, \mathrm{C} 4, \mathrm{C} 5$ e C6, que estão sobrepostos, sendo impossível distingui-los. Entre 4,40 e 5,00 ppm estão os sinais do hidrogênio ligado ao carbono. (MUZZARELI, 1994)

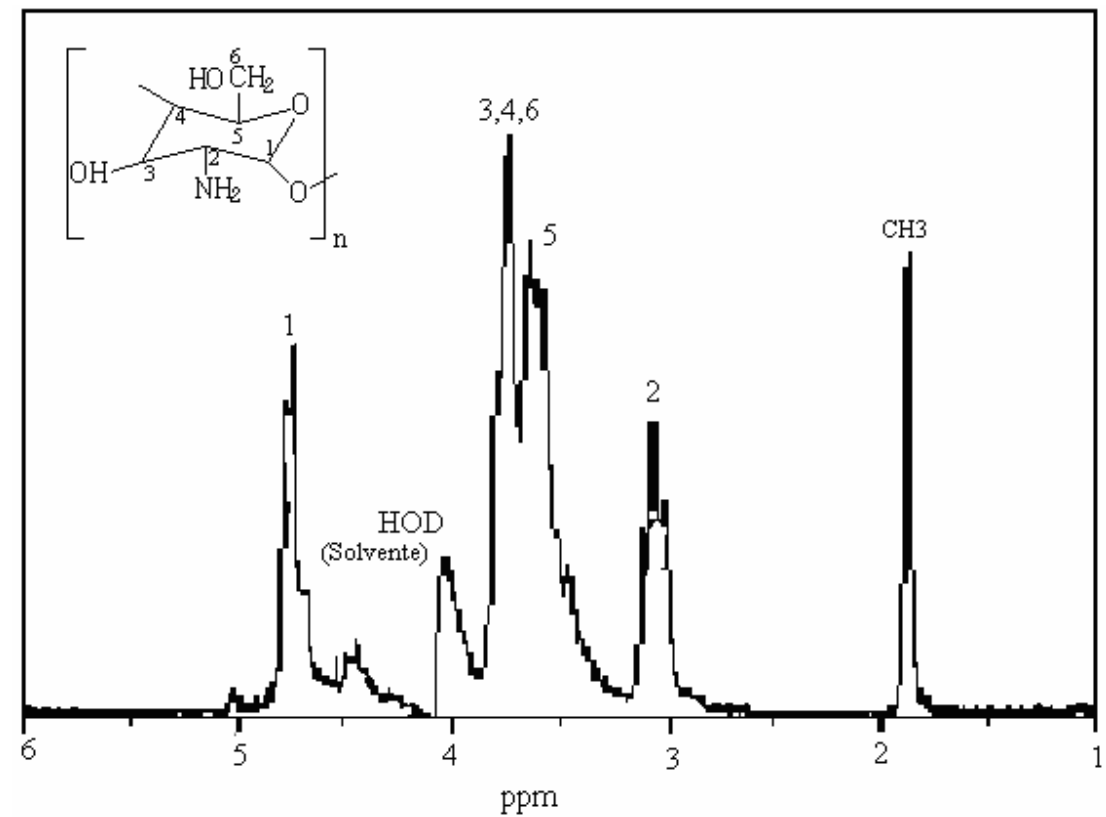

Figura 20: Espectro de Ressonância Magnética Nuclear $\left(\boldsymbol{R M N} N^{1} \boldsymbol{H}\right)$ da quitosana $(Q)$, obtido utilizando $\mathrm{D}_{2} \mathrm{O}$ como solvente, $\mathrm{NS}=16,80^{\circ} \mathrm{C}$.

As modificações estruturais introduzidas pela carboximetilação da quitosana, podem ser observadas comparando-se o espectro mostrado na figura 21 com o da figura 20. Embora tenham sido obtidas após carboximetilação, realizada com diferentes quantidades de ácido monocloroacético, todas as amostras apresentam espectros muito semelhantes, sendo observado um aumento na intensidade do sinal na região de 3,30 ppm (Figura 21) em relação à quitosana de partida. 


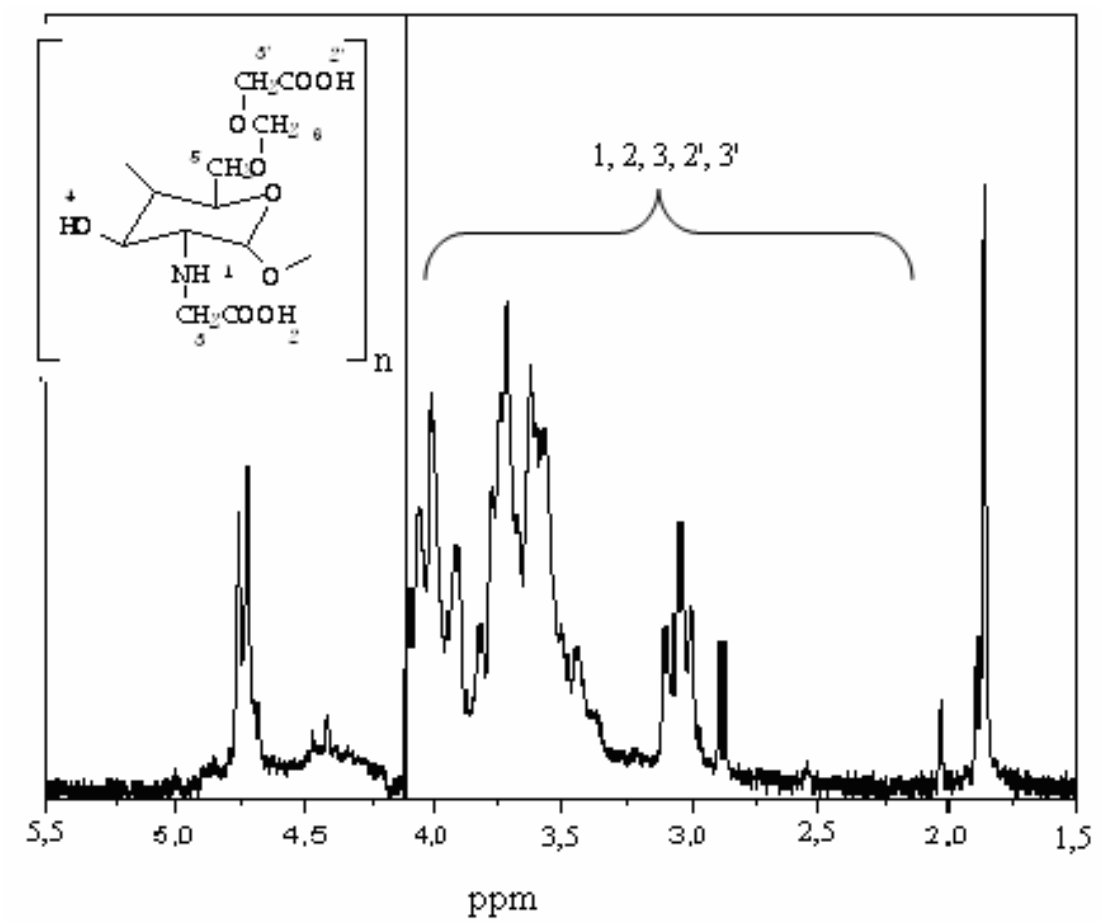

Figura 21: Espectro de Ressonância Magnética Nuclear (RMN $\left.{ }^{1} \boldsymbol{H}\right)$ de carboximetilquitosana $\mathrm{CMQ} 4 \mathrm{em} \mathrm{D}_{2} \mathrm{O} / \mathrm{HCl}(1: 100 \mathrm{em}$ volume $), 80^{\circ} \mathrm{C}$.

A evidência que ocorreu também a N-carboximetilação pode ser indicada pelos sinais na região de $\delta=3,10$ a 3,40 (Figura 21). De acordo com Muzzarelli et al. (1994) os sinais em $\delta=3,06$ e 3,22 são atribuídos a mono e disubstituição dos grupos amino. Deve-se lembrar que o sinal do hidrogênio do $C 2$, se sobrepõe aos sinais em $\delta=3,1$ a 3,4 atribuídos a $\mathrm{N}$-carboximetilação que também se localizam na região, o que dificulta uma análise mais detalhada.

Os espectros de ressonância magnética nuclear das outras amostras de CMQ se encontram em anexo.

\subsection{Carboximetilquitosana na forma ácida}

A técnica de espectroscopia na região do infravermelho também foi utilizada para avaliar as amostras carboximetiladas na forma ácida, visando determinar o grau médio de 
substituição $(\overline{G S})$. A figura 22 mostra os espectros da amostra CMQ1 como sal de sódio e na forma ácida.

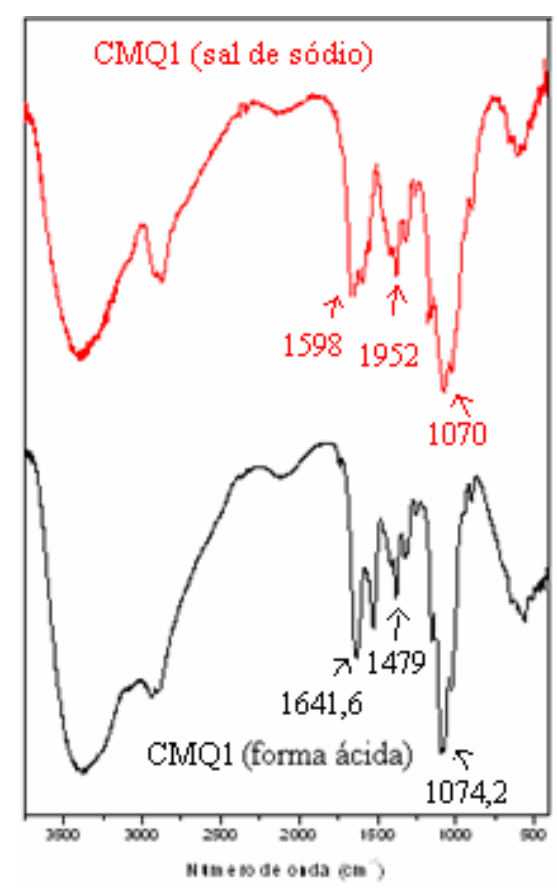

Figura 22: Espectro na região do infravermelho para carboximetilquitosana (CMQ1) na forma ácida e como sal de sódio.

Os espectros da CMQ1 na forma de sal de sódio (Figura 22) mostra a presença de bandas na região de $1598 \mathrm{~cm}^{-1}$ (-COONa) e $1592 \mathrm{~cm}^{-1}$ (-NH $\mathrm{NH}_{2}$. (CHEN; PARK, 2003). Já no espectro de carboximetilquitosana, após a conversão à forma ácida (Figura 22), pode-se observar bandas na região de $1641 \mathrm{~cm}^{-1}$ (-COOH), 1090-1155 cm-1 (-C-O-), 1632 e 1479 $\mathrm{cm}^{-1}\left(-\mathrm{NH}_{3}{ }^{+}\right)$, que são bandas características de carboximetilquitosana na forma ácida (ABREU, 2005), confirmando a conversão da amostra como sal de sódio para forma ácida. Os espectros correspondentes as outras amostras se encontram em anexo.

$\mathrm{O}$ espectro da carboximetilquitosana na forma ácida permite a determinação mais precisa do grau médio de substituição $(\overline{G S})$ das amostras, via espectroscopia na região do infravermelho, já que a superposição de bandas na região de maior interesse é evitada.

Para a determinação do $\overline{G S}$, deve-se determinar a razão de intensidade das das bandas em $1411 \mathrm{~cm}^{-1}$, referente a banda de deformação axial assimétrica COO, e $1321 \mathrm{~cm}^{-1}$ 
que corresponde a banda de amida III, sendo esta última a banda de referência, traçando-se a linha de base na região entre 1488-1224 $\mathrm{cm}^{-1}$. A Tabela 6 mostra os resultado obtidos.

Tabela 6: Grau médio de substituição $(\overline{G S})$, obtido por espectroscopia na região de infravermelho

\begin{tabular}{|c|c|}
\hline Amostra & $\overline{\boldsymbol{G S}}$ infravermelho \\
\hline CMQ1 & 0,6 \\
\hline CMQ3 & 0,5 \\
\hline CMQ4 & 0,8 \\
\hline CMQ5 & 0,8 \\
\hline CMQ6 & 1,0 \\
\hline CMQ7 & 1,1 \\
\hline
\end{tabular}

A amostra CMQ2 na forma ácida não foi caracterizada por espectroscopia na região do infravermelho, pois não foi possível obter o filme necessário para tal.

A figura 23 mostra a correlação entre $\overline{G S}$ e a quantidade de ácido monocloroacético utilizado, não tendo sido considerada a CMQ1, que foi obtida em meio diferente das demais.

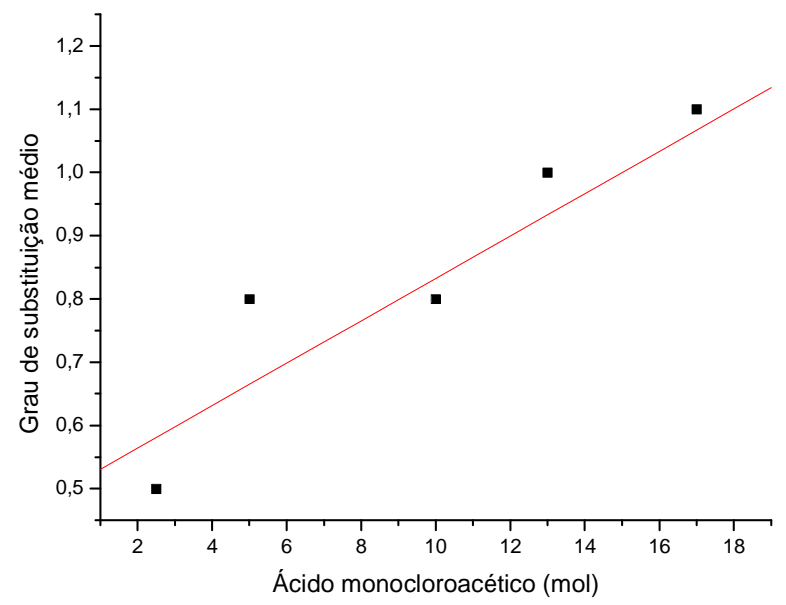

Figura 23: Curva de grau médio de substituição versus quantidade de ácido monocloroacético utilizado (meio: DMAc/LiCl). 
Pode-se considerar que existe uma correlação linear entre $\overline{G S}$ e a quantidade de ácido monocloroacético adicionada, o que permite controlar o grau de substituição médio, pelo menos dentro do intervalo de $\overline{G S}$ considerado, e no meio DMAc/LiCl.

\subsection{Análise Térmica: Termogravimetria}

A decomposição térmica das amostras, tanto da quitosana (Figura 24), quanto das amostras carboximetiladas (Figura 25), em atmosfera de nitrogênio ocorre em duas etapas. Na primeira, entre $50{ }^{\circ} \mathrm{C}$ e $110{ }^{\circ} \mathrm{C}$, ocorre a perda de água. A partir de $280{ }^{\circ} \mathrm{C}$, ocorre a decomposição da cadeia polimérica, principalmente devido à clivagem das ligações glicosídicas (HOLNE, et al., 2001), sendo que em torno de $330{ }^{\circ} \mathrm{C}$ ocorre o máximo de decomposição.

Para a quitosana, o máximo da decomposição térmica em $330{ }^{\circ} \mathrm{C}$ corresponde ao estágio de pirólise, quando ocorrem a desidratação, despolimerização e decomposição das unidades acetiladas e desacetiladas do polímero. A energia associada ao decomposição térmica da quitosana depende diretamente da grau de desacetilação do polímero. De fato, quanto maior o grau de desacetilação, maior a quantidade de energia envolvida. (PENICHE-COVAS; ARGULLES-MONAL; ROMÁN, 1993)

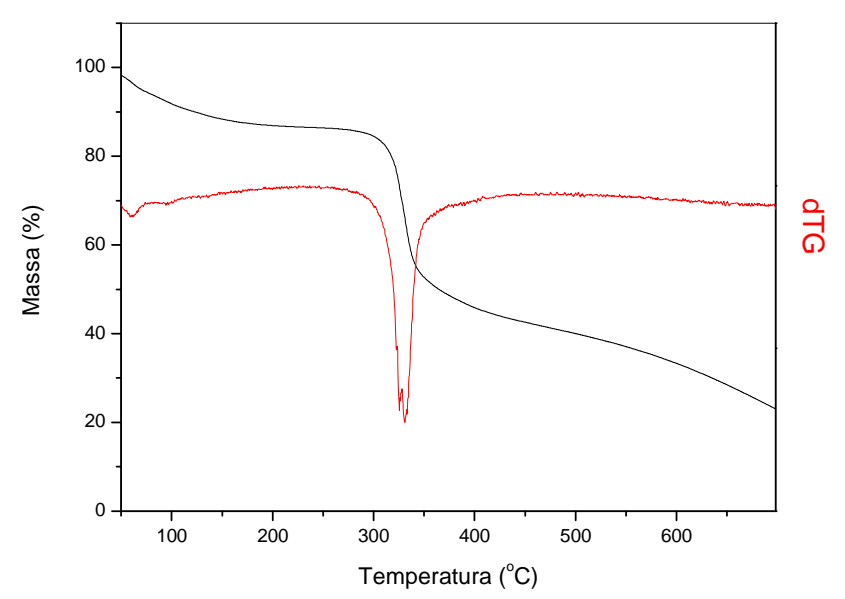

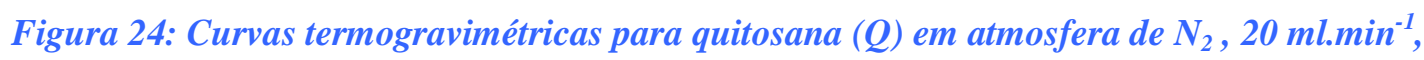
razão de aquecimento de $20^{\circ}$ C.min. ${ }^{-1}$ 


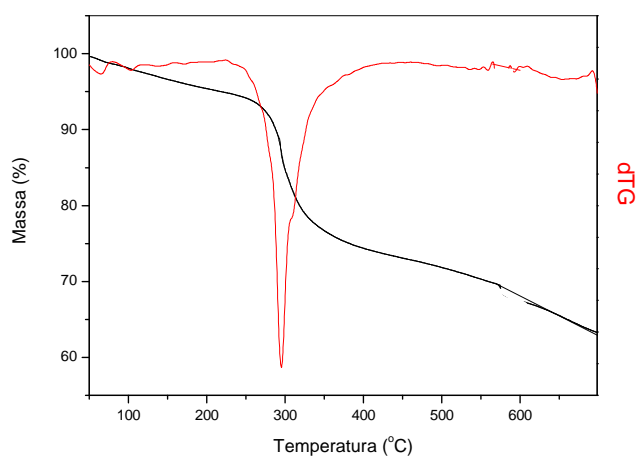

(a)

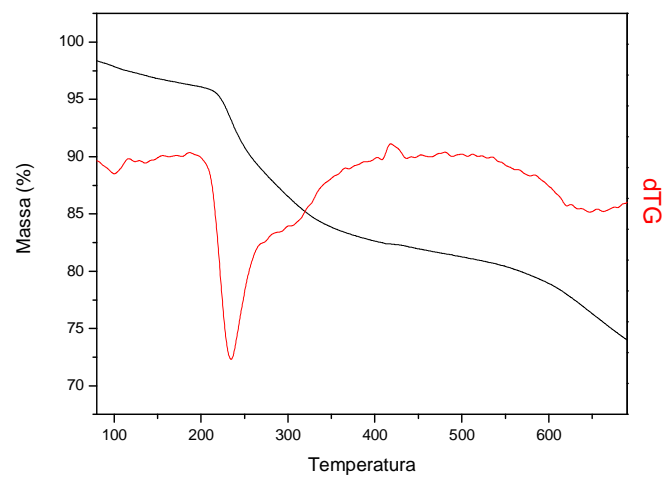

(b)

Figura 25: Curvas termogravimétricas das amostras carboximetilidas:(a)CMQ3 e (b)CMQ7, em atmosfera de $\mathrm{N}_{2}$ com fluxo de gás de $20 \mathrm{~mL}$.min ${ }^{-1}$ e razão de aquecimento de $20^{\circ} \mathrm{C} \cdot \mathrm{min}^{-1}$.

Pode-se observar que entre $50{ }^{\circ} \mathrm{C}$ e $110{ }^{\circ} \mathrm{C}$ (Figura24) a quitosana tem uma perda de massa de cerca de 10\%, enquanto as amostras carboximetiladas (Figura 25) apresentam cerca de $13 \%$ de perda de massa. As amostras carboximetiladas absorvem uma quantidade maior de água, devido a presença dos grupos carboxilatos hidrofílicos.

As curvas TG (Figura 25) mostram que as amostras de carboximetilquitosana apresentam perfis de degradação térmica diferentes daquele da quitosana de partida. Adicionalmente, pode-se dizer que a carboximetilquitosana é termicamente menos estável do que a quitosana, já que o máximo de decomposição daquela ocorre em torno de $280{ }^{\circ} \mathrm{C}$, enquanto que para a quitosana isto ocorre em torno de $330^{\circ} \mathrm{C}$.

As curvas TG da amostra CMQ7 (Figura 25,b), que tem maior $\overline{G S}$ (1,1, Tabela 6) mostram um deslocamento do máximo de decomposição, quando comparada a quitosana, para aproximadamente $225{ }^{\circ} \mathrm{C}$, evidenciando a decomposição decorrente da presença do grupo carboxílico.

Estudos reportaram dois picos de decomposição, em $239,4^{\circ} \mathrm{C}$ e $305,9^{\circ} \mathrm{C}$, para a $\mathrm{N}$ O- Carboximetilquitosana, que foram atribuídos a decomposição envolvendo os grupos carboxílicos e as unidades de glucosamina, respectivamente (LAMIN et al, 2006; CÁRDENAS; CUELLAR; NEIRAS, 2004). Portanto, a menor estabilidade térmica dos 
derivados, com relação a quitosana deve-se á substituição que ocorre nos grupos hidroxila e amino (TIRKISTANI, 1998).

As curvas TG correspondentes às outras amostras se encontram em anexo.

\subsection{Avaliação da atuação de CMQ como agente de estabilização de suspensões de alumina}

\subsubsection{Medidas de viscosidade}

Como mencionado na parte introdutória, a partícula de alumina pode apresentar em sua superfície cargas positivas e negativas dependendo do $\mathrm{pH}$ do meio. Nos valores de $\mathrm{pH}$ em que se encontra o ponto de carga zero, (pHpcz), a suspensão de alumina apresenta tendência de formar agregados, devido à atração eletrostática entre as partículas com cargas opostas. Neste intervalo de $\mathrm{pH}$, a viscosidade da suspensão se torna máxima e, portanto, a avaliação deste intervalo é de grande interesse, já que o processamento de suspensões pode apresentar dificuldades, devido à alta viscosidade. A figura 26 mostra a variação da viscosidade da alumina em função do $\mathrm{pH}$.

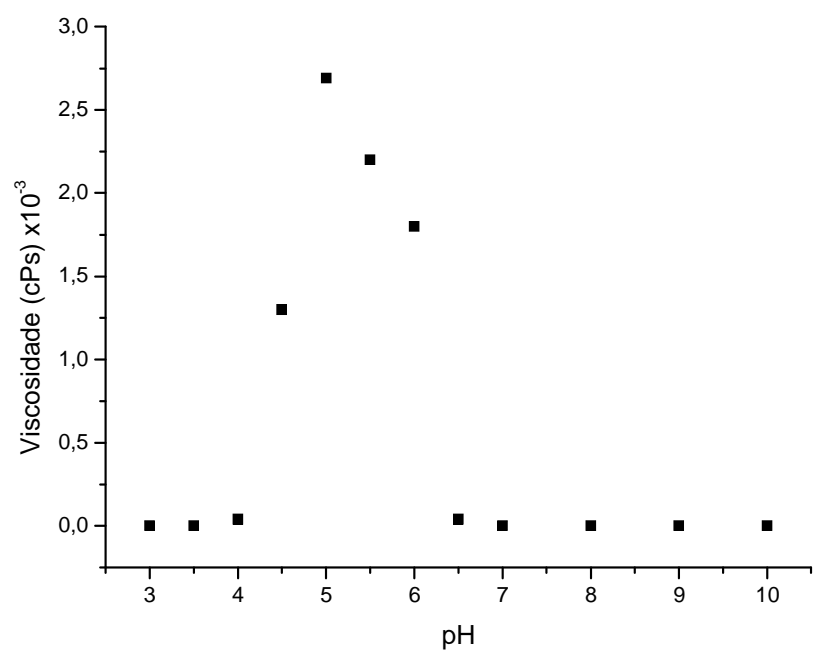

Figura 26: Viscosidade da suspensão aquosa de alumina em função do pH; temperatura ambiente. 
A figura 26 mostra que a viscosidade da suspensão aumenta entre $\mathrm{pH}$ 4,5 e 6,0, com um pHpcz em torno de $\mathrm{pH}$ 5,5. Adicionalmente, observa-se que, mesmo na ausência de agentes de estabilização, a viscosidade da suspensão é baixa quando o $\mathrm{pH}$ se situa entre 3,0 e 4,0 (superfície das partículas majoritariamente com carga positiva) e acima de 7,0 (superfície das partículas majoritariamente com cargas negativas). A repulsão entre cargas de mesmo sinal, predominantes na superfície das partículas de alumina é suficiente para dificultar a agregação, ocorrendo estabilização eletrostática.

No intervalo de maior viscosidade, que inclui o pHpcz, torna-se indispensável a adição de um agente de estabilização, já que a agregação é facilitada pela atração eletrostática entre as partículas de sinais opostos. (VASCONSELOS, 2005). O controle da reologia, no intervalo em que se insere o pcz, é imprescindível para o processamento cerâmico. Uma suspensão com agregados irá comprometer a homogeneidade e, consequentemente, a qualidade do produto final. Para tal finalidade, no presente trabalho, o comportamento das carboximetilquitosanas, assim como da quitosana, foi avaliado como estabilizante. A figura 27 mostra o comportamento da suspensão de alumina, em função da massa de estabilizante adicionada, quando o $\mathrm{pH}$ é mantido em 5,5, que aproximadamente corresponde ao pcz da amostra utilizada.

As amostras CMQ1, CMQ3, CMQ4, CMQ5, CMQ6, CMQ7 e Q foram analisadas como estabilizantes para suspensões aquosas de alumina, entretanto, o estudo em função da massa, para CMQ7 e CMQ1 não foi realizado devido à pequena quantidade de amostra disponível. A massa utilizada para estas amostras, quando se avaliou a variação de viscosidade em função do $\mathrm{pH}$, foi estimada,considerando o resultado obtido com as outras amostras. 


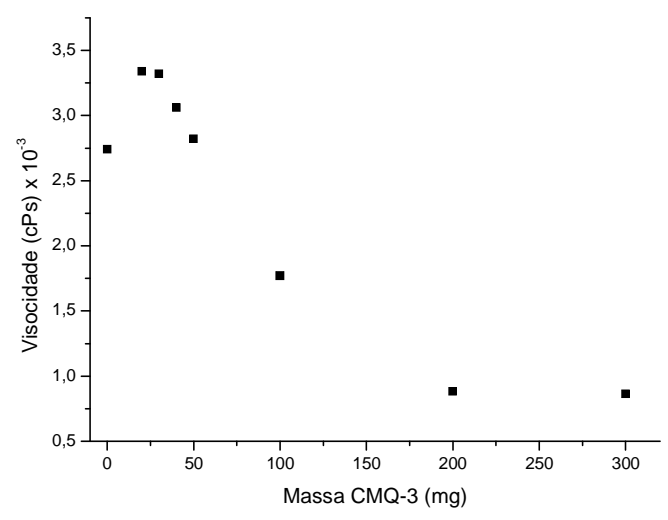

(a)

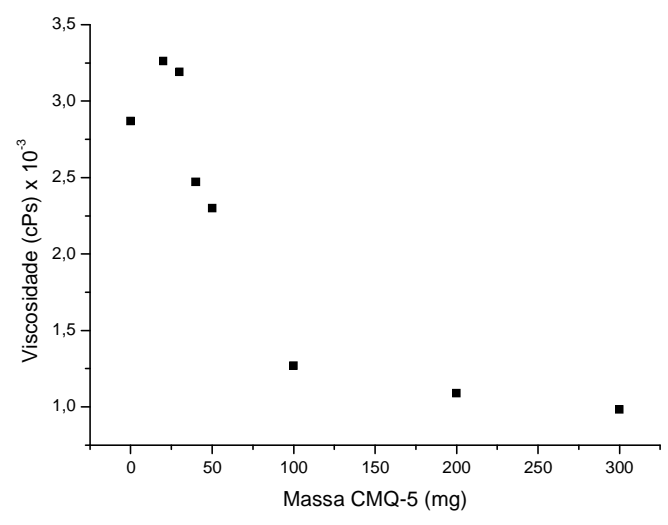

(c)

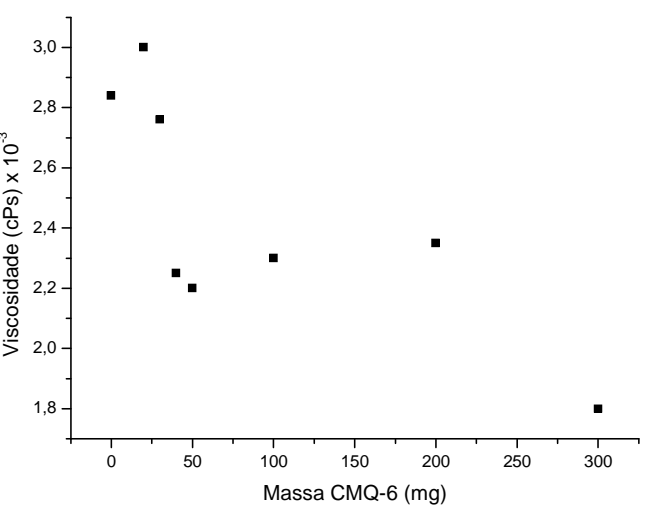

(d)

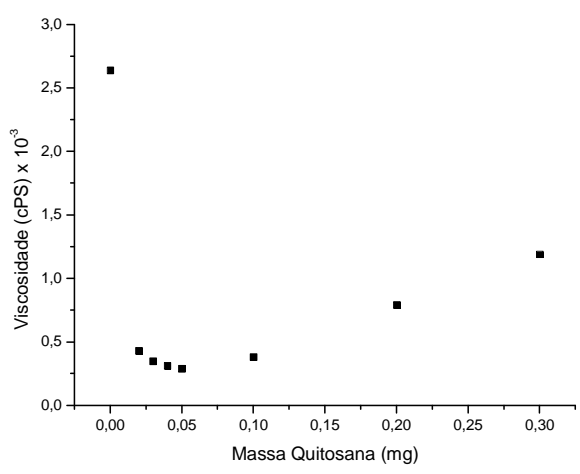

(e)

Figura 27: Viscosidade da suspensão de alumina em função da massa de aditivo: a)CMQ3, b)CMQ4, c)CMQ5 e d)CMQ6, (e) Q. pH 5,5, temperatura ambiente. 
Para a quitosana (Q), se observa que após uma queda inicial na viscosidade da suspensão, esta começa a aumentar, sugerindo que a interação entre as cadeias de quitosana e a superfície de alumina é relativamente fraca, ocorrendo a dessorção destas cadeias, o que aumenta a viscosidade do meio.

Os estabilizantes foram adicionados diretamente na forma de pó, pois quando em soluções aquosas, as cadeias de carboximetilquitosana podem sofrer agregação e, portanto, a sua eficiência como estabilizante poderia ser menor se fosse utilizada uma solução aquosa desta macromolécula. (ZHU et al, 2005; ZHU et al, 2006)

Considerando os efeitos da adição de diferentes massas dos estabilizantes na viscosidade da suspensão de alumina, foi na seqüência usado um valor fixo de massa, correspondente a menor viscosidade observada na figura 27. Esta massa foi adicionada às suspensões, verificando-se a influência de variação do $\mathrm{pH}$ sobre a viscosidade do meio.

A figura 28 mostra a variação da viscosidade com a adição dos agentes de estabilização em função do pH. 


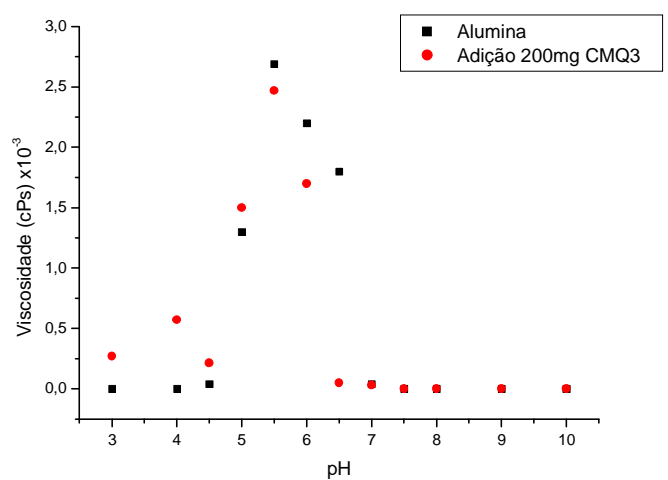

(a)

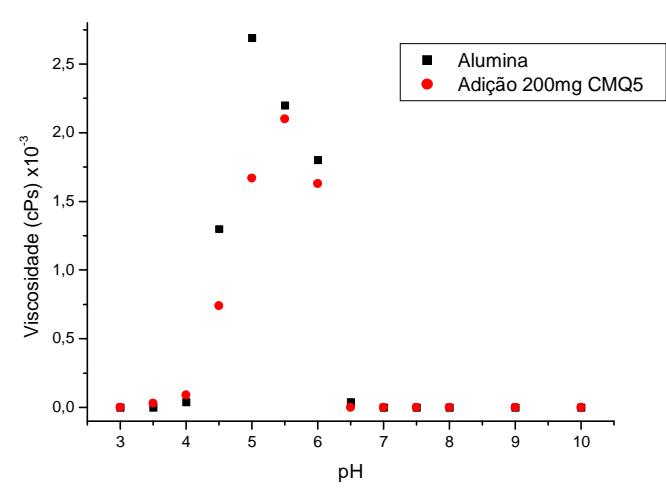

(c)

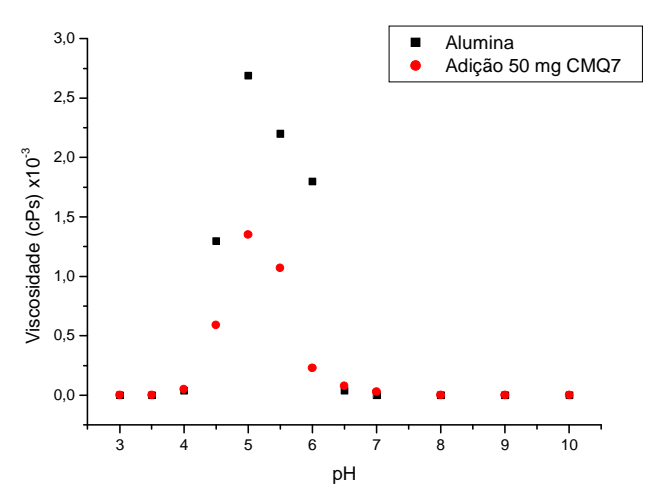

(e)

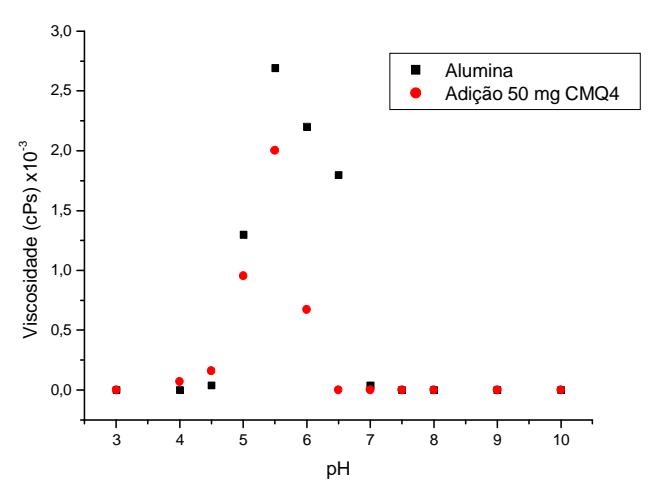

(b)

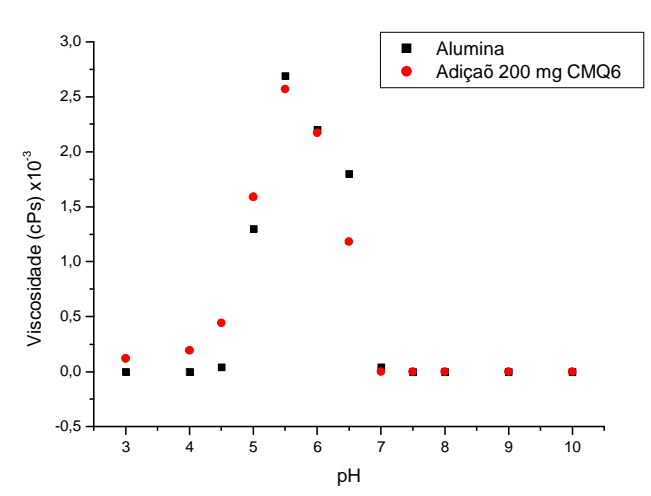

(d)

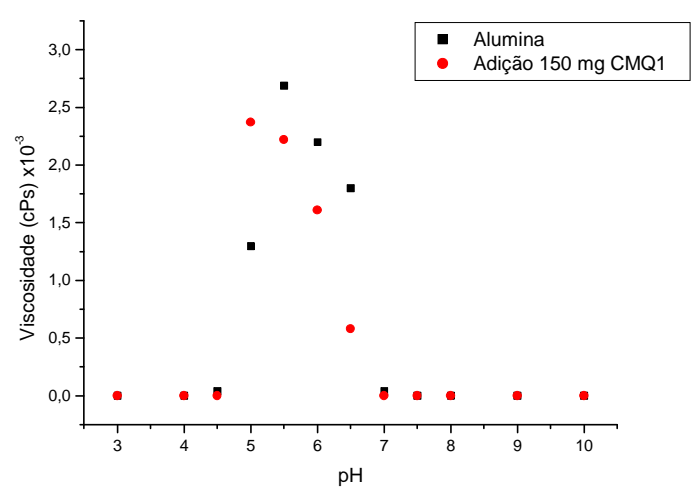

(f) 


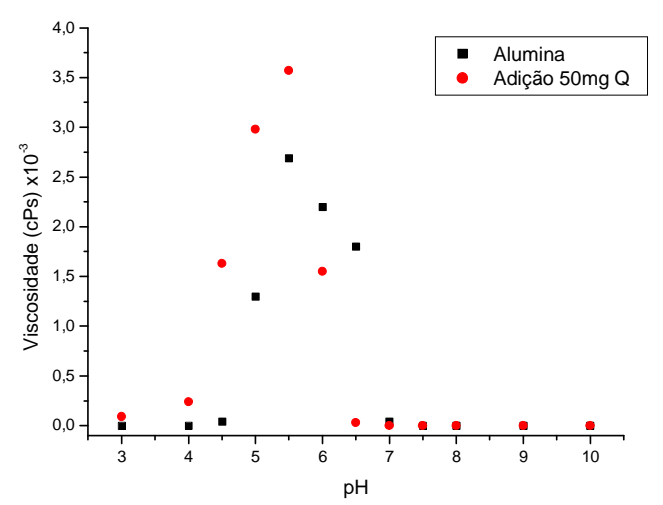

$(\mathrm{g})$

Figura 28: Viscosidade da suspensão de alumina em função do pH, para a adição de: (a) CMQ3,

(b) CMQ4, (c) CMQ5, (d) CMQ6, (e) CMQ7, (f) CMQ1 e (g) Q, temperatura ambiente.

A adsorção de uma cadeia polimérica na superfície dos óxidos metálicos, depende das interações entre ambas. Estas interações variam conforme o pH do meio, já que a proporção de sítios com cargas positivas e negativas, assim como de sítios sem cargas, tanto na superfície da alumina como nas macromoléculas consideradas como agentes de estabilização, dependerá do pH.

Os grupos carboximetila estão ionizados em maior ou menor extensão, dependendo do $\mathrm{pH}$, na faixa de $\mathrm{pH}$ entre 4 e 14 (CHEN et al, 2006). Quando as amostras de carboximetilquitosana são adicionados às suspensões de alumina, várias interações poderão ocorrer, envolvendo os grupos presentes, conforme ilustrado de forma esquemática na figura 29. 


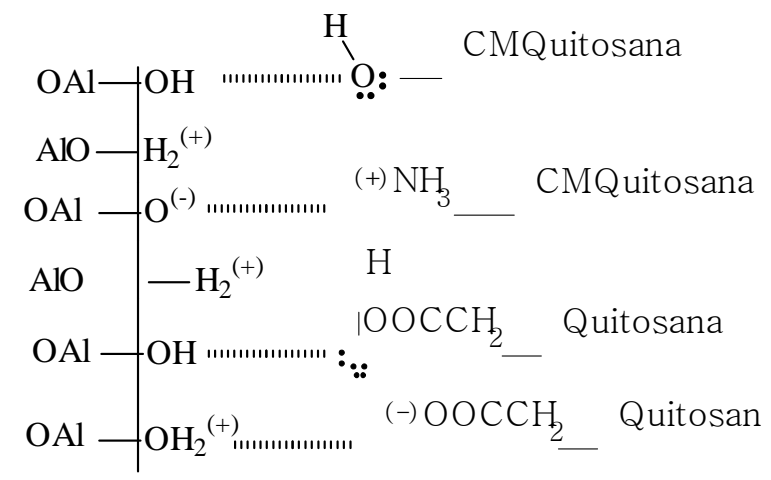

Figura 29: Representação esquemática das possíveis interações entre a superfície da alumina e carboximetilquitosana $(C M Q)$.

Os grupos funcionais presentes na carboximetilquitosana poderão interagir com os sítios da superfície das partículas de alumina por meio da interação via ligação hidrogênio, sendo que neste tipo de interação os grupos carboxílicos podem atuar como doador ou aceptor de prótons. Já os grupos carboxilatos agem como aceptor de prótons (YOKOSAWA; PANDOLFELLI; FROLLINI, 2002). Destaca-se ainda que a carboximetilquitosana é uma macromolécula linear, o que facilita a adsorção sobre as partículas, o que não ocorre com macromoléculas ramificadas.

Como mostrado pela figura 28, a adição das amostras de carboximetilquitosana, obtidas em meio DMAc/LiCl (CMQ3, CMQ4, CMQ5, CMQ6 e CMQ7), reduzem, em diferentes graus, a viscosidade da suspensão. A curva de viscosidade obtida com a adição de CMQ7 ( $\overline{G S}=1,1)$ apresentou um decréscimo mais acentuado na viscosidade, quando comparado às outras amostras. O maior $\overline{G S}$, portanto um maior número de grupos carboxílicos presente na amostra, aumenta as possibilidades de interação com as partículas de alumina.

Polímeros lineares, como a quitosana, podem adquirir conformações de cadeia estendida ou não, dependendo do balanço entre as atrações e repulsões intermoleculares (ZHU et al., 2006). Quando a reação é realizada em meio heterogêneo, a distribuição dos grupos carboximetílicos ao longo das cadeias pode não ser homogêneo, o que pode não permitir uma interação com as partículas de alumina de maneira eficiente. A amostra obtida por meio de reação em meio heterogêneo $(\mathrm{CMQ} 1, \overline{G S}=0,7)$ não mostra um 
comportamento muito diferente, em termos de variação de viscosidade, quando comparada às amostras de $\overline{G S}$ próximos, obtidas em meio DMAc/LiCl (CMQ4, CMQ5, $\overline{G S} \cong 0,8)$. No entanto, outros resultados que serão discutidos posteriormente, evidenciam algumas diferenças entre o comportamento de CMQ1 e as amostras obtidas em DMAc/LiCl.

Devido a menor solubilidade da quitosana no meio, e da a ausência de grupos carboxílicos, a adição deste polissacarídeo à suspensão não provocou redução significativa da viscosidade da suspensão.

\subsubsection{Medidas de Potencial Zeta}

A figura 30 mostra o resultado das medidas de potencial zeta da suspensão de alumina, sem adição de estabilizantes, em função do pH.

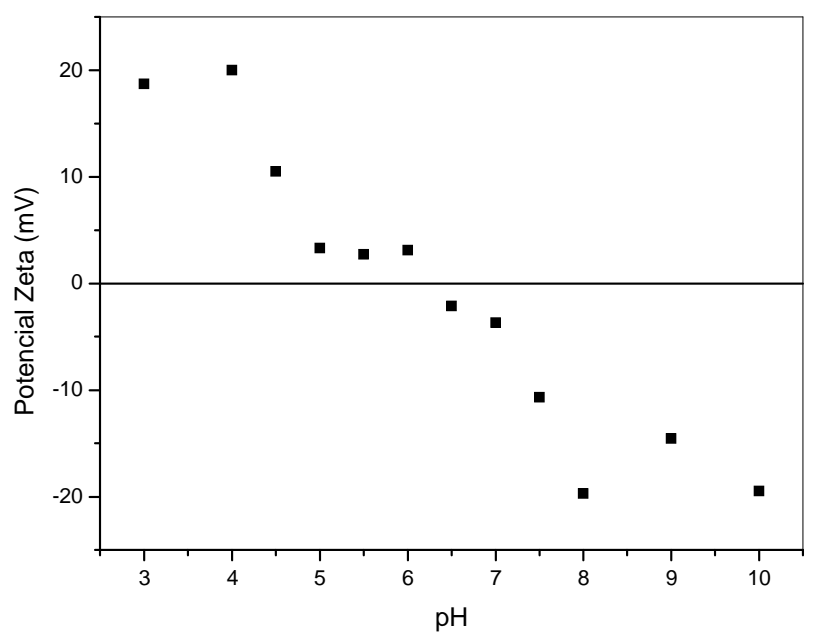

Figura 30: Potencial zeta da suspensão aquosa de alumina em função do pH; temperatura ambiente.

A figura 30 confirma a estimativa, feita por meio das medidas de viscosidade (Figura 26), de que o pHpcz da alumina está em torno de 5,5, já que nestes valores de pH o potencial zeta da alumina está próximo de zero, ou seja, o número de sítios positivos e negativos na superfície do óxido se iguala, resultando em potencial zeta nulo. 
Inicialmente, as medidas de potencial zeta foram feitas para se determinar a quantidade mais eficiente de estabilizante que deveria ser utilizada a fim de se obter uma suspensão coloidal estabilizada. As medidas foram feitas em função da massa adicionada, quando o pH da suspensão da alumina foi mantida em pH5,5. Os resultados são mostrados na figura 31 .

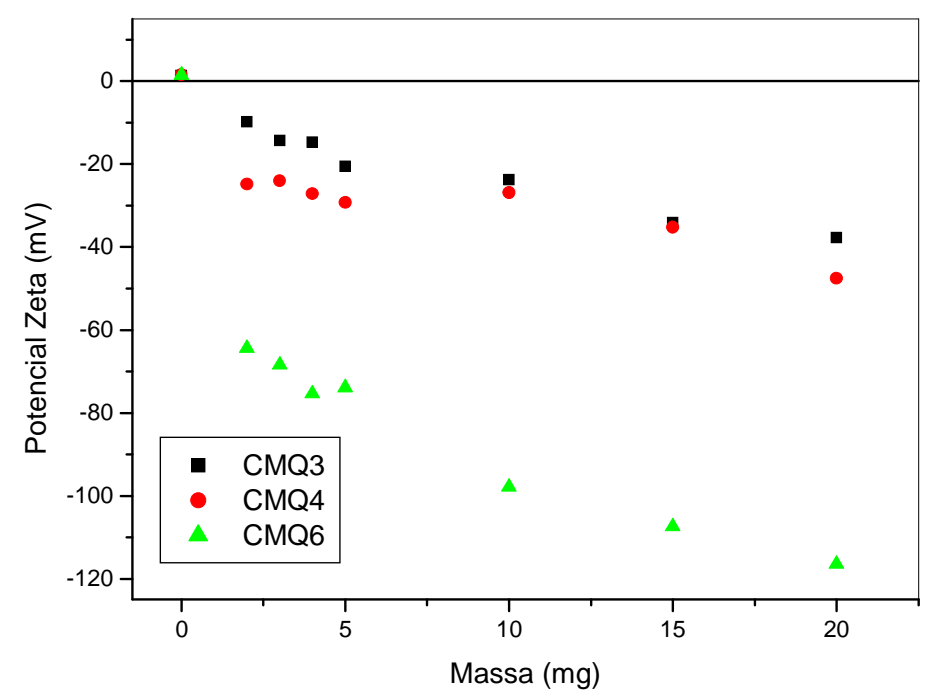

Figura 31: Potencial zeta da suspensão de alumina em função da massa de aditivo: CMQ3

$(G S=0,5), C M Q 4(G S=0,8)$ e CMQ6 $(G S=1,0)$. pH= 5,5, temperatura ambiente.

Observa-se que a carboximetilquitosana com maior grau de substituição (CMQ6), dentre as consideradas na figura 31 , leva à suspensão com maior valor de potencial zeta, devido a maior concentração de cargas negativas.

A partir dos estudos de variação do potencial zeta em função da massa, foi determinada a quantidade mínima, suficiente para que ocorresse o aumento máximo na magnitude do potencial zeta nos valores de pzc. A figura 32 mostra a variação de potencial zeta em função do $\mathrm{pH}$, usando as quantidades ótimas para cada amostra. Devido à pequena disponibilidade de massa das amostras, foram feitos estudos em função da massa apenas para as amostras CMQ3, CMQ4 e CMQ6, sendo que para as outras o valor de massa foi estimado considerando os resultados obtidos para as amostras citadas. 


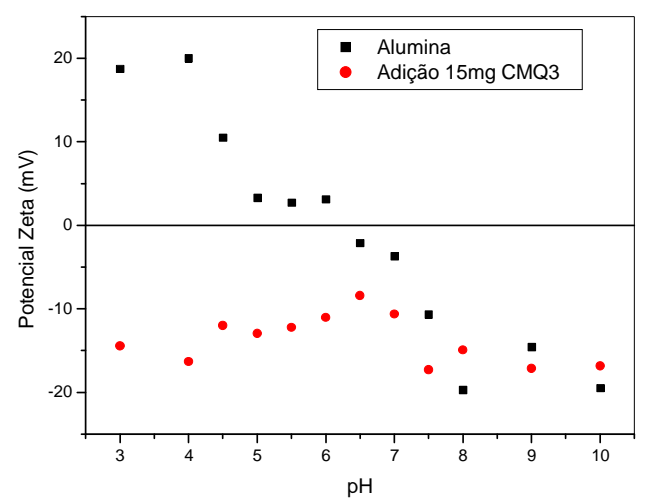

(a)

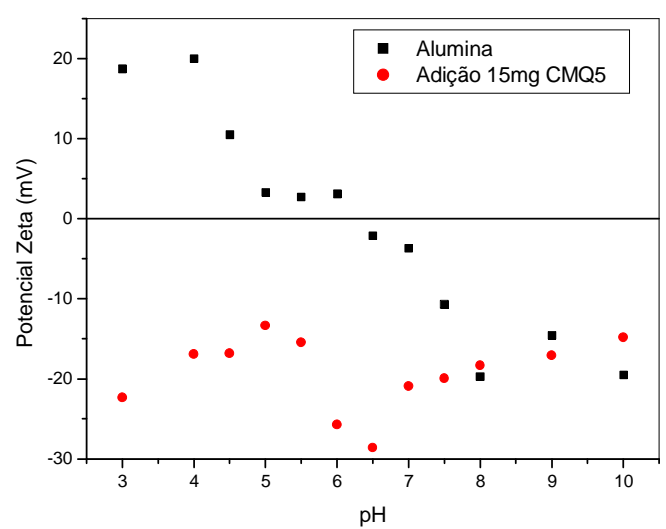

(c)

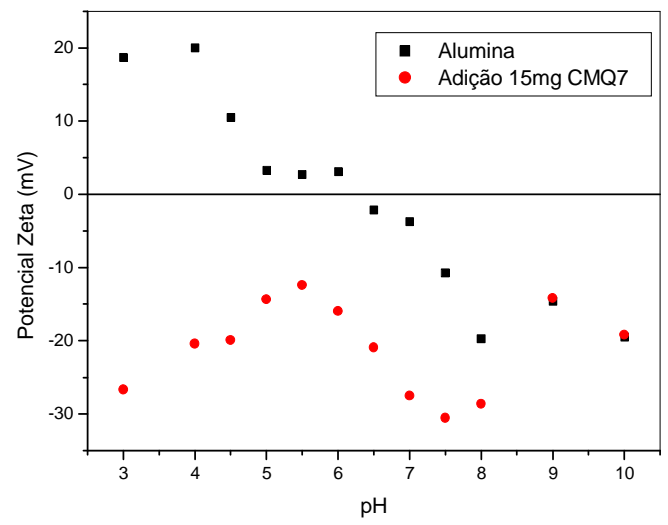

(e)

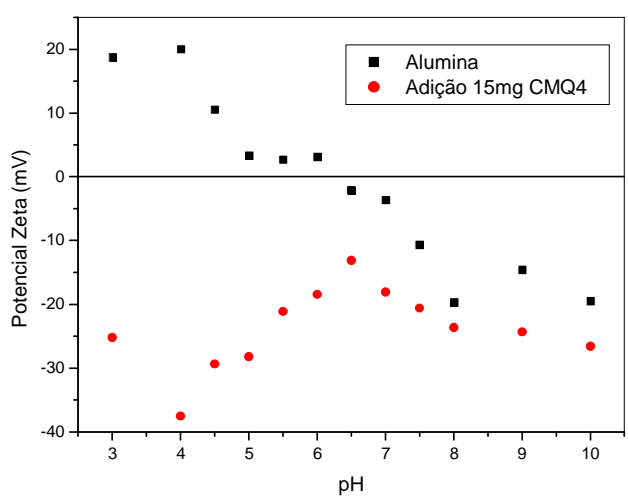

(b)

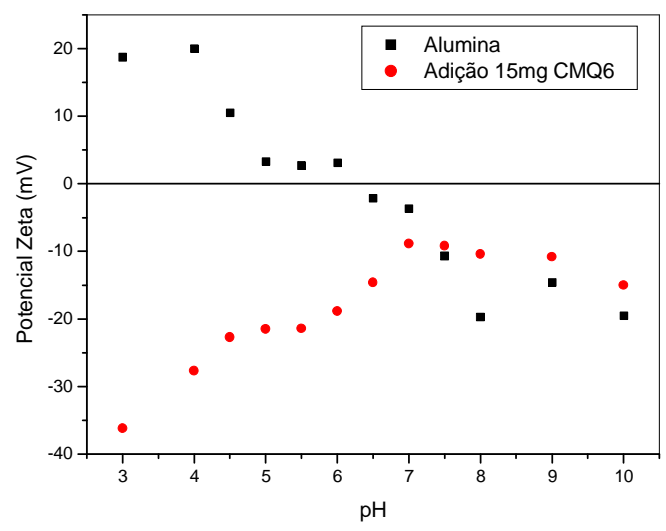

(d)

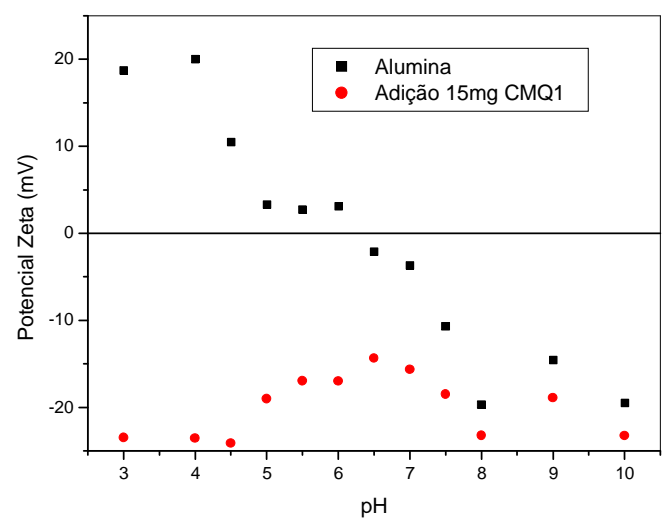

(f) 


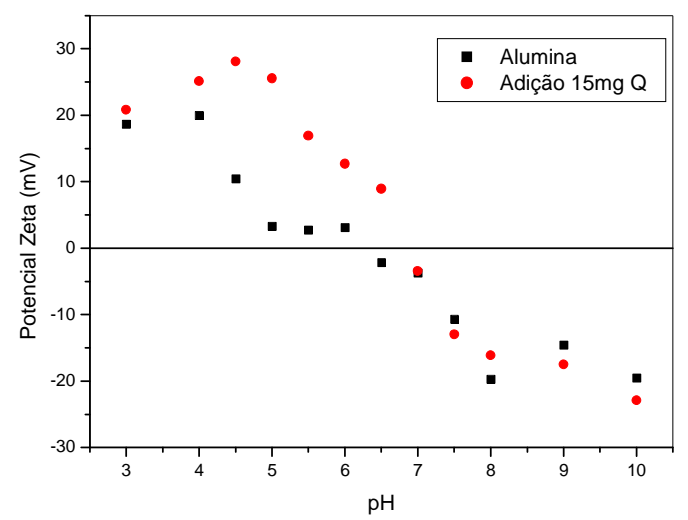

$(\mathrm{g})$

Figura 32: Potencial zeta da suspensão de alumina em função do pH, para a adição de: (a) CMQ3, (b)CMQ4, (c)CMQ5, (d)CMQ6, (e)CMQ7,(f)CMQ1 e (g)Q; temperatura ambiente.

A adição de carboximetilquitosana modifica o perfil elétrico da dupla camada elétrica ao redor de cada partícula. A adsorção das cadeias sobre a superfície da alumina pode blindar cargas positivas ou negativas, dependendo do $\mathrm{pH}$ e do grau de dissociação, tanto do estabilizante como da alumina, prevenindo a agregação..

Como mostrado pela figura 32(a, b, c, d, e, f), a adição de carboximetilquitosana torna o potencial zeta da suspensão negativo, independentemente do $\mathrm{pH}$ e da amostra adicionada. O potencial zeta negativo é uma conseqüência da carga negativa das partículas, que é resultado da adsorção das cadeias de carboximetilquitosana. Tal resultado é consistente com o fato da carboximetilquitosana ser um estabilizante aniônico. Os resultados indicam que a estabilização eletrostática é o principal mecanismo de estabilização da suspensão.

Em pH superior a 8, não ocorreu mudança significativa na magnitude do potencial zeta, quando foi adicionado carboximetilquitosana, pois neste $\mathrm{pH}$ os grupos carboxílicos estão na forma $-\mathrm{CH}_{2} \mathrm{COO}^{-}$, enquanto na superfície da alumina, predominam os sítios negativos. Logo, a adsorção não deve ocorrer por meio de mecanismo eletrostático e, a carga da superfície não será alterada.

Em meio ácido, a concentração de grupos ${ }^{+} \mathrm{NH}_{3}$ na cadeia de quitosana é maior, fazendo com que na presença deste polissacarídeo, entre $\mathrm{pH} 3,0$ e 6,0, a suspensão 
apresente potencial zeta maior. A partir de aproximadamente $\mathrm{pH} 7,0$, o potencial zeta da suspensão sem e com quitosana é aproximadamente o mesmo.

A adição de polieletrólitos à suspensão torna mais complexo o entendimento das medidas de potencial zeta em termos de propriedades de sistemas coloidais. Quando o meio aquoso contem apenas alumina, esta medida pode ser vista como a carga superficial líquida do óxido. Já quando um polieletrólito é adicionado, a carga líquida será definida pela carga da própria cadeia, pela carga superficial do óxido, e pela intensidade de adsorção na superfície do óxido (YOKOSAWA; PANDOLFELLI; FROLLINI, 2002). Portanto, as medidas de potencial zeta devem ser utilizadas em conjunto com as medidas de viscosidade e diâmetro de partícula, que serão mostradas a seguir, para que a estabilização das suspensões seja avaliada de forma mais ampla.

\subsubsection{Diâmetro de Partícula}

A ausência de forças repulsivas e o movimento browniano, que toda suspensão coloidal apresenta, levam à formação de agregados de partículas, o que consequentemente leva ao aumento do diâmetro de partícula da suspensão, considerando como aproximação, que estas são esféricas. Suspensões que apresentam estes aglomerados também apresentam elevada viscosidade, que interfere no processamento cerâmico. Portanto, para que uma suspensão seja estável, faz-se necessário o controle do tamanho das partículas.

A figura 33 apresenta as medidas de diâmetro médio de partícula da suspensão aquosa de alumina, sem adição dos agentes de estabilização. 


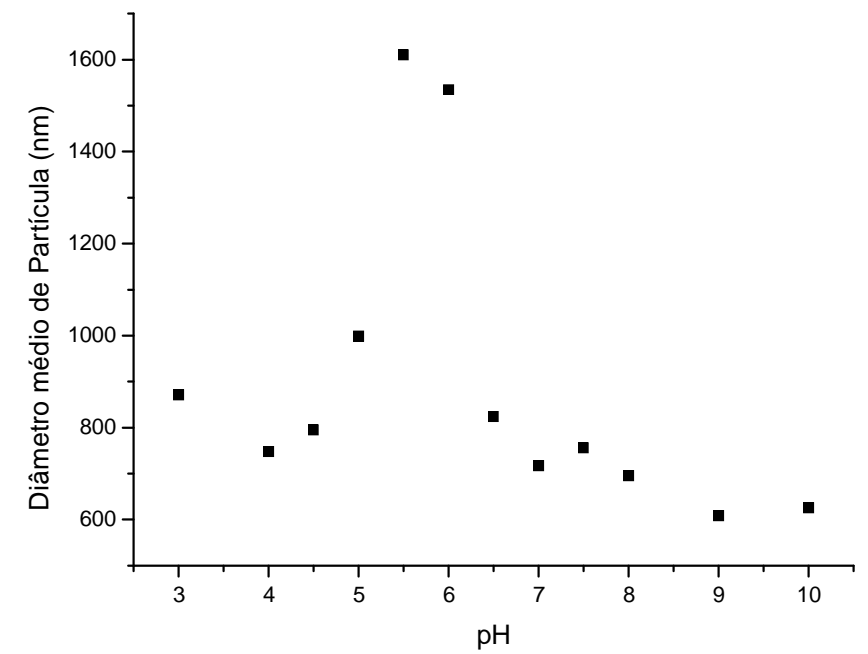

Figura 33: Diâmetro médio de partícula, em função do pH e sem a adição de estabilizantes, para a suspensão de alumina. Temperatura ambiente.

Quando em pH 5,5, o diâmetro médio de partícula para suspensão sem adição dos agentes de estabilização, apresenta seu máximo, sendo que visualmente se observa rápida sedimentação. Por este motivo, foram feitas análises de diâmetro médio de partícula neste valor de pH em função da massa de algumas amostras (Figura 34). 


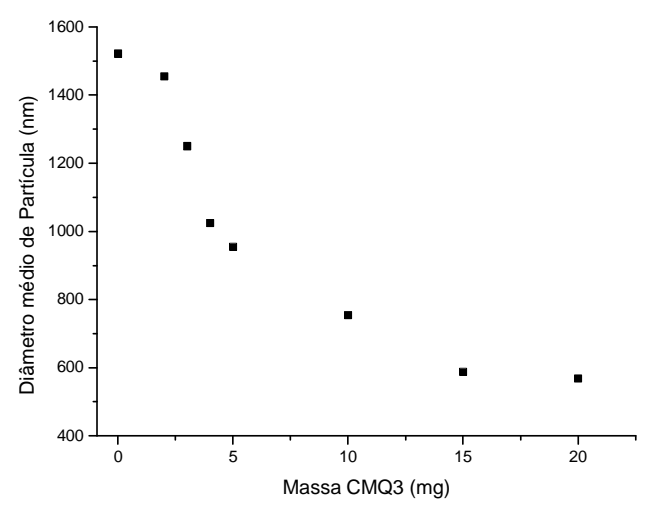

(a)

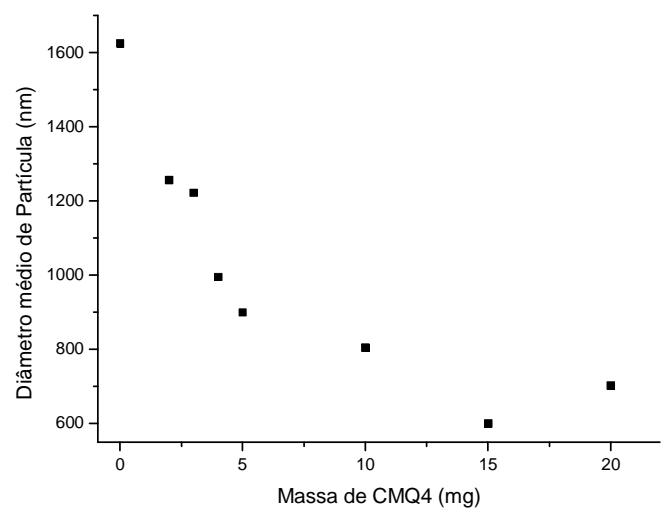

(b)

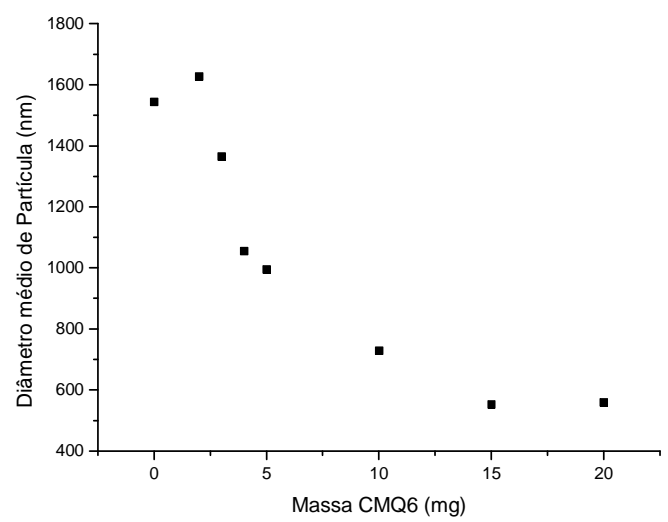

(c)

Figura 34: Diâmetro de partícula da suspensão de alumina em função da massa de aditivo:

(a)CMQ3, (b)CMQ4, (c)CMQ6. Temperatura ambiente.

A quantidade de $15 \mathrm{mg}$ mostrou-se suficiente para que ocorresse a diminuição do diâmetro médio de partícula da alumina, por isso, esta quantidade foi considerada para todas as amostras e adicionada à suspensão, sendo realizadas medidas em função do pH.. Os resultados são mostrados na figura 35 . 


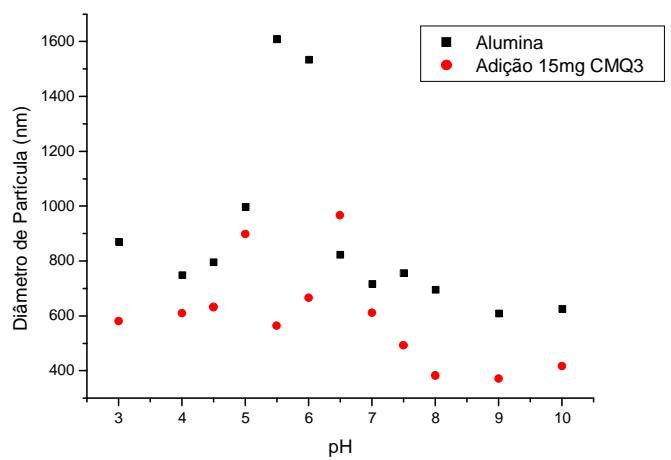

(a)

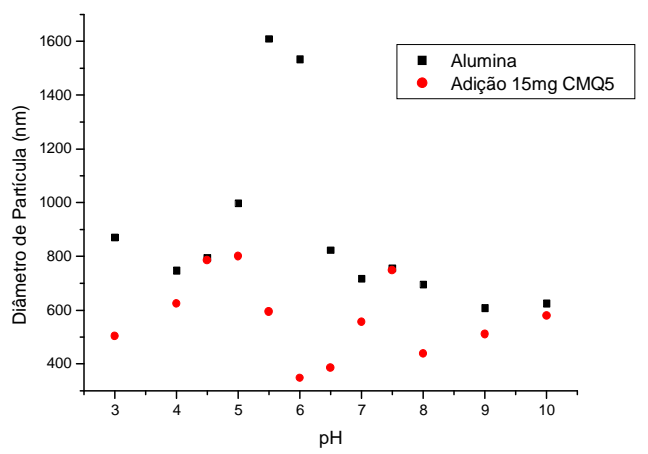

(c)

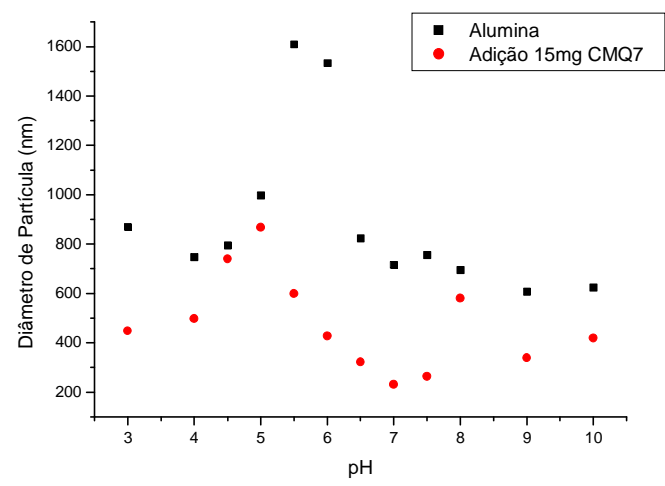

(e)

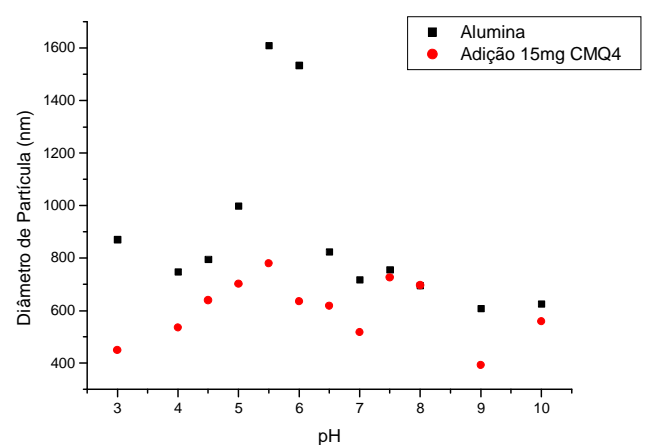

(b)

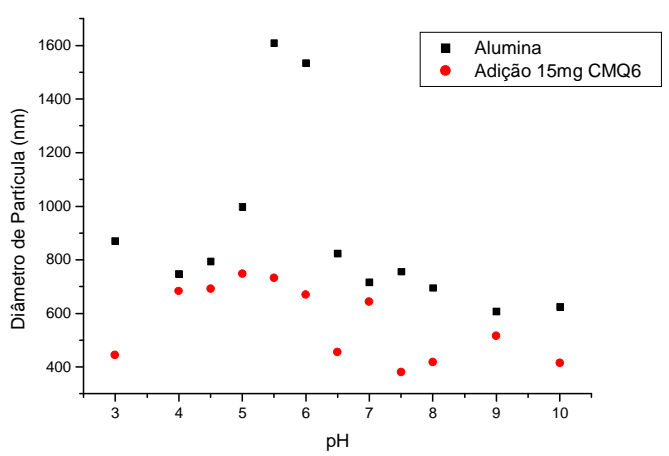

(d)

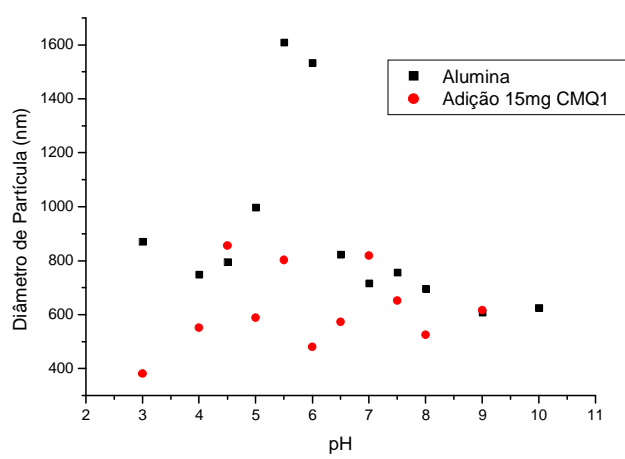

(f) 


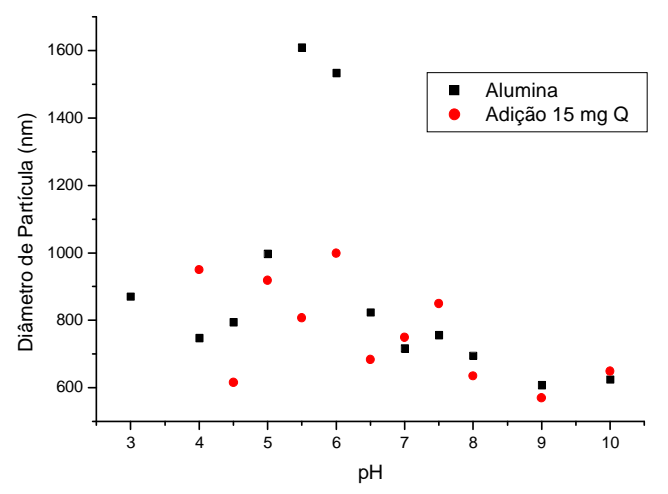

(g)

Figura 35: Diâmetro médio de partícula da suspensão de alumina, em função do pH, para a adição de 15 mg de: (a)CMQ3, (b)CMQ4, (c)CMQ5, (d)CMQ6, (e)CMQ7, (f)CMQ1 e (g)Q. Temperatura ambiente.

Entre pH 3,0 e 4,5 (Figura 35), se observa que a adição de carboximetilquitosana não provoca uma diminuição de diâmetro médio de partícula tão acentuada, como aquele que ocorre entre $\mathrm{pH}$ 5,0 e 6,0. No intervalo de $\mathrm{pH}$ entre 3,0 e 4,5, sítios com carga positiva estão majoritariamente presentes na superfície da alumina, conforme mostrado pelos valores de potencial zeta da suspensão (Figura 30). Assim, as interações repulsivas entre partículas de alumina dificultam a agregação, ocorrendo a estabilização da suspensão principalmente por efeito eletrostático. Embora neste intervalo de $\mathrm{pH}$ a suspensão se mantenha estável na ausência de estabilizantes, na presença destes ocorre interações entre os agentes de estabilização e as partículas de alumina, o que pode influir na distribuição de tamanho de partícula, como será discutido posteriormente.

Acima de pH 6,0 na ausência de agentes de estabilização o potencial zeta da suspensão se aproxima de zero, ou valores negativos de pequena magnitude, (Figura 30), o que deve favorecer a agregação, confirmado pela alta viscosidade do meio (Figura 26).

Os dados da figura 35 mostram uma significativa diminuição no tamanho médio das partículas de alumina acima na região do pHpcz, quando os agentes de estabilização são adicionados, confirmando os resultados de viscosidade que indicam que a interação da carboximetilquitosana com a alumina leva a suspensões mais estáveis. As cadeias adsorvidas proporcionam um impedimento estérico à aproximação das partículas, além de 
ocorrer interações repulsivas entre sítios de carga negativa presentes, principalmente nos valores mais altos de $\mathrm{pH}$. Assim, pode-se considerar que a suspensão é estabilizada por efeito eletrostático, não se observando muita diferença entre os comportamentos das diferentes amostras de carboximetilquitosana.

A adição de quitosana também leva a diminuição no tamanho médio de partícula, o que sugere interação entre as cadeias e a superfície de alumina. No entanto, as medidas de viscosidade mostram que a dessorção ocorre, aumentando a viscosidade do meio, conforme já mencionado.

A figura 36 mostra a distribuição de diâmetros de partículas, para a suspensão aquosa de alumina, em diferentes valores de $\mathrm{pH}$.

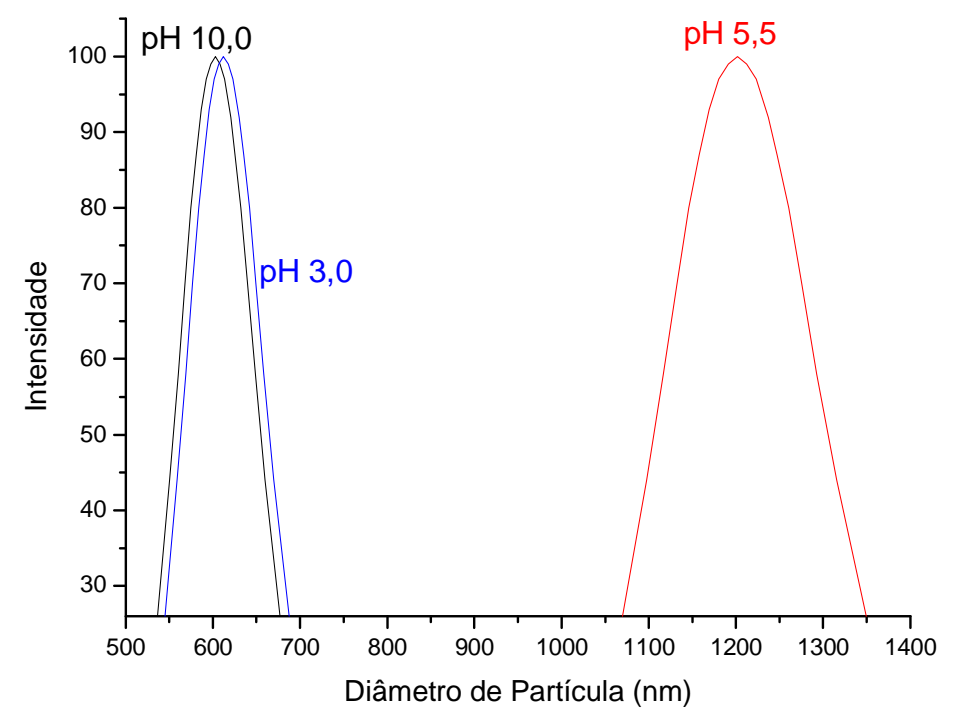

Figura 36: Distribuição de diâmetro de partícula da alumina, em função da intensidade do sinal.

Temperatura ambiente.

Como pode ser observado pela figura 36 , no $\mathrm{pH}$ correspondente ao pHpzc, a variação na distribuição de tamanhos de partícula é maior (em torno de $200-300 \mathrm{~nm}$ ), enquanto para os valores de $\mathrm{pH}$ em que predomina a repulsão eletrostática entre as partículas, a variação é em torno de $100 \mathrm{~nm}$. A avaliação do efeito causado pela adição de 
estabilizantes nestas faixas de $\mathrm{pH}$ é importante para que se conheça o efeito do estabilizante sobre a distribuição de tamanhos de partícula.

Os resultados são confirmados pela figura 37 , que mostra o efeito da adição de carboximetilquitosana em diferentes $\mathrm{pH}$, incluindo o $\mathrm{pHpzc}$ da alumina.

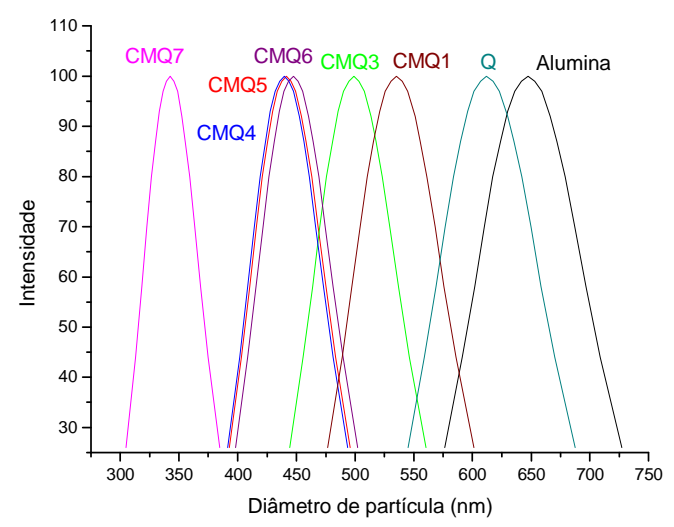

(a) $\mathrm{pH} 3,0$

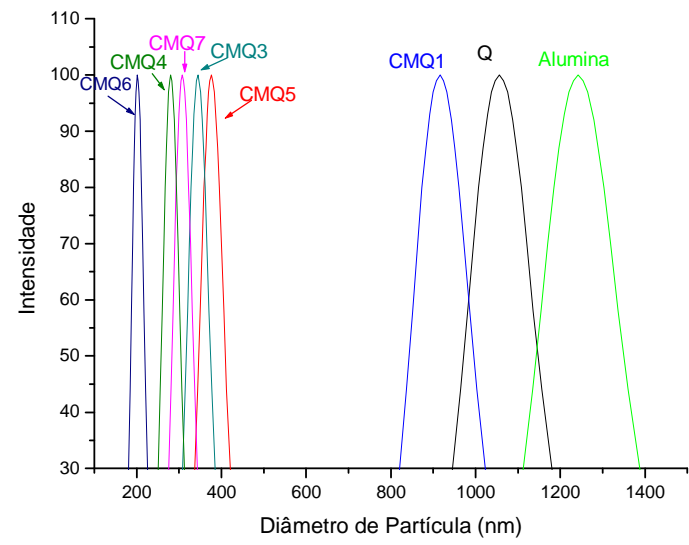

(b) $\mathrm{pH} 5,5$

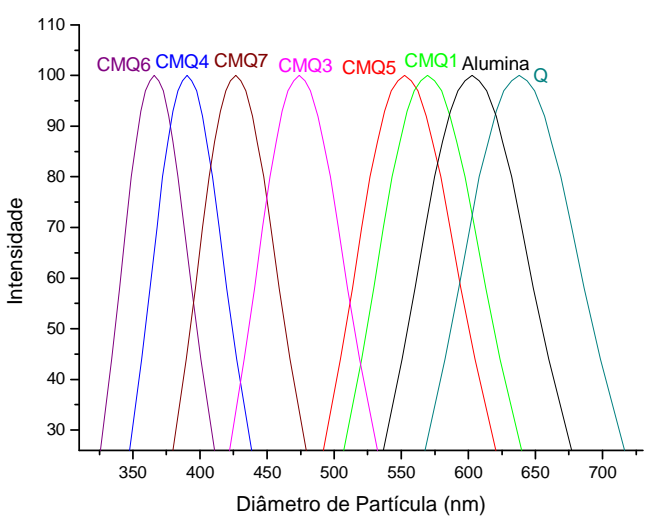

(c) $\mathrm{pH} 10,0$

Figura 37: Distribuição do diâmetro de partícula, em função do sinal para a suspensão de alumina a pH: (a)3,0, (b)5,5 e (c)10,0. Temperatura ambiente.

Pode-se observar (Figura 37, b) que a adição de CMQ1 (obtida em meio heterogêneo $\overline{G S}=0,7)$ e de Q, no pHpzc (pH5,5), provocaram uma pequena diminuição no diâmetro médio de partícula e em sua distribuição. Entretanto, todas as amostras preparadas 
em meio DMAc/LiCl, levaram a um diâmetro menor e a uma distribuição consideravelmente mais estreita, com destaque para CMQ7 $(\overline{G S}=1,1)$, CMQ6 $(\overline{G S}=1,0)$ e CMQ4 $(\overline{G S}=0,8)$. Estas medidas podem indicar que a maior acessibilidade dos reagentes ao sítios reacionais da quitosana, para reações que ocorreram no sistema de solvente DMAc/LiCl, pode ter levado a uma distribuição mais homogênea dos grupos carboxílicos ao longo das cadeias, facilitando a interação com sítios da superfície da alumina.

A eficiência da carboximetilquitosana como estabilizante para suspensões de alumina pode ainda ser comprovada pela figura 37(a) e (c). Nestes valores de pH a suspensão sem agentes de estabilização apresenta estabilidade, devido à repulsões eletrostáticas entre as partículas de mesma carga. No entanto, a pH 3,0, a adição de carboximetilquitosana, com destaque para CMQ7, leva a uma distribuição mais estreita de tamanho de partícula. Um efeito similar é observado a pH 10,0, com destaque para as CMQ 4,6 e 7. 


\section{CONCLUSÃO}

No presente trabalho, carboximetilquitosanas foram obtidas dissolvendo-se inicialmente a quitosana em $\mathrm{DMAc} / \mathrm{LiCl}$, dando-se então sequiência às reações. Até onde chega nosso conhecimento, este corresponde ao primeiro relato em que se descreve esta rota para obtenção de carboximetilquitosana . Para efeito de comparação de propriedades como agente de estabilização, uma amostra foi preparada em meio heterogêneo.

Os resultados obtidos mostraram que tanto as carboximetilquitosanas obtidas em meio homogêneo quanto aquela obtida em meio heterogêneo atuam como agente de estabilização de suspensão aquosa de alumina.

Todas as amostras utilizadas como estabilizante provocaram certk decréscimo na viscosidade da suspensão, bem como aumento na magnitude do potencial zeta e decréscimo no valor do diâmetro médio de partícula, na região do $\mathrm{pHpcz}$, em torno de $\mathrm{pH}$ 5,5. Adicionalmente, o estudo de distribuição de diâmetro de partícula permitiu a comprovação da eficiência dos polissacarídeos polieletrólitos como estabilizantes, já que a adição destes tornou a curva de distribuição mais estreita, sendo que aqueles preparados em meio DMAc/LiCl se mostraram mais eficientes.

$\mathrm{O}$ conjunto de resultados permite afirmar que as carboximetilquitosnas, consideradas no presente trabalho, correspondem a boas alternativas aos polímeros obtidos de matéria prima não renovável, e que são normalmente utilizados como agentes de estabilização de suspensões de alumina.

Como proposta para futuros trabalhos, destaca-se a preparação de carboximetilquitosanas com grau de substituição médio, superior àqueles obtidos no presente trabalho, assim como a avaliação destas amostras como agentes de estabilização de suspensões aquosas de alumina. 
ABREU, F.R. Estudos de obtenção e caracterização de esferas entrecuzadas de carboximetilquitosana. 2006. 158f. Tese (Doutorado) - Instituto de Química de São Carlos, Universidade de São Paulo, 2006.

BAKLOUTI, S.; ROMDHAME, M.R.B. ; BOUF, S.; PAGNOUX, C.; CHARTIER, T.; BAUMARD, J.F. Effect of copolymer dispersant structure on the properties of alumina suspensions. Journal of the European Ceramic Society, v. 23, p. 905-911. 2003.

BAUMANN, H.; FAUST, V. Concepts for improved regioselective placement of O-sulfo, $\mathrm{N}$-sulfo, $\mathrm{N}$-acetyl, and N-carboxymethyl groups in chitosan derivatives. Carbohydrate Research, v. 331, n.1, p. 43-57, 2001.

BOUHAMED, H.; BOUFI, S.; MAGNIN, A. Dispersion of alumina suspension using comb-like and diblock copolymers produced by RAFT polymerization of AMPS and MPEG. Journal of Colloid and Interface Science, v. 312, n .2, p. 279-291, 2007.

BUSCAl, R.; CORNER,T.; STAGEMAN,J.F (Eds.). Polymer colloids. 1.ed. Inglaterra: Elsevier Applied Science. 1985. 324p.

CARASCHI, José Cláudio. Estudos das relações estruturas/propriedades de carboximetilcelulose obtida por derivatização de polpa de bagaço de cana-de-açucar. 1997. 188f. Tese (Doutorado) - Instituto de Química de São Carlos, Universidade de São Paulo, 1997.

CÁRDENAS, G.; CUELLAR, J.D.; NEIRA, K. Synthesis and characterization of carboxymethyl chitosan-arg and carboxymethyl chitosan-lys derivatives. Journal of the Chilean Chemical Society, v. 49, n. 3, p. 237-240, 2004.

CASTRO, R.H.R.; GOUVÊA, D. The influence of the Chitosan adsorption on the stability of $\mathrm{SnO} 2$ suspensions. Journal of the European Ceramic Society, v.23, n.6, p. 897-903, 2003. 
CERRUTTI, B.M. Estabilização de suspensões aquosas de alumina pela adição de taninos e quitosana quaternizada. 2005. 86f. Dissertação (Mestrado em Físico-Química)Instituto de Química de São Carlos, Universidade de São Paulo, São Carlos, 2005.

CHEN, X-G.; PARKE, H-J. Chemical characteristics of O-carboxymethyl chitosans related to the preparation conditions. Carbohydrate Polymers, v. 53, n. 4, p. 355-359, 2003.

CHEN, Y.; LIU, S.; WANG, G. Kinetics and adsorption behavior of carboxymethyk starch on $\alpha$ - alumina in aqueous medium. Journal of Colloid an Interface Science, v. 303, p. 380-287, 2006.

CRUZ, R.C.D.; REINSHAGEN, J.; OBERACKER, R.; SEGADÃES, A.M.; HOFFMANN, M.J. Electrical conductivity and stability of concentrated aqueous alumina suspensions. Journal of Colloid and Interface Science, v. 286, n. 2, p. 579-588. 2005.

DHARA, S.; BHARGAVA, P. Influence of nature and amount of dispersant on rheology of aged aqueous alumina gelcasting slurries. Journal of. American. Ceramic Society, v. 88, n. 3, p. 547-552, 2005.

DHARA, S.; BHARGAVA, P. Influence of nature and amount of dispersant on rheology of aged aqueous alumina gelcasting slurries. Journal of the American Ceramic Society, v. 88, n. 3, p. 547-552, 2005.

EVERETT, D. H. Basic principles of colloid science. London: Royal Society of Chemistry, 1989.

FUENTES, S.; RETUERT, P.J.; UBILLA, A . Relationship between composition and ctructure in chitosan-based hybrid Films. Biomacromolecules, v. 1, n. 2, p. 239-243, 2000.

GAYDARDZHIEV, S.; AY, P.; JANECZKO, M. Comparative studies of dispersant optimization techniques for evaluating stability of alumina slurries. Particle and Particle Systems Characterization, v. 23, n. 2, p. 205-209, 2006.

GE, H-C.; LUO, D.K. Preparation of carboxymethyl chitosan in aqueous solution under microwave irradiation. Carbohydrate Research, v. 340, p. 1351-1356, 2005. 
GOCMEZ, H. The interaction of organic dispersant with alumina: a molecular modeling approach. Ceramics International, v. 32, n. 5, p. 521-525, 2006.

GONZALES, E.R.; TICIANELLI, E. Eletroquímica. São Paulo: EDUSP, 1998. 224p.

GREENWOOD, R. Review of the measurement of zeta potentials in concentrated aqueous suspensions using electroacoustics. Advances in Colloid Interface Science, v. 106, p. 5581, 2003.

GUO, Z.; CHEN, R.; XING, R.X. Novel derivatives of chitosan and their antifungal activities in vitro. Carbohydrate Research, v.341, n.3, p.351-354, 2006.

HACKLEY, V.A. Colloidal processing of silicon nitride with poly(acrylic acid): II, rheological properties. Journal of the American Ceramic Society, v. 81, n. 9, p. 24212428, 1998.

HARBOUR, J.P.; DIXON, D.R.; SCALES, P.J. The role of natural organic matter in suspension stability. 1-Electrokinetic-rheology relationships. Colloids and Surfaces A: Physicochemistry and Engineering Aspects, v. 295, n. 1-3, p. 38-48, 2007.

HIEMENZ,P.C. Principles of colloid and surface chemistry.2. ed. New York: Marcel Dekker, 1986. 650p.

HOLME, H.K.; FOROS, H.; PETTERSEN, H. Thermal depolymerization of chitosan chloride. Carbohydrate Polymers, v. 46, n. 3, p. 287-294, 2001.

HUNTER, R.J. Zeta potential in colloid science. Academic Press. Londres, 1981. 385p.

HUNTER, R.J. Foundations of Colloid Science. Vol1. Oxford Science Publications. New York, 1981. 489p.

JONES, F. F.; BERARD, M. F. Ceramics industrial processing and testing. 2. ed. Iowa: State University Press, 1993. 206p. 
KASAAI, M. R. Calculation of Mark-Houwink-Sakurada (MHS) equation viscosimetric constants for chitosan in any solvent-temperature system using experimental reported viscosimetric constant data. Carbohydrate Polymers, v. 68, p. 477- 488, 2007.

LAMIN, R.; FREITAS, R.A.; RUDEK, U.I.; WILHEM, H.M.; CAVALCANTI, O.A. Films of chitosan and N-carboxymethylchitosan. Part II: effect of plasticizers on their physiochernical properties. Polymer International, v. 55, n. 8, p. 970-977, 2006.

LAVERTU, M.L.; XIA, Z. ; SERREQI, A.N. ; BERRADA, M. ; RODRIGUES, A. ; WANG, D.; BUSCHMANN, M.D. ; GUPTA, A. A validated ${ }^{1}$ H NMR method for the determination of the degree of deacetylation of chitosan. Journal of Pharmaceutical and Biomedical Analysis, v. 32, n. 6, p. 1149-1158, 2003.

LI,L.; HSIEH, Y-LO. Chitosan bicomponent nanofibers and nanoporous fibers. Carbohydrate Research, v. 341, n .3, p. 374-381, 2006.

LIU, Y.; GAO, L. Dispersion of aqueous alumina suspensions using copolymers with synergistic functional groups. Materials Chemistry and Physics, v. 82, p. 362- 369, 2003.

LIU, Y.; GAO, L.; SUN, J. Effect of acrylic copolymer adsorption on the colloidal stability of a 3Y-TZP suspension. Journal of the European Ceramic Society. v. 22, n. 6, p. 863871. 2002.

LIU, Y-F.; HUANG, K-L.; PENG D-M.; DING, P.; LI, G-Y. Preparation and characterization of glutaraldehyde cross-linked O-carboxymethylchitosan microspheres for controlled delivery of pazufloxacin mesilate. International Journal of Biological Macromolecules, v. 41, n. 1, p. 87-93, 2007.

LUCKHAM, P.F.; ROSSI, S. The colloidal and rheological properties of betonite suspensions. London: [s.n.], 1998. $1 \mathrm{v}$.

MEGIATTO, J.D.J. Estudo da estabilização de suspensões aquosas de alumina pela adição de lignossulfonato de sódio. São Carlos, 2001. Monografia (curso de Bacharelado)- Instituto de Química de São Carlos, Universidade de São Paulo. 
MILAS, M. Polieletrólitos. São Carlos: Instituto de Física e Química de São Carlos, 1991. $84 \mathrm{p}$.

MIRANDA, M.E.S.; MARCOLLA, C.; RODRÍGUES, C.A.; WILHEM, H.M. Chitosan and N-carboxymethylchitosan: I. The role of N-carboxymethylation of chitosan in the thermal stability and dynamic mechanical properties of its films. Polymer International, v. 55, n. 8, p. 961-969, 2006.

MUZZARELLI, R.A.A.; ILARI, P.; PETRALURO, M. Solubility and structure of N carboxymethylchitosan. International Journal of Biological Macromolecules, v.16, p.177-180, 1994.

MUZZARELLI, R.A.A. Carboxymethylated Chitins and Chitosans. Carbohydrate Polymers, v.8. p. 1-21, 1998.

ORTEGA, F.S.; SEPULVEDA, P; PANDOLFELLI, V.C. et al. Colloid Stabilization of alpha-alumina in aqueous media using polyelectrolyte. Advanced Powder Technology, v. 299, n. 3, p.104-114, 1999.

ORTEGA, F.S.; CASTRO, R.H.R.; GOUVÊA, D.; PANDOLFELLI, V.C. The rheological behavior and surface charging of gelcasting alumina suspensions. Ceramic International, v34, n.1, p.237-241, 2008.

PALMQVIST, L.; LYCKFELDT, O.; CARLSTROMA, E.; DAVOUST, P.; KAUPPI, A.; KRISTER, H. Dispersion mechanisms in aqueous alumina suspensions at high solids loadings. Colloids and Surfaces: A-Physicochemical and Engineering Aspects, v. 274, p. 100-109, 2006.

PANDOLFELLI, V.C. et al. Dispersão e empacotamento de partículas. princípios e aplicações em processamento cerâmico. São Paulo: Fazendo Arte, 2000. 224p.

PENICHE-COVAS, C.; ARGÜELLES-MONAL, W.; ROMÁN, J. S. A kinetic tudy of the thermal degradation of chitosan and a mercaptan derivative of hitosan. Polymer Degradation and Stability, v. 39, n. 1, p. 21-28, 1993. 
RABEA, E.I. Chitosan as antimicrobial agent: applications and mode of action.

Biomacromelecules, v. 4, n. 6, p. 1457-1465, 2003.

RAICHUR, A. M. Dispersion of colloidal alumina using a rhamnolipid biosurfactant.

Journal of Dispersion Science and Technology, v. 28, p. 1272-1277, 2007.

RAMOS, L. A.. Correlação entre propriedades físico-químicas de celuloses e sua solubilização e derivatização em LiCl/DMAc e DMSO/TBAF.3H2O. 2005. 263f. Tese

(Doutorado em Físico-Química) - Instituto de Química de São Carlos, Universidade de São Paulo, São Carlos, 2005.

RAYMOND, L.; MORIN, F. G.; MARCHESSAULT, R. H. Degree of deacetylation of chitosan using conductometric titration and solid state NMR. Carbohydrate Research, v. 246, p. 331-336, 1993.

RINAUDO, M.; MILAS, M.; DUNG, P. L. Characterization of chitosan. Influence of ionic strength and degree of acetylation on chain expansion. International Journal of

Biological Macromolecules, v.15, p. 281-285, 1993.

ROMDHANE, R.B.M.; BAKLOUTI, S.; BOUAZIZ, J.; CHARTIER, T.; BAUMARD, J-F. Dispersion of $\mathrm{Al}_{2} \mathrm{O}_{3}$ concentrated suspensions with new molecules able to act as binder. Journal of the European Ceramic Society, v. 24, n. 9, p. 2723-2731, 2004.

SAKAR-DELIORMANLI, A.; POLAT, H.; CIFTCIOGLU, M. Alumina/water suspensions in the presence of PEO-PPO-PEO triblock copolymers. Journal of the European Ceramic Society, v.24, n. 10-11, p. 3063-3072, 2004.

SARAVANAN, L.; SUBRAMANIAN, S.; KUMAR, A. B. V.; THARANATHAN, R. N. Surface chemical studies on SiC suspension in the presence of chitosan. Ceramics International, v. 32, n. 6, p. 637-646, 2006.

SEGNINI, R. Estudo das relações estruturas/propriedades de quitina e quitosana. 2006, 166f. Tese (Doutorado) - Instituto de Química de São Carlos, Universidade de São Paulo, 2006. 
SHAW,D.J. Introdução à química dos coloídes e de superfícies. Tradução de J. H. Maar. São Paulo: Ed. Edgard Blücher. 1975. 185p.

SHIN, Y-J.; SU, C-C.; SHEN Y-H. Dispersion of aqueous nano-sized alumina suspensions using cationic polyeletrolyte. Materials Research Bulletin, v. 41, n. 10, p. 1964-1971, 2006.

SHMURADKO, V.T.; ROMAN, O. R.; IL'YUSHCHENKO, A. F.; FOMIKHINA, I. V. Directed synthesis of multilayer structures in ceramic and refractory technology.

Refractories and Industrial Ceramics, v.48, n. 3, 2007.

SIGNINI, R.; CAMPANA-FILHO, S. P. Purificação e caracterização de quitosana comercial. Polímeros: Ciência e Tecnologia, n. 4, p. 63-68, 1998.

SINGH, B. P.; MENCHAVEZ, R.; FUJI, C. T. M.; TAKAHASHI, M. Stability of dispersions of colloidal alumina particles in aqueous suspensions. Journal of Colloid and Interface Science, v. 291, n. 1, p. 181-186. 2005.

SINGH, B.P. Characterization of concentrated colloidal ceramics suspensions: a new approach. Colloid and Interface Science, v. 300, p.163-168, 2006.

SINGH, B.P.; BHATTTACHARJEE, S.; BESRA, L. Influence of surface charge on maximizing solids loading in colloidal processing of alumina. Materials. Letters., v. 56, n. 4, p. 475-480, 2002.

SOLOMONS, T.W.; FRYHLE, C.B. Química Orgânica 2. Rio de Janeiro: LTC, 2006. $542 p$.

SONG, S.; ZHANG, Y. Stability of colloidal alumina dispersion in aqueous alkyl sulfate solutions. Surface Review and Letters, v. 14, n. 3, p. 395-401, 2007.

STAIGER, M.; BOWEN, P.; KETTERER, J.; BOHONEK, J. Particle size distribution measurement and assessment of agglomeration ceramic particles. Journal of Dispersion Science and Technology. v. 23, n. 5, p. 619-630, 2002. 
THONGMEE, N.; WATCHARAPASORN, A.; JIANSIRISOMBOON, S. Structureproperty relations of ferroelectric $\mathrm{Pb}(\mathrm{Zr} 0.52 \mathrm{Ti} 0.48) \mathrm{O}-3-(\mathrm{Bi} 3.25 \mathrm{La} 0.75) \mathrm{Ti} 3 \mathrm{O} 12$ ceramics. Current Applied Physics, v. 8, n. 3-4, p. 367-371, 2008.

TIRKISTANI, F.A.A. Thermal analysis of some chitosan Schiff bases. Polymer Degradation and Stability, v. 60, n. 1, p. 67-70, 1998.

VASCONSELOS, C.L.DE.; PEREIRA, M.R.; FONSECA, J.L.C. Polyeletrolytes in solution and the stabilization of colloids. Journal of Dispersion Science and Technology, v. 26, p. 59-70, 2005.

WANG, H.; SHEN, Y.; FEI, G.; LI, G.; ZHANG, Y. Effects of Modified Poly(methacrylic acid) Copolu]ymer on Rheological Properties of Ceramic Suspension and Sintered Ceramic Strenght. Journal of Applied Polymer Science, v. 102, n. 3, p. 2661-2667. 2006.

WIŚNIEWSKA, M. Temperature study of nonionic polymers adsorption at the alumina solution interface. Journal of American Ceramic Society, v. 90, n. 11, p. 3608-3614, 2007.

YAN, Y.D. The flocculation efficiency of polydisperse polymer flocculants. International Journal of Mineral Processing, v. 73, p. 161-175, 2004.

YOKOSAWA, M.M. Atuação de polímeros na estabilização de dispersões de alumina. 1996. 109f. Dissertação (Mestrado) - Instituto de Química de São Carlos, Universidade de São Paulo, 1996.

YOKOSAWA, M.M. Polieletrólitos sintéticos e derivados de polímeros naturais na estabilização de suspensões aquosas de alumina. 2001. 134f. Tese (Doutorado) Instituto de Química de São Carlos, Universidade de São Paulo, 2001.

YOKOSAWA, M. M.; FROLLINI, E. Effect of the addition of a cationic derivative of natural polysaccharide guar gum on the stability of an aqueous dispersion of alumina. Journal Macromolecules Science Pure Applied Chemistry, v. 39, n. 7, p. 709-721, 2002 (A). 
YOKOSAWA, M. M.; PANDOLFELLI, V. C.; FROLLINI, E. Influence of pH and time on the stability of aqueous suspensions containing sodium polyacrylates: a revisited process. Journal of Dispersion Science and Technology, v. 23, n. 6, p. 827-836, 2002 (B).

ZHANG, L.; SOMASUNDARAN, P.; MIELCZARSKI, J.; MIELCZARSKI, E. Adsorption mechanism of $n$-dodecyl- $\beta$-D-maltoside on alumina. Journal of Colloid and Interface Science, v.256, n.1, p.16-22, 2002.

ZHU, A.; Chan-Park, M. B.; Dai, S.; Li, L. The aggregation behavior of O carboxymethylchitosan in dilute aqueous solution. Colloids and Surfaces B:

Biointerfaces, v. 43, n. 3-4, p. 143-149,2005.

ZHU, A.; DAI, S.; LI, L.; ZHAO, F. Salt effects on aggregation of Ocarboxymethylchitosan in aque solution. Colloids And Surfaces B: Biointerfaces. v. 47, p. 20-28, 2006. 


\section{ANEXO A - CURVA DE TITULAÇÃO CONDUTIMÉTRICA E POTENCIOMÉTRICA PARA A QUITOSANA}
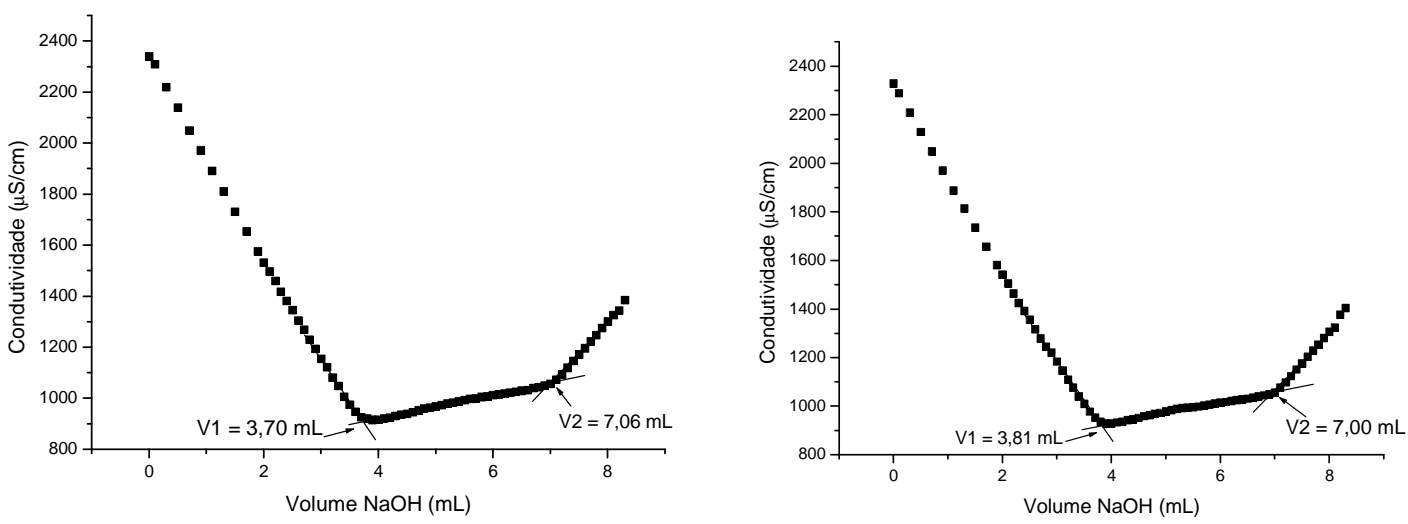

duplicata e triplicata respectivamente
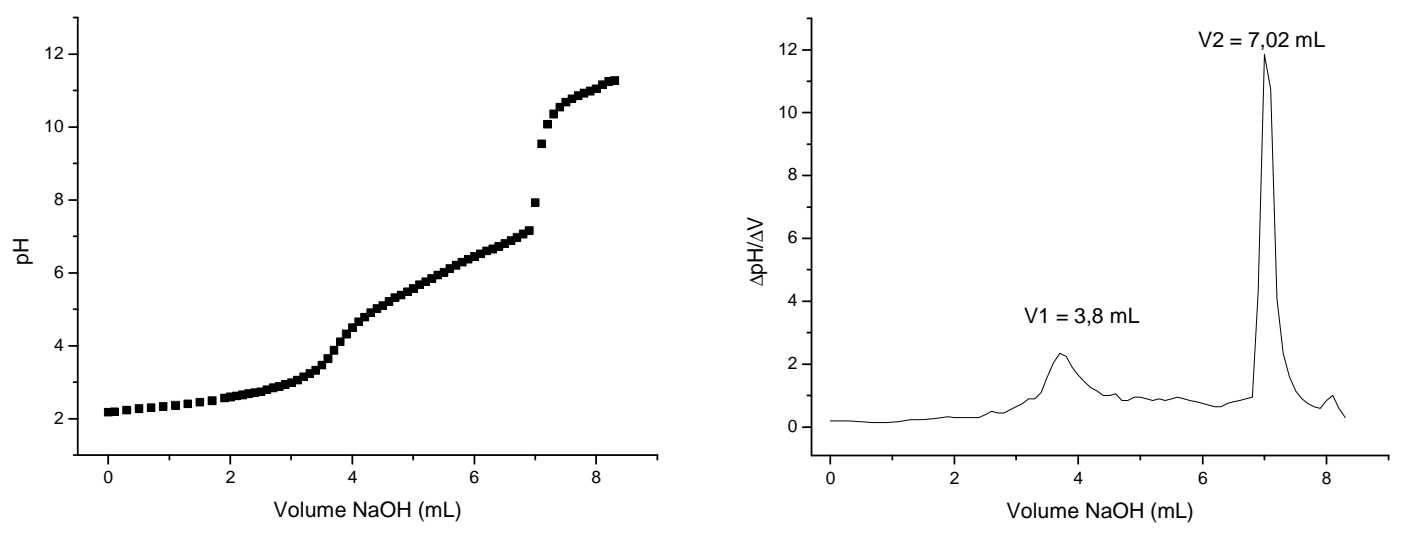

Curva de titulação potenciométrica da quitosana e respectiva derivada primeira (duplicata) 

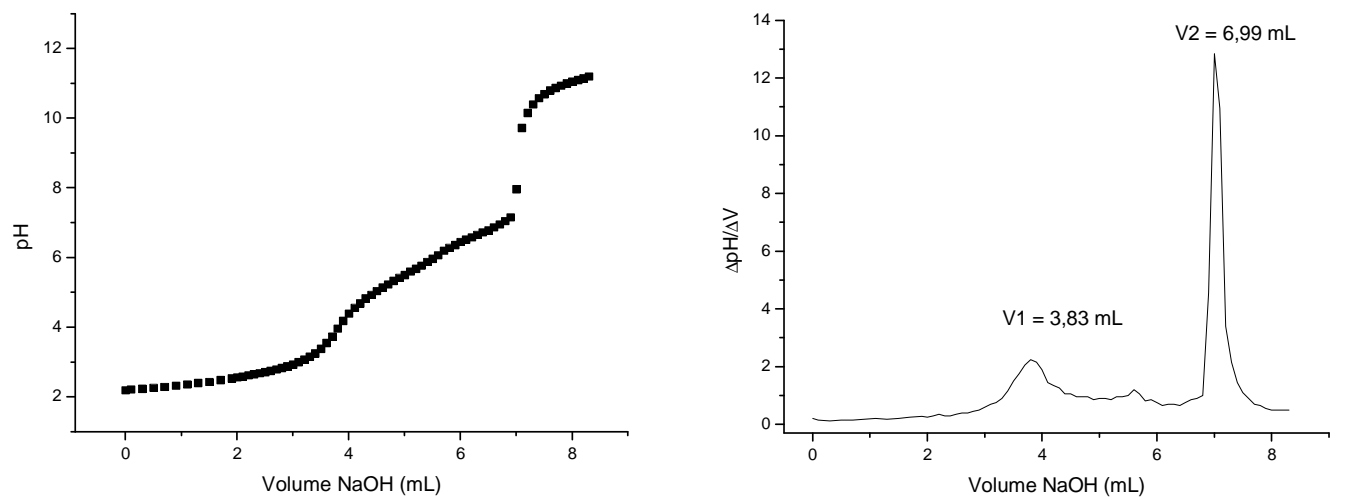

Curva de titulação potenciométrica da quitosana e respectiva derivada primeira (triplicata) 


\section{ANEXO B - ESPECTRO NA REGIÃO DO INFRAVERMELHO}

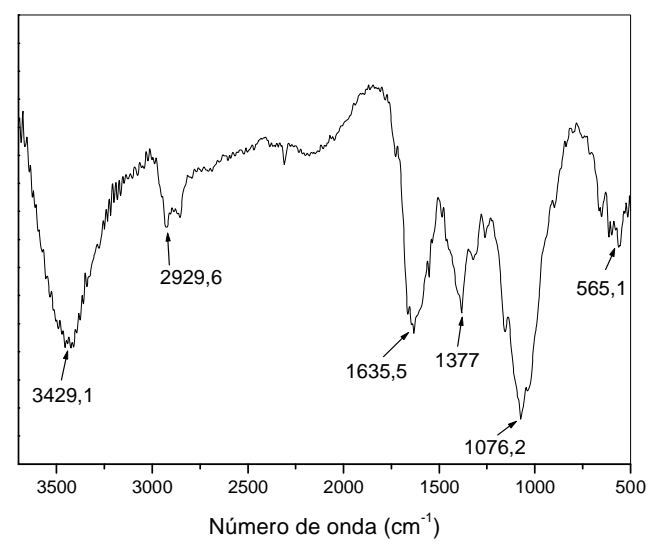

CMQ3

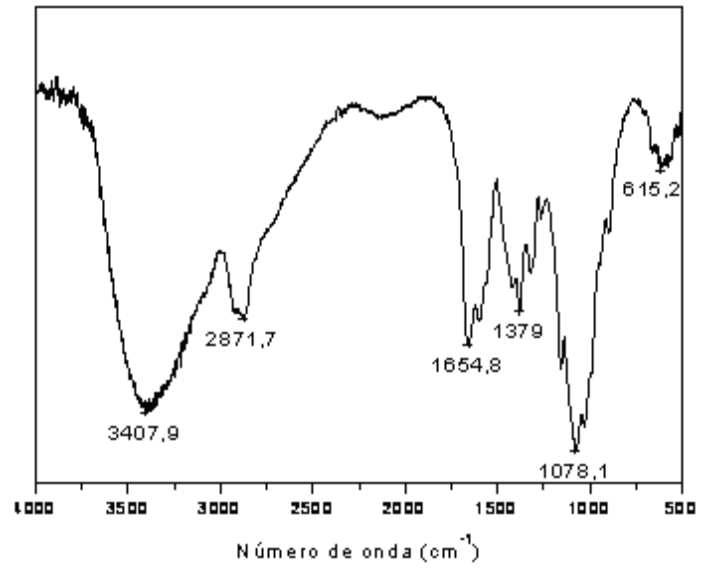

CMQ4

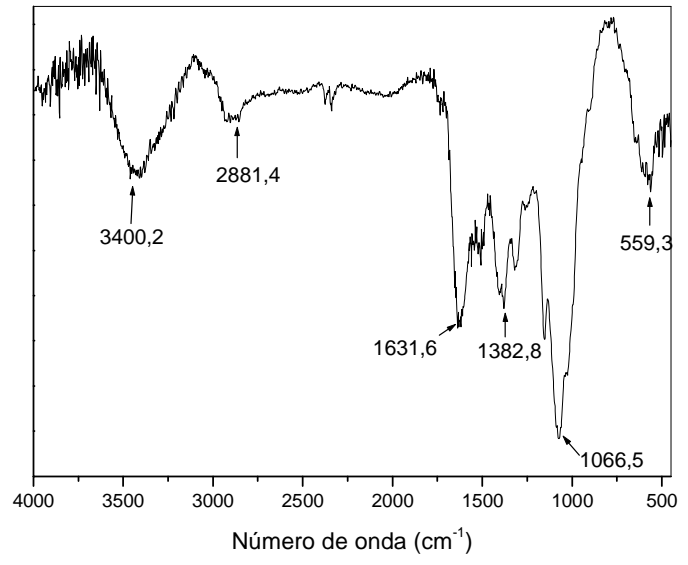

CMQ5

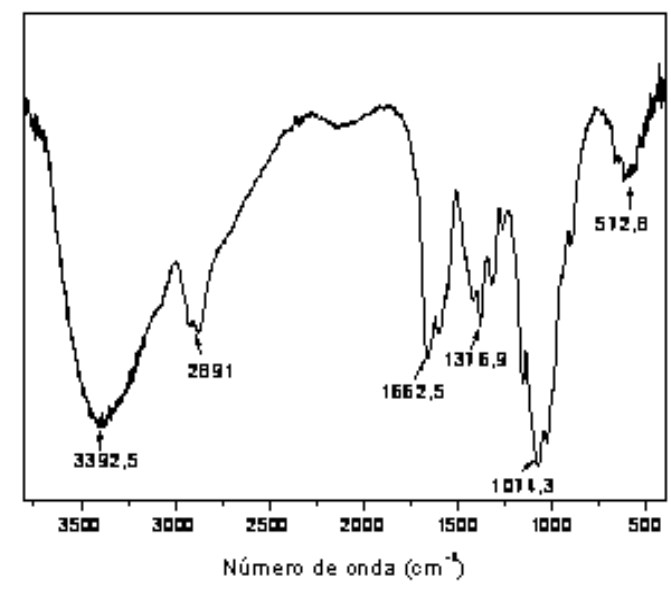

CMQ6 


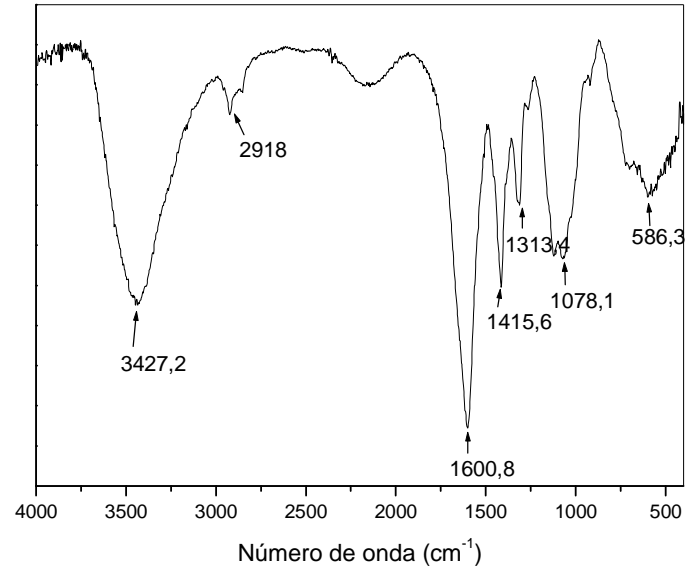

CMQ7. 
ANEXO C - ESPECTROS DE CARBOXIMETILQUITOSANA NA FORMA ÁCIDA

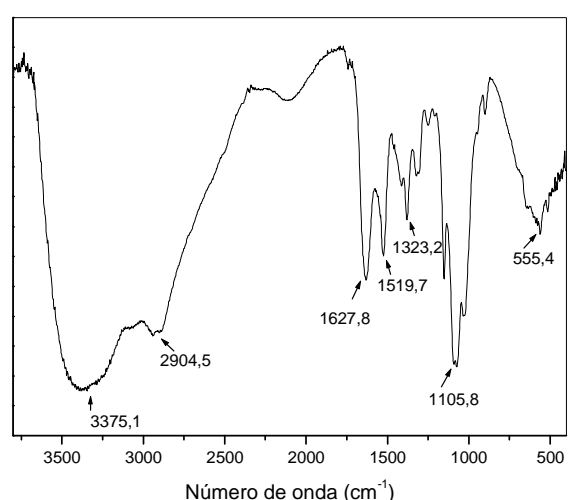

CMQ3

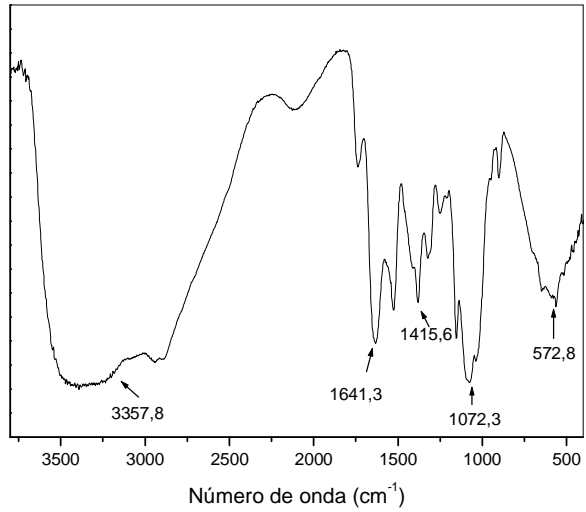

CMQ5

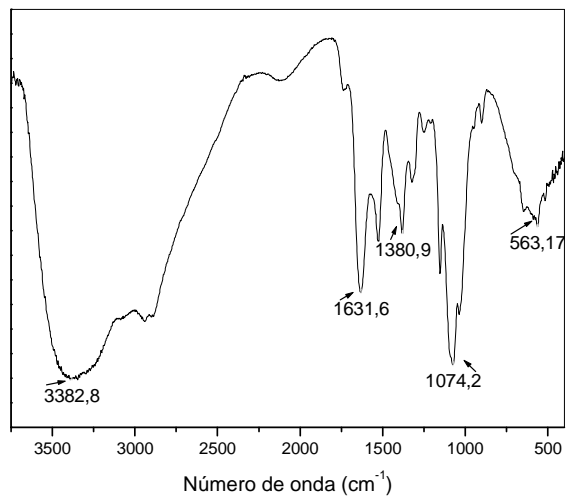

CMQ7

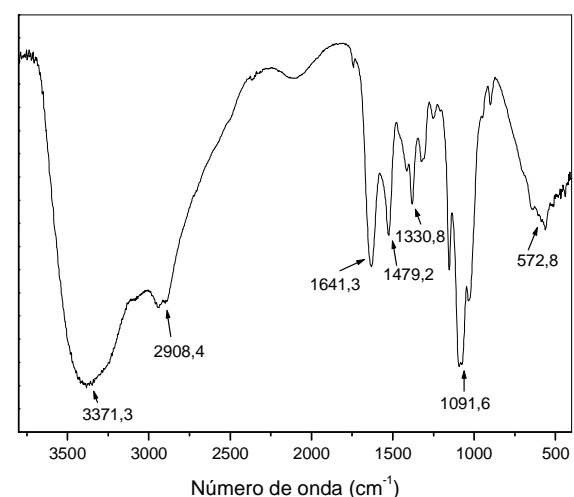

CMQ4

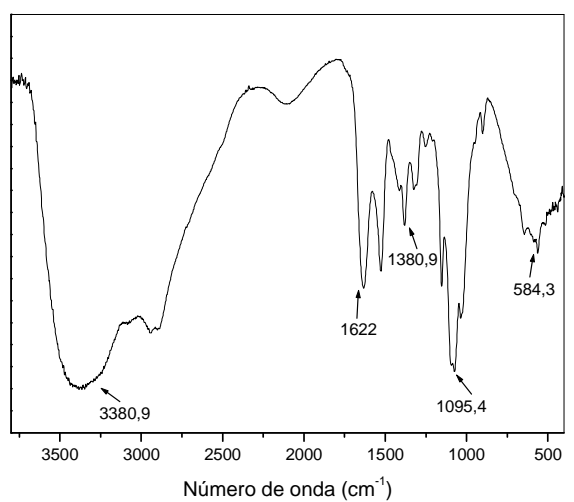

CMQ6

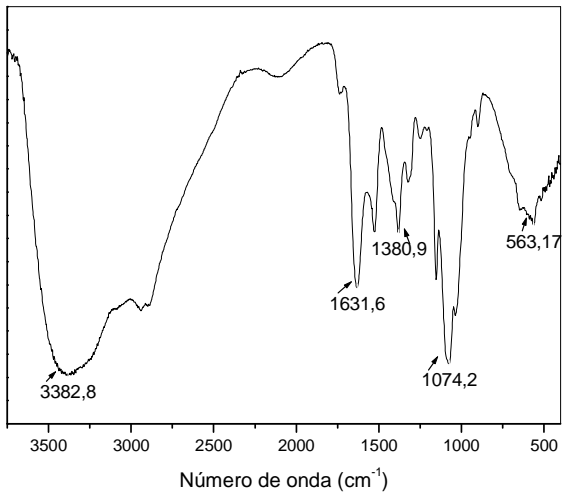

CMQ1 
ANEXO D: CURVAS TERMOGRAVIMÉTRICAS AS AMOSTRAS

CARBOXIMETILIDAS

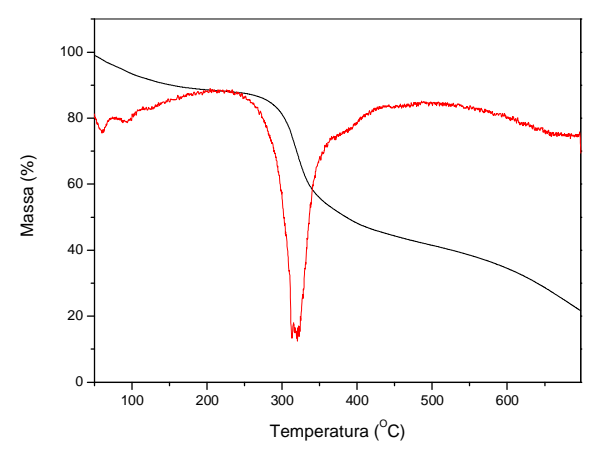

(a)

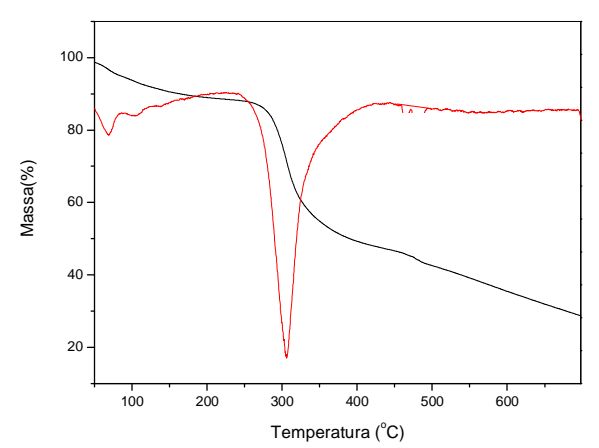

(c)

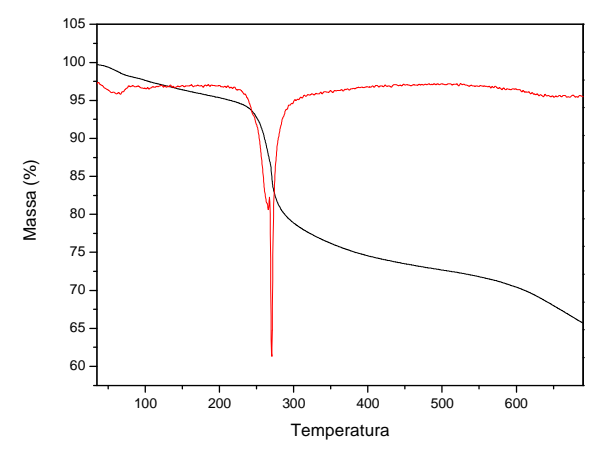

(b)

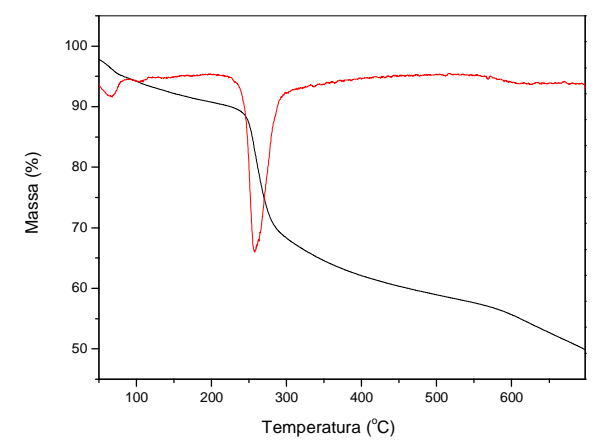

(d)

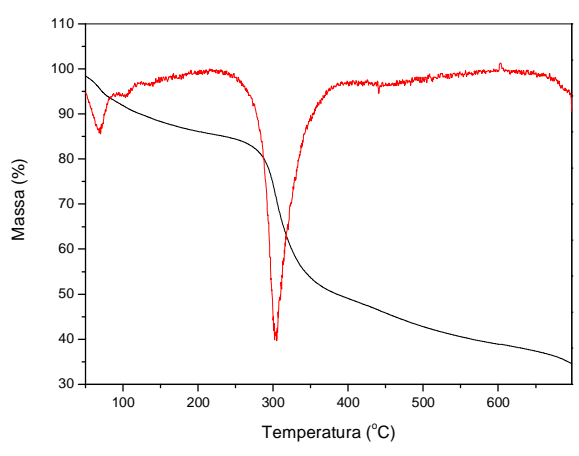

(e)

(a)CMQ2, (b)CMQ4, (c)CMQ5, (d)CMQ6, (e)CMQ1, em atmosfera de N2 com fluxo de gás de $20 \mathrm{~mL} \cdot \mathrm{min}^{-1}$ e razão de aquecimento de $20{ }^{\circ} \mathrm{C} \cdot \mathrm{min}^{-1}$. 
ANEXO E - ESPECTRO DE RESSONÂNCIA MAGNÉTICA NUCLEAR (RMN1H) DE CARBOXIMETILQUITOSANA

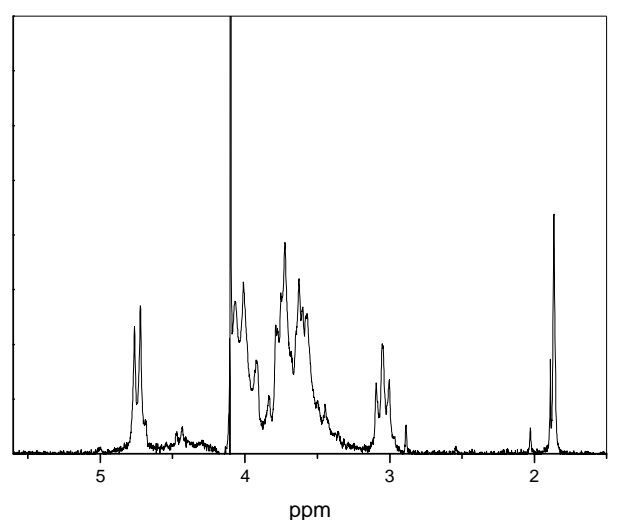

CMQ3

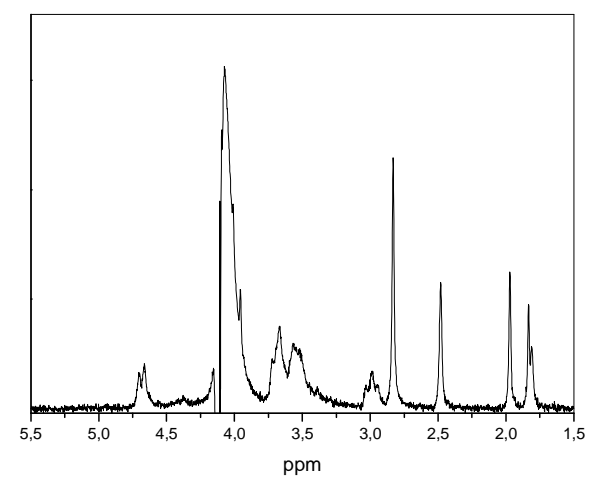

CMQ6

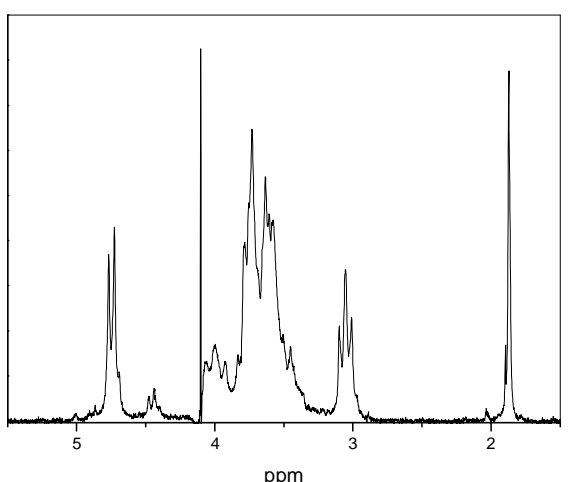

CMQ5

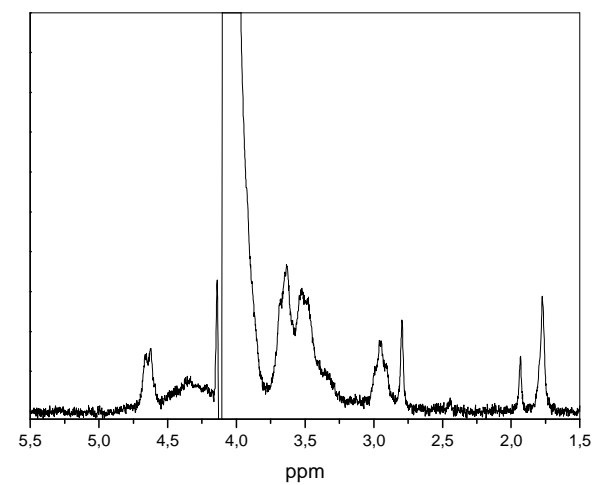

CMQ7 